MASTER EN DIVERSIDAD CULTURAL. UN ENFOQUE MULTIDISCIPLINAR Y TRANSFRONTERIZO

\title{
DISEÑO Y VALIDACIÓN DEL CUESTIONARIO Recurso para Estudiar la Gestión y Las Actitudes hacia la Regla (R.E.G.L.A.R.)
}

\section{Autora}

Carlota Torres-Blanco

\section{Tutora}

Dra. Inmaculada Alemany-Arrebola 


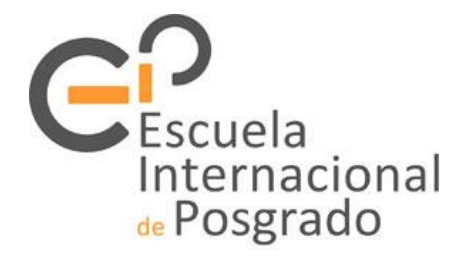

D. ${ }^{2}$ Carlota Torres Blanco con DNI n 31013346P, alumna del Master Universitario en Diversidad Cultural. Un enfogue multidisciplinar $y$ transfronterizo garantiza al firmar este Trabajo Fin de Máster, que este trabajo ha sido realizando respetando los derechos de otros autores a ser citados, cuando se han utilizado sus materiales, resultados o publicaciones.

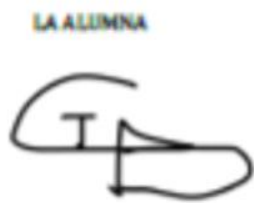

Ne:Cariota Turse Alano 
"No me sorprende que las mujeres hayamos estado tanto tiempo oprimidas por los hombres, pienso restregando mis bragas con un cepillo de uñas y un jabón de brea en el cuarto del baño. Quitar la sangre seca del algodón es un coñazo. Estábamos tan ocupadas frotando y frotando que no pudimos hacer campaña a favor del voto femenino hasta que aparecieron las primeras lavadoras."

Caitlin Moran "Cómo ser mujer" (2013:28).
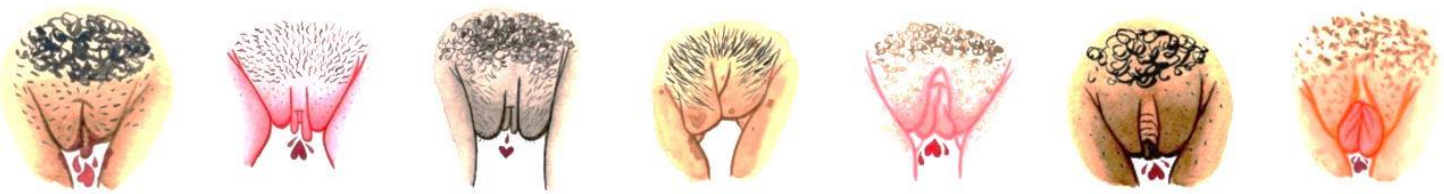


\title{
Resumen
}

En la presente investigación, de tipo descriptiva, se profundiza en un problema sumido en el silencio que actualmente sigue siendo un impedimento más para alcanzar la igualdad de género: la gestión de la menstruación. Por esto, los objetivos que se plantean en esta investigación son: diseñar y validar el Cuestionario y conocer la situación en la que se encuentran las menstruantes para poder visibilizarla. Para ello, se ha diseñado y validado el cuestionario "R.E.G.L.A.R.", el cual se ha aplicado a 100 personas que tienen o han tenido la menstruación del Campus de Melilla (UGR). El cuestionario está conformado por cinco bloques: 1. Conocimiento, uso y accesibilidad de productos y medicinas; 2. Espacios; 3. Canales de información; 4. Creencias y actitudes y, por último, 5. Mitos. Las variables independientes o atributivas analizadas son: edad, nivel económico y religión o creencias. Una vez analizado el cuestionario, se concluye que R.E.G.L.A.R. puede ser considerado un instrumento válido y fiable que ayuda a conocer y visibilizar la gestión de la menstruación.

Palabras clave: Cuestionario, menstruación, gestión menstrual, mitos, actitudes.

\begin{abstract}
In the following descriptive research, an unspoken issue that at the moment continues being an impediment regarding the goal of reaching gender equality is addressed: the management of the menstruation. Therefore, the aims set out in this research are: designing and validating the questionnaire and getting to know the situation in which the menstruants are in order to be able to visualize it. For this purpose, the "R.E.G.L.A.R." ("TO M.E.N.S.T.R.U.A.T.E.") questionnaire has been designed and validated, which has been applied to 100 people who currently have or have had their period from the Melilla Campus (UGR). The questionnaire is made up of five blocks: 1 . Knowledge, use and accessibility of products and medicines; 2 . Areas; 3. Information channels; 4. Beliefs and attitudes , and finally, 5. Myths The independent or attributive variables analyzed are: age, economic level and religion or beliefs. Once the questionnaire is analyzed, it is concluded that "R.E.G.L.A.R." can be considered a valid and reliable instrument that helps to know and makes the management of menstruation visible.
\end{abstract}

Key words: Questionnaire, menstruation, menstrual management, myths, attitudes. 


\section{CONTENIDO}

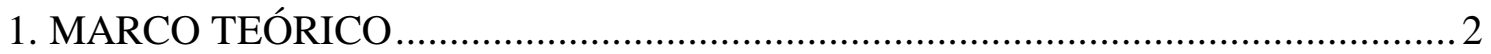

1.1. CONOCIMIENTO DE LA MENSTRUACIÓN ................................................ 5

1.2. PRODUCTOS ADECUADOS Y ASEQUIBLES PARA ABSORBER O RECOGER LA SANGRE Y ACCESO A LA MEDICINA..................................... 10

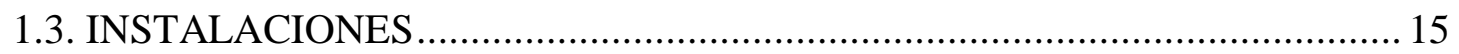

1.4. ¿QUÉ SE HA LOGRADO HASTA EL MOMENTO?..................................... 16

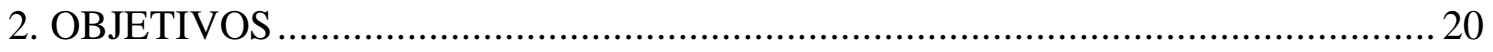

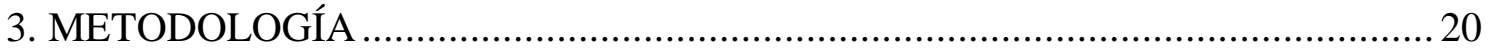

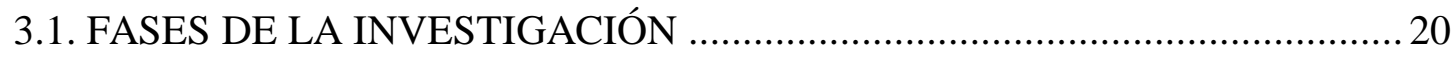

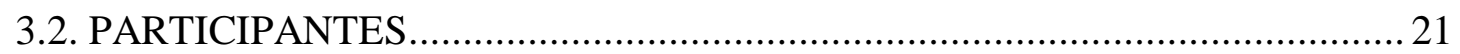

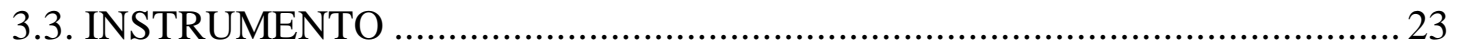

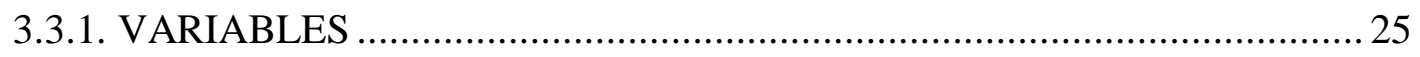

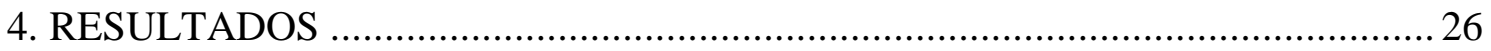

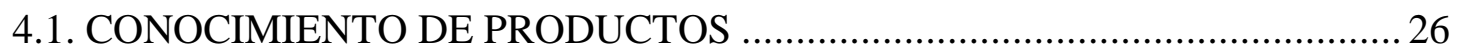

4.2. CONOCIMIENTO MEDICINA Y CONSULTA GINECOLÓGICA ................ 31

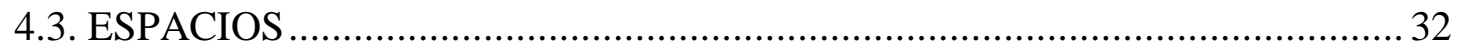

4.4. CANALES DE INFORMACIÓN SOBRE LA MENSTRUACIÓN ................... 33

4.5. CREENCIAS, ACTITUDES Y TABÚES .................................................... 34

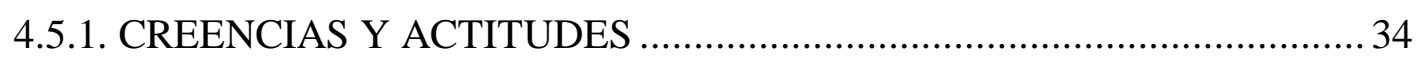

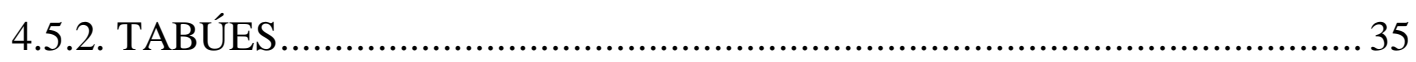

5. DISCUSIÓN Y CONCLUSIONES …............................................................. 41

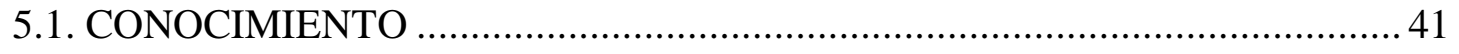

5.2. ACCESO A MEDICAMENTOS .............................................................. 41

5.3. INSTALACIONES PARA CAMBIAR MATERIALES MENSTRUALES ...... 42

5.4. CANALES DE INFORMACIÓN SOBRE LA MENSTRUACIÓN ................... 43

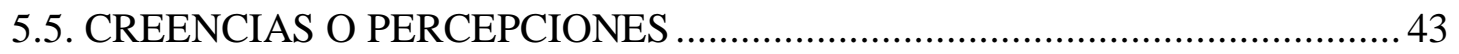

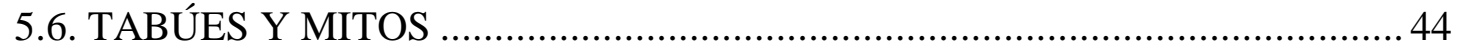

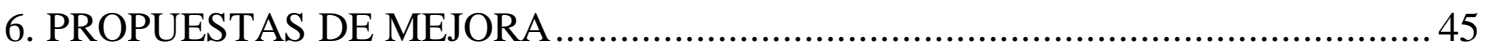

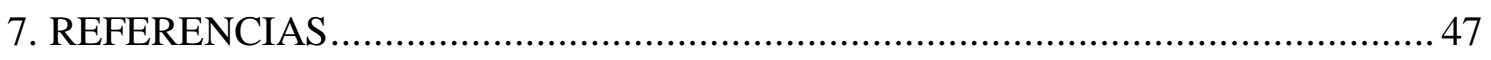

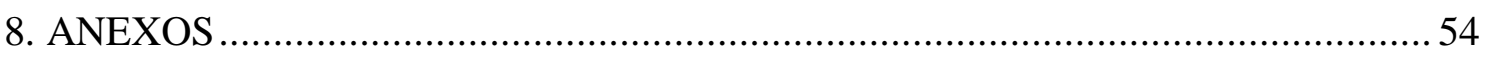

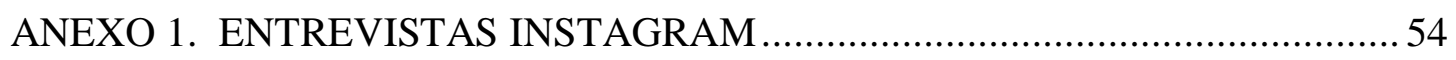

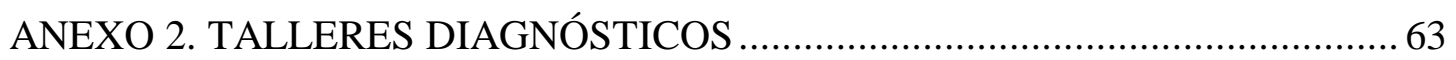

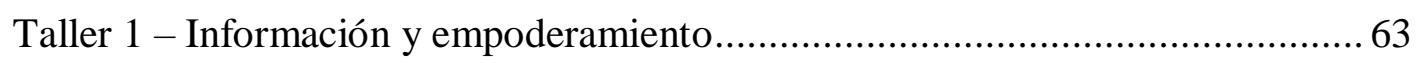

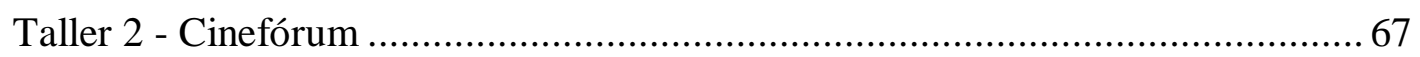

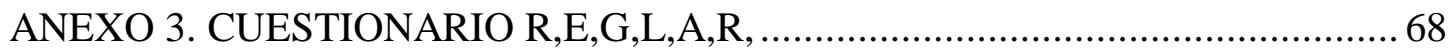




\section{INTRODUCCIÓN}

La menstruación en relación a derechos humanos o calidad de vida y dignidad, es un tema que ha empezado a ser tratado hace muy pocos años. En 2017, Human Rights Watch y WASH United llevaron a cabo una primera guía con el objetivo de ofrecer un marco en el que se basasen los proyectos realizados al respecto y con una serie de características a analizar en las menstruantes entendiendo que, de no ser cumplidas, hay derechos humanos tales como el derecho a la participación, información o salud, que se ven vulnerados.

Aunque ha habido intentos en diferentes países para de cambiar la situación, únicamente en Escocia se ha logrado que entre en las agendas políticas de manera holística la gestión de la menstruación en un sector de la población menstruante (mujeres y niñas desde el colegio a la universidad).

Existe la necesidad de comprender la situación real de las menstruantes, sin olvidar la necesaria mirada interseccional y, por tanto, entendiendo la diversidad de cuerpos, independientemente de las diferencias en cuanto a género, religión o creencias, nivel económico, etc. Por esto, se ha creado a través de un previo análisis bibliográfico a nivel internacional y nacional y un trabajo de campo de tipo cualitativo mediante talleres y entrevistas, un cuestionario en el que se atienden los diferentes factores que influyen en la gestión de la menstruación, tales como los tabúes, creencias, espacios, productos o medicinas.

Después de su creación, fue validado a fin de que se pueda utilizar para diferentes sectores de la población y así comprender y visibilizar la situación de las menstruantes en relación a la gestión de la regla. El cuestionario R.E.G.L.A.R., conformado por varios bloques, ofrece una fiabilidad medida a través del Alfa de Cronbach adecuada, por lo que se puede considerar un instrumento válido para los objetivos propuestos. 


\section{MARCO TEÓRICO}

El feminismo es entendido en esta investigación como el instrumento que poco a poco a lo largo de la historia ha ido quitando las piedras que nos interpone en el camino el heteropatriarcado, en busca de la igualdad de las condiciones de vida de la población en general. Tenemos que entender que no es un concepto ni una lucha novedosa o puntual. Siguiendo a Freedman (2004), “quizás sea más exacto ver el feminismo no como un surgimiento de oleadas, sino como un continuo de pensamiento y acción” (p. 23). Siempre ha habido mujeres descontentas y luchando para cambiar su situación, solo que con más o menos presencia o voz institucional o mediática y con más o menos represión para alzar la voz.

Otro aspecto importante a tener en cuenta del feminismo es que en el análisis y la lucha no podemos cometer el error de olvidar las diferencias de edad, identidades sexuales, religiosas, de género, color de piel, etc., y en consecuencia, no entender la interseccionalidad. Así, siguiendo a Esteban (2003)

El uso de la categoría 'mujer' (o 'mujeres') ha dificultado en gran medida percibir la construcción de otras diferencias de clase, de etnia, de nacionalidad, de edad, de orientación sexual, entre otras, que son fundamentales en la realidad de las mujeres, y ha impedido ver la articulación entre distintos factores de estratificación incluido el género. ( p.22)

El hecho de que estemos relegadas a un estatus secundario universal genera que algunos de los intereses de la mujer no puedan ser escuchados ni atendidos.

Siguiendo la -errónea- dicotomía hombre/mujer entendemos que presentamos diferencias. Tenemos una serie de características biológicas desiguales que vienen acompañadas de un conjunto de necesidades que si fuesen contempladas por igual no debería de suponer ningún impedimento para gozar de una igualdad de condiciones de vida.

Como sabemos, la realidad difiere de esta idea y parece que el fin de las políticas sociales en pro de la igualdad de género atiende a la idea de que las mujeres podamos aspirar a los mismos derechos de los que ya gozan los hombres, lo que supone un claro error ya que las diferencias hay que contemplarlas y atenderlas. Entre las existentes, podemos ir a la que parece ser la más clara: los genitales. Las mujeres tenemos vagina y nos lleva a menstruar. 
Ahora bien, para no olvidar la interseccionalidad en el análisis feminista tenemos que tener en cuenta que la dicotomía hombre/mujer partiendo del sexo es una idea que cae por su propio peso. Hay hombres con vagina y mujeres con pene, al mismo tiempo que hay hombres y mujeres que presentan órganos sexuales masculinos y femeninos al mismo tiempo.

Esta es otra cara de la diferenciación sexo/género quizás más acorde con la realidad y el mundo en el que vivimos que entiende que hay un amplio abanico de personas y maneras de vivir y sentir su ser que no se identifican con la cissexualidad, como por ejemplo, las transgénero o las intersexuales. ¿Quién menstrúa entonces y por qué hemos olvidado el tema en las agendas políticas mundiales?

La realidad es que menstruamos todas las personas con capacidad de hacerlo porque nuestros órganos reproductivos nos lo permiten, independientemente de si nos sentimos hombres, mujeres -o ninguna de las anteriores- por lo que hemos de desmitificar la idea de que es algo únicamente de mujeres y, además, lo que nos define como tales. Como explica Guillo-Arakistain (2013):

La idea de la menstruación como proceso común a todas las mujeres es una representación biomédica, pero es al mismo tiempo, un lugar común de la cultura popular: la regla como algo que no sólo tienen todas las mujeres, sino algo que nos hace mujeres. (p. 236)

Las menstruantes, vivimos en un continuo ciclo durante unos 36 años de vida (de media) que comienza con el primer día de sangrado. Haciendo un cálculo aproximado, tenemos unos 470 ciclos menstruales en nuestra vida [50 años (climaterio) - 14 años $($ menarquia $)=36$ años x 365 días al año $=13140.13140 / 28=470$ sangrados menstruales potenciales] y la mayor parte de las menstruantes no tenemos garantizados nuestros derechos humanos en este tiempo, en mayor o menor medida.

A pesar de que llevemos menstruando desde antes de la misma existencia humana y de que, al menos, la mitad de la población mundial lo haga, es una asignatura que a fecha de 2019 aún tenemos pendiente de añadir a nuestras agendas políticas. Es importante entender la trascendencia social que conlleva tanto individual como socialmente para visibilizarla y hacer esfuerzos para que mejore.

Como afirman en Human Rights Watch (2017), este proceso fisiológico que nos acompaña a todas las menstruantes no debería ser un obstáculo para la igualdad de 
género ni frustrar la posibilidad de que ejerzamos nuestros derechos humanos, aunque la realidad es la opuesta.

En Human Rights Watch y WASH United (2017), llevaron cabo una guía como primer intento de ofrecer una base universal para asegurar tanto que no se vulneren nuestros derechos por el hecho de menstruar, como que en todas las organizaciones de asistencia al desarrollo, así como otras profesiones que trabajan con mujeres y niñas, se aborde la dimensión de derechos humanos y menstruación de la mano.

Como se expone en la guía, mujeres y niñas de todo el mundo nos enfrentamos a numerosos desafíos en el manejo de la menstruación. Puede que por no tener medios para hacerlo, porque nos enfrentemos a normas culturales discriminatorias o prácticas que hagan difícil el mantener una buena higiene. Vemos más adelante Human Rights Watch y WASH United, (2017):

Cuando las mujeres y las niñas no tienen esta información y manejan la menstruación inadecuadamente, por ejemplo, utilizando absorbentes antihigiénicos para la sangre menstrual, pueden experimentar impactos negativos en la salud o, en otras palabras, no disfrutar plenamente de su derecho a salud.(p.8)

En esta guía de enfoque holístico, encontramos tres cuestiones a analizar en cada menstruante, entendiendo que si no se cumplen, sus derechos están siendo vulnerados.

Siguendo a Human Rights Watch y WASH United, 2017 (p.17), estas son:

1. Productos adecuados y asequibles para absorber o recoger la sangre y el acceso a la medicina por dolor causado por la menstruación.

2. Instalaciones adecuadas para cambiar materiales menstruales con privacidad, dignidad y seguridad y la posibilidad de usar jabón y agua para lavar el cuerpo, teniendo en cuenta la necesaria disponibilidad en aquellos lugares en los que las mujeres pasen gran parte del tiempo como pueda ser el lugar de trabajo, escuelas o centros de salud.

3. Conocimiento de la menstruación a fin de que sean las mujeres y niñas las que puedan escoger entre las opciones disponibles sin vergüenza ni esfuerzo extraordinario. 
La menstruación representa actualmente no solo un obstáculo para alcanzar la igualdad de género, sino también para aspirar a tener cubiertos todos nuestros derechos humanos y por tanto una vida digna. Manteniendo una gestión de la menstruación insuficiente o incluso dañina hay derechos humanos fundamentales que se ven violados como, por ejemplo, el derecho a la igualdad (Art 1), no discriminación (Art. 2), a recibir información (Art 19), a la participación (Art. 21) a la salud (Art. 25) o a satisfacer los derechos económicos, sociales y culturales indispensables para el libre desarrollo de la personalidad (Art. 22).

En la misma guía se expone también otra cuestión muy importante: aquellos aspectos a tener en cuenta por todas las personas que, como en este caso, hagamos proyectos o estudios en relación con el tema. Éstas son (Human Rights Watch y WASH United, 2017, p.18):

(1) Tener conciencia del estigma y las prácticas nocivas relacionadas con la menstruación en el contexto cultural específico para permitir a las mujeres y niñas superar las restricciones. (2) Apoyar los esfuerzos para cambiar las normas y prácticas culturales dañinas para las mujeres que generan estos estigmas. (3) Abordar formas interseccionales de discriminación. (4) Conocer e incorporar los principios de derechos humanos en su programación y defensa, incluyendo la participación y el acceso a información.

Aunque la guía presente el error de olvidar las diferencias de género de las menstruantes, hemos tomado cada punto de los mencionados como referencia para basar la presente investigación. Así, comenzaremos a analizar cada uno de ellos.

\subsection{CONOCIMIENTO DE LA MENSTRUACIÓN}

Éste será el primer punto a tratar ya que se entiende que sin tener información, no podemos conocer los productos existentes ni probablemente visualizar cómo debería ser el espacio en el que nos aseemos, independientemente de los productos que queramos escoger o cuestionarnos los diferentes mitos y tabúes que nos transmiten desde pequeñas.

El conocimiento de la menstruación está íntimamente ligado al tabú de la misma. Casa aquí la expresión "la pescadilla que se muerde la cola", ya que si nos enseñan a 
que no podemos hablar de la misma no vamos a compartir información, escuchar ni comparar. En muchas zonas, a causa del mismo tabú, no se ofrece educación menstrual en los colegios ni quienes conforman las familias tienen las herramientas necesarias para enseñarnos a manejarla por lo que en la mayoría de las ocasiones, la información que nos llega es errónea y mitificada siendo la única de la que disponemos, encontrándonos ante una discordancia entre lo que vivimos y lo que vemos o escuchamos.

La relación entre la menstruación y el miedo, vergüenza, maldiciones, impureza y, en resultado, la estigmatización de la menstruante a lo largo de la historia han llevado a la ocultación y en definitiva al tabú de la menstruación. Ésto genera que los mitos sobre el tema se transmitan de generación en generación sin que se hablen de los mismos y por ende sin su eliminación. Las indicaciones que tenemos sobre lo que tenemos que hacer mientras sangramos o lo que debemos de evitar generan miedo de las menstruantes hacia a qué podría ocurrir si no se cumplen con las normas marcadas.

Todo lo relacionado con la menstruación ha estado "imbuido", en las mayoría de las informantes, de miedos profundos sin ningún fundamento científico o médico; miedos que, debido al desconocimiento de las propias mujeres en los temas de la salud reproductiva, se han ido transmitiendo de generación en generación hasta llegar a nuestros días. (Botello y Casado, 2015, p. 17)

Miedos como a que "se corte", a quedarse "tonta", a que se formen quistes o tumores, a volverse loca, a que te dé una embolia o quedarse paralítica por el hecho de lavarse durante los días de sangrado. (Botello y Casado, 2015).

Frazer, James y Georg (1890) estudiaron los tabúes de las mujeres menstruantes analizando diferentes culturas y zonas geográficas. Expone ejemplos de países y mitos como por ejemplo el de Uganda donde explica: "La vajilla que una mujer toca debe ser destruida cuando la impureza de su catamenio o de su puerperio está en ella.” (p.250), o el de Costa Rica donde los únicos platos donde pueden comer son hojas de plátano que posteriormente se tendrán que esconder porque una vaca que las comiese moriría y tendrán que beber de un vaso especial pues si una persona bebe del mismo después de ella moriría.

Hay estudios como el llevado a cabo por Gulla, Mayo y Kimwaga, (2013) en Tanzania en el que muestran que de las adolescentes de la zona, únicamente el 2\% había 
recibido información en la escuela y el $44,4 \%$ por sus madres después del primer sangrado. En otro llevado a cabo en Singur (India), cuando preguntaron a las mujeres a qué se debe la menstruación, el 97,5\% respondieron no saberlo, (Dasgupta y Sarkar, 2008).

Esta situación no solamente se da en zonas económicamente pobres, sino que la escasez de educación menstrual está extendida en el mundo en general, al igual que sucede con la publicidad sobre la misma repleta de mensajes de ocultación y normas de comportamiento a seguir.

Pessi (2009) explica cómo ciertos valores morales o prejuicios construyen en gran parte los anuncios publicitarios. En el caso de la menstruación, tanto el producto como la práctica caen en el tabú, obedeciendo a estas convicciones sociales. La publicidad, no solamente muestra cómo se debe actuar, sino que también condena ciertas maneras de ver el mundo, como por ejemplo el siguiente caso:

Las toallas femeninas y los tampones son imprescindibles para la mujer que tiene que sentirse segura, confortable, protegida, limpia, seca y sobre todo cómoda. Si tiene alguna duda la interesada puede llamar a un 0-800 o solicitar un folleto ilustrativo que llegará al hogar sin ninguna leyenda. Lo mejor es que estos productos son discretos, vienen en diferentes colores para que nadie se dé cuenta, tanto que ni vos te das cuenta (Pessi, 2009, p.4).

En resumen, con este gran mecanismo de manipulación, nos venden una y otra vez la misma idea, haciéndonos ver y sentir que nuestra misión principal mientras sangramos es que nadie sepa que lo estamos haciendo, apoyando así el argumento de no hablar del tema. Como explicaba Beauvoir (1987);

Se le ha dado una simbología al periodo menstrual como un hecho nefasto, maldito, contaminante, que se debe ocultar, hasta tal punto que algunas culturas los hombres retiren a las mujeres por considerarlas impuras. Mostrando que el pene extrae del contexto social su valor privilegiado, del mismo modo es el contexto el que hace de la menstruación una maldición, pues el uno simboliza la virilidad, la otra la feminidad y la feminidad significa alteridad e inferioridad, su revelación es acogida como escándalo, por eso debe ocultarse. (Citada en Rojas, $2014, p .35)$ 
Esto ha sido estudiado desde la antropología, donde han tratado las normas sociales y escritas- de la misma y la relación que tienen éstas con la religión. A pesar de que religión no sea un sinónimo de cultura, sí es un pilar con mucha trascendencia en nuestro mundo que marca una serie de normas de comportamiento transmitidas de generación en generación sobre muchos temas de la vida en general y, entre ellos, la menstruación.

Preston (2005) realizó un estudio sobre los métodos de purificación y de contaminación religiosa en diferentes culturas, entre los que están las funciones biológicas corporales, las presiones sociales y el mantenimiento de los límites entre lo santo y lo sagrado.

Como explica, hay emisiones del cuerpo humano que están vinculadas a procesos de suciedad y limpieza en casi todas las sociedades. La sangre menstrual, al igual que la placenta o el vómito, se consideran en muchas sociedades portadoras de cualidades contaminantes y todas las excreciones corporales tienen una función social cuando afectan al conjunto de personas por estar fuera de control de quien las expulsa. Entonces, la persona tiene que actuar con pureza a fin de no contaminar a la sociedad en conjunto. Como explica Gómez (1976), los tabúes religiosos que guardan relación con la sangre son universales pues constituyen el denominador común de todas las culturas. (Citado en Perea, 2008).

Perea (2009) hizo también un estudio comparativo entre las coincidencias funcionales de las leyes sagradas griegas y hebraicas en relación a los rituales de impureza sexual de la mujer, entre las que se incluye la menstruación. Nos muestra cómo en textos como el Levítico, la Mishná, las Leyes Sagradas Griegas, el Pentateuco o los Manuscritos del Mar Muerto entre otros, existen una serie de normas coincidentes sobre la menstruación basadas en la impureza y los tabús, como la prohibición de mantener relaciones sexuales o bañarse.

(...) ambos conjuntos legislativos parecen estar concebidos por un mismo tabú religioso ancestral concerniente a la impureza de la sangre -particularmente la sangre menstrual- y todo lo relativo a la sexualidad humana y los flujos corporales emitidos durante las relaciones sexuales. (pp. 275-276). 
Por su parte, Alarcón-Nivia (2005) hace un estudio antropológico de la menstruación en el que analiza la interpretación en las religiones musulmana y católica. Como explica:

Por obediencia de los preceptos del Purdah, un ritual religioso-social de muchas comunidades musulmanas, hindúes y del medio oriente, las mujeres son literalmente aisladas del resto del público y aún dentro de su familia, pues las casas tienen muros, ventanas mínimas, velos o láminas que las separan en ambientes individuales. (p. 38)

En cuanto a la religión cristiana, en el Levítico o libro de la biblia de la Tribu de Leví, dedica el capítulo XV a la manera de limpiarse de dos impurezas: la gonorrea y la menstruación. Considerándose la menstruación como una inmundicia que puede transmitir esa condición a cualquier persona u objeto que toque a la menstruante en esos días. "Tener la menstruación convierte a la mujer en una persona inmunda, por esta razón puede transmitir esta especie de desgracia a todo aquello que la rodea" (AlarcónNivia, 2005, p.39).

Así, un conjunto de razones llevan a que no podamos hablar de la menstruación como de cualquier otro tema, generando incongruencias entre lo sentido y las expectativas que tenemos de la misma. Los tabúes y mitos no se han quedado en los textos sagrados o en el pasado sino que la sociedad está impregnada de ellos actualmente.

Por ejemplo, por el hecho de ocultar el sangrado, en zonas como la India, las mujeres únicamente se cambian dos veces al día para que nadie las vea con la idea de que si los hombres les viesen, perderían la vista. Los productos que usen, deben de ser escondidos -a menudo lo hacen entre tejas- para que no sean vistos, provocando situaciones insalubres y graves riesgos médicos (Murthy, 2006). En otras zonas como Bangladesh, descubrieron que al menos un tercio de las mujeres, esconden sus trapos en lugares húmedos y sucios para secarlos, sin poder lavarlos entre cambio y cambio de los mismos o que se los ponían húmedos, causando serias infecciones. (UNICEF Bangladesh, 2008), (citados en House, Mahon y Cavill, 2012, p.93).

Así, con diferentes normas como evitar coger un bebé, ducharse, tocar semillas, cocinar o tomar ciertos alimentos, hacer deporte...se nos priva a las menstruantes de poder llevar nuestro día a día con normalidad. Además, la mayoría de actitudes frente a 
la menstruación tanto de las menstruantes como de la sociedad en general, han generado que se estigmatice a la mujer, sobre todo en el periodo de pre-menstruación como débiles emocionales, enfermas mentales, histéricas, irracionales o violentas entre otras características (Johnston-Robledo y Crhrisler, 2011) Si creemos que nuestro ciclo afecta a nuestro estado psicológico, podemos experimentar otros cambios que etiquetemos como consecuencia del ciclo menstrual (Chrisler y Levy, 1990).

Lo que ocurre es que si continuamos en silencio, no avanzaremos y seguiremos estando privadas de nuestros derechos por un hecho biológico que nos acompaña en la mayor parte de nuestra vida. Aprender a apreciar, o al menos, no aborrecer la menstruación, puede tener un impacto positivo en el bienestar de las niñas y mujeres, así como en su condición social (Johnston-Robledo y Chrisler, 2011).

A fin de visibilizar la menstruación, romper el tabú que nos oprime y crear conciencia sobre el papel fundamental que la buena gestión de la higiene menstrual desempeña, se inició a raíz de la propuesta de Wash United (2014), el Día de la Higiene Menstrual, fechado el 28 de mayo.

Como se ha dicho anteriormente, el conocimiento y la posibilidad de comprar productos de retención o absorción del sangrado menstrual están de la mano, ya que entre otras cosas, hemos de saber cuáles existen para acceder a ellos.

\subsection{PRODUCTOS ADECUADOS Y ASEQUIBLES PARA ABSORBER O RECOGER LA SANGRE Y ACCESO A LA MEDICINA}

Recordemos que tenemos unos 470 sangrados potenciales, quien más y quien menos. Durante estos sangrados la mayoría de menstruantes usamos productos para absorber o retener la sangre. Al igual que cada cual tiene un ciclo con un sangrado y un proceso propios, los productos que utilicemos se tienen que adaptar a nuestro cuerpo y deseos, siendo unos los adecuados para unas personas y otros para otras.

A pesar de que en el mercado podamos encontrar un gran abanico de productos como son tampones, algodones, compresas, bragas o calzoncillos absorbentes, compresas reutilizables, tampones de crochet, copas menstruales, bragas o calzoncillos de plástico, esponjas marinas, salva slip de un solo uso o lavables y reutilizables o telas y compresas de gasa no todas tenemos la oportunidad si quiera de saber de su existencia. Además, la accesibilidad de compra no es la misma para todas las personas 
ni en todas las zonas porque algunos de ellos no se venden en supermercados o farmacias, habiendo quienes carecen de acceso a internet y, por tanto, de la posibilidad de posibilidad de comprar estos productos.

Otro aspecto a tener en cuenta es el precio de los productos. Un precio desorbitado teniendo en cuenta el uso que se hace de ellos siendo la regla algo que no decidimos tener. En España por ejemplo, estos productos tienen el IVA de producto de lujo y, además, la llamada Tasa Rosa, que es:

Una expresión amplia que hace referencia al sobreprecio de ciertos productos dirigidos a la mujer, idénticos o muy similares a los dirigidos a los hombres (salvo en el color, que en ocasiones es rosa). Pero también (...) el coste que tiene ser mujer, refiriéndose al precio de los productos de uso exclusivo por la mujer sin equivalente masculino. (Manzano, Martínez y Gavilán, 2008, pp. 369-384)

En un estudio realizado por Omar, Aggarwal y Perkins,(1998), se muestra que en Virgina (Estados Unidos de América) un 9\% de las mujeres jóvenes de entre 17 y 21 años usan compresas, $29 \%$ usan tampones y $52 \%$ usan ambas, con un total del $81 \%$ de las encuestadas usando tampones solos o en combinación.

El uso estimado de cada tampón es de 4 horas ergo usaríamos 6 tampones diarios. La duración media estipulada de cada etapa de sangrado menstrual es de 5 días $(6 \times 5)=30$ tampones. 30 tampones $\times(12$ meses en los que sangramos $\times 5$ días $)=360$ tampones al año.

Suponiendo que solo usásemos tampones y que los comprásemos en España, podemos hacer un cálculo estimado del dinero que gastamos a lo largo de un año de la siguiente manera:

Buscando información de los tampones más vendidos en uno de los supermercados más populares de España, nos encontramos con uno de los productos de la marca Tampax, que vende cada tampón a 0,17 euros. 360 tampones x $0,17=61,2$ euros al año o 5,1 euros mensuales

En el caso de que usásemos compresas únicamente, las más vendidas en España son las de un solo uso de la marca Ausonia, cuyo precio por unidad es de 0.33 euros x 360 compresas al año: 118,8 euros anuales o 9,9 mensuales. Todo esto teniendo en cuenta que no tengamos ningún tipo de alteración hormonal ni enfermedad relacionada con la menstruación y tuviésemos un sangrado de ciclos de unos 28 días de media. 
Hay quienes no pueden afrontar la carga económica mensual de los productos de higiene, que desconocen su existencia o no tienen acceso a ellos ya sea por distancia, imposibilidad de acceso a internet $\mathrm{u}$ otros muchos factores. Estos desafíos y dificultades a los que se enfrentan, pueden tener como consecuencia la negación de los derechos humanos, convirtiendo un simple hecho biológico en una barrera para alcanzar la igualdad de género.

En el estudio llevado a cabo por El-Gilany, Badawi y El-Fedawy (2005) en Mansoura (Egipto) con adolescentes, exponen que únicamente el 66,8\% de las entrevistadas usaban productos comprados, frente al $33.2 \%$ restante usaban trapos, gasas, ropa vieja, algodón o nada en absoluto.

También nos encontramos con información recogida como en el documental creado por Zehtabchi et. al. (2018) en el que nos muestran cómo viven la menstruación las mujeres y niñas de un pueblo de Nueva Delhi (India) de las cuales muchas no sabían de la existencia de ningún producto para absorber o retener la sangre a parte de las telas o no tenían acceso económico a ellos, viéndose en muchos casos obligadas a abandonar su escuela o trabajo.

Además de la carga económica, los productos que usamos mayoritariamente de un solo uso generan daños ecológicos y en nuestra propia salud ya que contienen blanqueantes nocivos que actúan sobre las mucosas y la piel de la vulva y la vagina (Guillo-Arakistain, 2013).

Así, como explica Ortiz (2018), para la fabricación de los tampones, compresas y salva slip de uso único, se utiliza un grupo de minerales llamado "asbesto", minerales de grupo silicato producidos en la naturaleza que son separados por fibras para formar la tela que usan en la creación de estos productos. Esta sustancia contiene componentes y efectos totalmente dañinos para nuestro cuerpo. Además, el asbesto contiene dioxina que es cancerígena y tóxica para el sistema reproductivo, causando alteraciones en la mucosa del útero, endometrio y puede ser causante de endometriosis. Además, la absorción de la tela genera dioxina, un contaminante usado para potenciar la absorción, que se almacena durante el tiempo que los productos están en contacto con el cuerpo generando problemas como puedan ser los "shocks tóxicos"; infecciones vaginales con síntomas como dolores de cabeza o visión borrosa. Otro efecto secundario del asbesto es el aumento de las hemorragias. 
Otro aspecto a tener en cuenta es el acceso y conocimiento de la medicina para paliar el dolor relacionado con la menstruación.

En muchas ocasiones en diferentes fases del ciclo experimentamos cambios que pueden manifestarse en forma de dolor o molestias, cansancio, hinchazón...y es común que desde la menarca consumamos medicamentos para paliar estos efectos. El uso de los mismos forma parte de la esfera cultural en torno al tema a tratar, siendo un hábito construido culturalmente que contribuye a la consideración del cuerpo de la mujer como patologizado (Cardozo, 2015).

Además de este aspecto psicológico que acompaña a la estigmatización, hay una serie de enfermedades o trastornos menstruales comunes como el síndrome de ovarios poliquísticos, amenorrea, dismenorrea, endometriosis, cáncer del cuerpo del útero y hemorragia uterina disfuncional (Lugones, Yamilé y Cruz, 1997) entre otras que se pueden tratar de diferentes maneras, que se diagnosticarán en la consulta ginecológica.

En muchas ocasiones, por vergüenza, falta de acceso económico al no ser la sanidad universal o por normalizar efectos en nuestro cuerpo al no tener una educación menstrual adecuada, vivimos con estos problemas sin acudir a la consulta ginecológica. Según la OMS (Organización Mundial de la Salud) y la SEGO (Sociedad Española de Ginecología y Obstetricia), en caso de tener vagina, se debe de ir a la consulta ginecológica una vez se hayan mantenido relaciones sexuales con penetración o, en caso de no haberlas mantenido, a partir de los 20 años a hacer revisiones una vez al año. (Citado en Fernández, 2018).

En el caso de España, muchas personas se quedan sin acceso sanitario gratuito en su mayoría las que menos ingresos económicos tienen- como la ciudadanía extranjera que no tenga establecida su residencia en territorio español (Ley Nº102, 1986), aun así, "casi un 30\% de las consultas al médico especialista se realizan sin financiación pública" (Regidor et. al., 2006, p. 357). Según la OMS, (2009) la sociedad y los sistemas de salud están incumpliendo con sus obligaciones con las mujeres, habiendo carencias en los mismos que las privan de asistencia sanitaria.

Por ejemplo, las mujeres tienen mayores gastos de salud que los hombres porque utilizan más los servicios asistenciales, pero, por comparación con los varones, suelen ser más pobres y están desempleadas o trabajan a tiempo parcial o en el sector informal, que no ofrece prestaciones sanitarias. (OMS, 2009, p.4) 
Por otro lado, para la mayor parte de estos desórdenes o enfermedades se recetan pastillas anticonceptivas, al igual que en muchas ocasiones las mujeres las toman por decisión propia como método anticonceptivo o por alterar su ritmo en el ciclo menstrual para emigrar en patera, viaje de bodas, exámenes, etc.

En muchas de las ocasiones la anticoncepción hormonal o pastillas anticonceptivas no son necesarias y se toman de manera naturalizada y sin necesidad médica, asumiendo (muchas veces sin conocer) los riesgos que las mismas generan, tales como náuseas y vómitos, cefaleas, retención de líquidos, irritabilidad, menorragia, disminución de la libido, pigmentación cutánea, vagina reseca, acné... (Lugones, Yamilé y Cruz, 1997) y una lista bastante larga de contraindicaciones.

En cambio, es curioso que los anticonceptivos para quienes poseen genitales masculinos no estén aprobados. De hecho en diversos textos médicos, las características que exigen para que así sea son tales como: tener un costo accesible, que no afecte a la libido, que no tenga riesgos para la salud ni efectos secundarios, que proteja contra el VIH, etc. (Aspilcueta-Gho, 2013) una serie de condiciones que, como hemos visto no se cumplen en la anticoncepción hormonal para quienes tenemos aparato reproductor femenino y parece no preocupar.

Al tener tan poca información sobre las causas, riesgos, posibles problemas relacionados con la anticoncepción y sobre nuestro cuerpo en general, nos medicamos sin necesidad en muchas ocasiones provocando consecuencias físicas y psicológicas, como en el caso del uso de pastillas anticonceptivas, de geles íntimos o desodorantes para la vulva o en el uso excesivo de antiinflamatorios como ibuprofenos, todos ellos con contraindicaciones en un uso habitual.

A parte de la medicina occidental o farmacológica, hay quienes proponen alternativas para paliar molestias, dolores, enfermedades... como por ejemplo Nissim, (1984) quien estudia maneras de paliar el dolor como son los orgasmos, cataplasmas de sal marina caliente, ejercicio, aceites esenciales, plantas, alimentos y vitaminas... En su estudio, la autora explica médicamente cada una de las enfermedades, trastornos hormonales, etc. desde la perspectiva médica, presentando la respuesta común y proponiendo una alternativa con la medicina natural. 
Así, deberíamos de saber cuáles son no solo las posibles enfermedades que tenemos y los medicamentos, sino también las alternativas a los mismos y las repercusiones que pueden tener todos éstos en nuestro organismo.

\subsection{INSTALACIONES}

Por último, que no menos importante, debemos tener en cuenta cuáles son los espacios en los que pasamos más tiempo y las características de los mismos, teniendo en cuenta que tienen que contar con las condiciones adecuadas para cambiar los materiales menstruales con privacidad, dignidad y seguridad en los espacios en los que pasemos gran parte del tiempo como pueda ser el lugar de trabajo, escuelas o centros de salud. Las condiciones que se deben cumplir son: puerta, jabón, agua y algo para secarnos, con el fin de disponer de un aseo con privacidad, dignidad y seguridad.

Así, como explican (Mahon \& Fernandes, 2010)., tener acceso a cantidades suficientes de agua potable, acceso a un sitio limpio y privado donde defecar, vivir en un ambiente libre de excrementos humanos y comportarse de una forma higiénica, son requisitos esenciales para la salud y la dignidad de todos. A fecha de 2014, había 46 países en los que al menos la mitad de la población no tenía servicios de saneamiento mejorados, unas mil millones de personas. Así, nueve de cada diez personas han de defecar a la intemperie en zonas rurales (Osseiran y Jasarevic, 2014).

En los estudios, se hace referencia a que uno de los impedimentos más relevantes de no disponer de un buen aseo es el hecho de defecar -y es cierto que es importante- pero también lo es el que nos atañe en esta investigación. Aun así, se entiende que un lugar en el que no puedan defecar o lo tengan que hacer al aire libre, no reúne las condiciones para poder cambiarse y lavarse dignamente.

Desde la edad concebida como adolescencia hasta la madurez de todo el mundo, debido a la menstruación, se enfrentan a tabúes, vergüenza y mala salud; sobre todo en los países en desarrollo, donde las niñas faltan a la escuela o deben de aislarse (28\% de las mujeres en un estudio realizado en la India). De los 113 millones de infantes sin escolarizar en todo el mundo, el 60\% son niñas. Así, existen pruebas concluyentes de que la asistencia de las niñas a la escuela se incrementa a través de la mejora del saneamiento (Bharadwaj y Patkar, 2004). 
En un estudio realizado en institutos de Tanzania, se expuso que en los cuartos de baño, el 48,3\% de las adolescentes únicamente tenían agua, el 35,6\% agua y jabón, el $15,4 \%$ papel higiénico en los baños y el 0,7\% otros materiales. En cuanto a las condiciones de limpieza de los baños se muestra que el 33,3\% afirma que están limpios, el 50\% medio limpios y el 16,7\% sucios. (Gulla E., Mayo A.W. y Kimwaga, R., 2013)

Sin ir más lejos, en España como viene en el INE, (2012) hay un total de 4.513 mujeres sin hogar, un incremento del 16\% frente al año 2005. A partir de este dato, se puede presuponer que han subido cuantiosamente a raíz de la crisis económica en la que estamos inmersas. ¿En qué espacio se pueden asear cuando están menstruando?

A parte de todo lo visto anteriormente, hay menstruantes que se encuentran en situación de dependencia, es decir, que necesitan ayuda de alguien para realizar ciertas actividades diarias, entre ellas la de la higiene relacionada con la menstruación. En el INE (2008) nos encontramos en España con un total de 32.100 personas que necesitan ayuda en su higiene relacionada con la menstruación aunque en la Ley N³9 (2006) no se hace mención a la misma.

\section{4. ¿QUÉ SE HA LOGRADO HASTA EL MOMENTO?}

Todas las cuestiones anteriormente tratadas a fin de que las menstruantes podamos gozar de una calidad de vida digna y aspirar a la igualdad de género deberían de ser tratadas por los gobiernos mundiales pero ¿Está siendo así realmente?

A pesar de que la lucha por esta causa no está visibilizada, en algunas zonas del mundo han hecho proyectos destinados a dar respuesta a este grave problema. Todos ellos de la mano de la guía de Human Rights Watch y WASH United (2017).

En la $2^{\text {a }}$ edición del "ABC de los derechos de las trabajadoras y la igualdad de género", por la Oficina Internacional del Trabajo, (2008), hay un apartado llamado "licencia de enfermedad". En éste, la menstruación y menopausia figuran entre las cuestiones específicas a las que podemos recurrir como licencia de enfermedad debido a las dolencias ligadas al mismo (amenorrea, menorragia, dismenorrea, síndrome premenstrual o menopausia), siempre y cuando sea resultado de un examen médico que reconozca los problemas menstruales aunque, como veremos más adelante, no es un derecho del que goce un alto porcentaje de las mujeres del mundo en el que vivimos. 
En Japón, si miramos el Perfil Nacional de la Legislación laboral, atendiendo a la contribución de Jung (s.f.), nos encontramos con que en el artículo 68 de la LSL de 1948, está expuesto que las mujeres pueden solicitar días libres durante sus periodos de menstruación, aunque no tienen por qué estar aseguradas de baja laboral, es decir, pueden no cobrar esos días.

En otras zonas como Bélgica o Francia se ha conseguido disminuir el IVA de artículos de higiene al 6 y 5,5\% respectivamente. Como explica Chacón (2018), en la India decidieron en julio del 2018, eliminar el sobre-impuesto del $12 \%$ de estos productos, en Canadá en 2015 y en 2011 en Kenia.

En todo el mundo, el proyecto que ahora mismo está teniendo más trascendencia es el que está llevando a cabo Lennon (2017), en Escocia. En él, explica que el acceso a los productos de la menstruación debería de ser un derecho humano básico bajo la premisa de que ninguna mujer elige menstruar y de que hay mujeres y niñas que por el hecho de tener problemas financieros se ven forzadas a una situación en la que tienen que elegir entre una disposición sanitaria y otra de necesidades básicas. Lo que pretende finalmente es crear un derecho universal al acceso a productos de higiene menstrual gratuitos para toda Escocia y presentar específicamente un deber en las escuelas, universidades y colegios para proporcionar productos en sus baños. Un deber para los ministros escoceses de introducir un sistema universal de provisión gratuita de productos sanitarios. Se convierte así en el primer gobierno del mundo que ha empezado a poner la menstruación como foco de desigualdad. A fecha de 2018, Mónica Lennon, consiguió presionar al gobierno de Escocia para ofrecer a todas las estudiantes de estudios secundarios y universitarios, e incluso a las de primaria en edad menstrual, acceso gratuito a productos sanitarios de primera necesidad como compresas y tampones (Parlamento Europeo, 2018).

Hay otro proyecto de ley de Buenos Aires, que surgió de la campaña \#menstruacción, de la organización Economía Femini(s)ta por Portos (2017), Diputada Provincial de Unidad Ciudadana, con el que también lucha por estos objetivos. Se basa en dos demandas principales; provisión gratuita de artículos de higiene menstrual en escuelas, refugios, comedores, cárceles, universidades y espacios comunitarios y la supresión del IVA para que sean considerados como artículos de primera necesidad. 
En Nueva York, como explica Collins (2016), el día 23 de junio del 2016 se aprobaron un conjunto de proyectos de ley que requieren productos gratuitos de higiene menstrual en escuelas públicas, cárceles y albergues, lo que la convierte en la primera ciudad del país en aprobar la que se denomina legislación de "equidad menstrual", proyecto del que es principal patrocinadora para las escuelas Julissa Ferreras-Copeland y Melissa Mark-Viverito en relación a refugios e instalaciones correccionales. La ciudad presupuestará en estas zonas los tampones, compresas, papel higiénico y jabón de manos

En España comenzó a debatirse oficialmente el tema en el año 2016 en la Comisión para la Igualdad de las Cortes Generales de la mano de Esquerra Republicana y el Grupo Socialista (Número de expediente 161/000274 y 161/000676 respectivamente), entendiendo que "El consumo de los productos de higiene íntima representa para las mujeres una necesidad primordial y regular. Sin embargo, estos artículos están gravados como productos de consumo, lo cual comporta que un artículo sanitario indispensable para las mujeres se convierte nada más y nada menos que en un producto de lujo.” (p.3)

El propósito en materia de productos de higiene menstrual era defender ante la Comisión Europea la capacidad para establecer tipos reducidos o superreducidos de IVA para estos productos de primera necesidad y a reconocer la rebaja al $4 \%$ de IVA.

Vemos entonces cómo las políticas de nuestro país - fueron propuestas llevadas a cabo por mujeres-, comenzaron a poner sobre la mesa la necesidad de disminuir el precio de estos productos considerándolos como necesidades básicas.

Aun así, estudiando el Boletín Oficial del Estado, vemos que en la Ley N³, (2007), para la igualdad efectiva de mujeres y hombres, aunque hay leyes encaminadas a lograr la equidad, no se incluye el problema de la menstruación que estamos hablando a pesar de que, como hemos visto, en muchos países ya sea catalogado como un derivante de desigualdad.

Así, desde que se comenzó a debatir en el 2016, a fecha de 2019 seguimos en la misma situación con respecto al precio de los productos y sin que se incluya en las políticas de igualdad nada con respecto a los derechos de las menstruantes, es decir, sin incluir todos los aspectos anteriormente mencionados. 
De hecho, dada esta situación, existe una iniciativa llamada TamponsFromCanada, que hace pedidos masivos a Canadá de tampones para presionar la bajada del impuesto en este país a un 4\%, con el argumento de "nos sale más barato comprar los tampones en Canadá que en el supermercado de la esquina" TamponsFromCanada (2016).

Así, observando el mapa del mundo a fecha de 2019 en cuanto a políticas entorno a la menstruación que se están llevando a cabo, se vería como en la siguiente imagen:

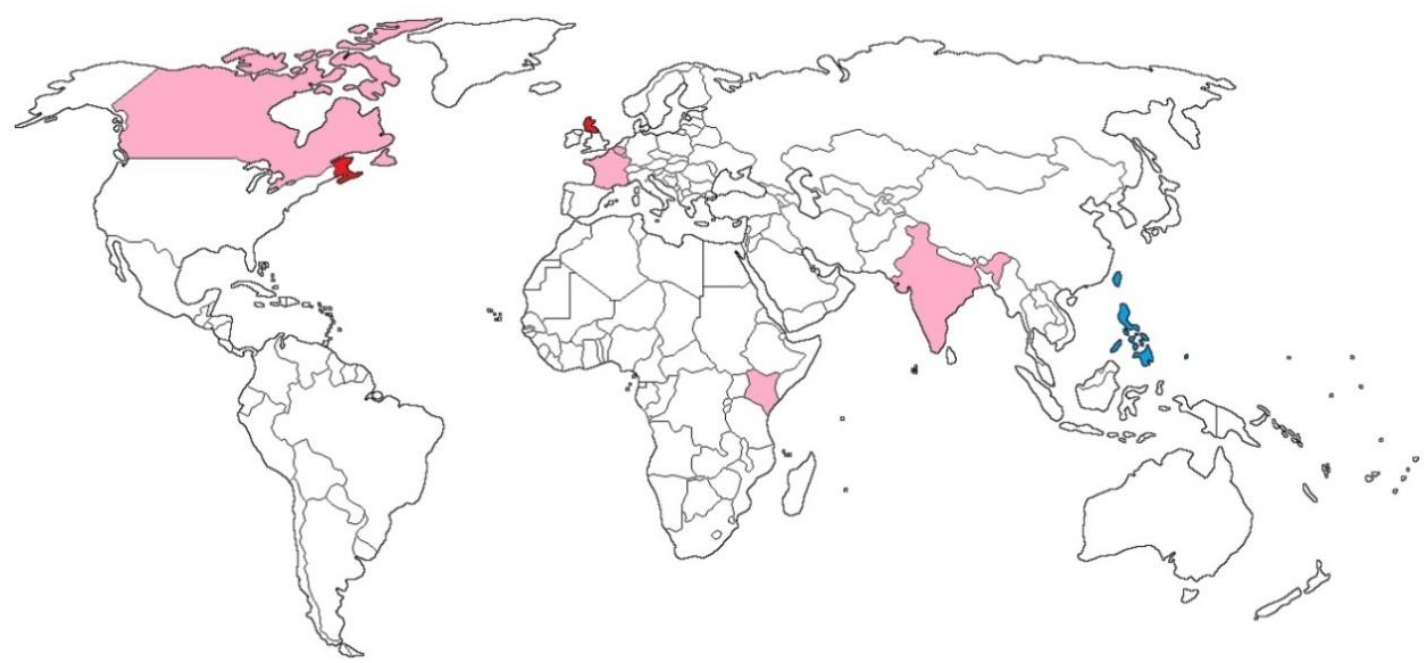

Figura 1. Mapamundi con los países en los que se están llevando a cabo políticas a favor de una gestión digna de la menstruación coloreados.

Nota: Elaboración propia a partir de mapa político mudo de Outline World Maps Images (2018)

En el mapa quedan representados los países en diferentes colores con diferentes significados. En primer lugar, se ven los que están en color rojo (Escocia y Nueva York), que son las zonas en las que se están llevando a cabo políticas en relación a la gestión menstrual más relevantes, después las que se representan en rosa (Canadá, Francia, Bélgica, India y Kenia), que son en las que se ha conseguido reducir o suprimir el IVA o Tasa Rosa añadida a los productos de retención o absorción de sangre y en azul (Japón), zona en la que se contemplan derechos laborales para las menstruantes. 


\section{OBJETIVOS}

Los objetivos de esta investigación son, por un lado, diseñar y validar un cuestionario para conocer la situación de las menstruantes en cuanto a la gestión menstrual y, por otro lado, visibilizar la situación en la que nos encontramos.

- OE1. Analizar y estudiar la bibliografía existente en relación a la menstruación.

- OE2. Comprender las vivencias de las menstruantes desde su propia experiencia.

- OE3. Analizar cuáles son las creencias, mitos o enseñanzas transmitidas culturalmente y la influencia que éstos tienen para el desarrollo de una gestión de la menstruación digna.

- OE4. Analizar el conocimiento, el uso, la facilidad de las menstruantes para encontrar los productos y la accesibilidad económica de los mismos.

- OE5. Analizar el conocimiento y acceso de medicamentos u otras alternativas para paliar dolores o desórdenes hormonales causados por la menstruación.

- OE6. Evaluar cómo y quién les ha informado a lo largo de su vida.

- OE7. Examinar cuáles son las condiciones de los espacios en los que se asean.

- OE8. Analizar cuáles son las creencias, mitos o enseñanzas transmitidas culturalmente y la influencia que éstos tienen para el desarrollo de una gestión de la menstruación digna.

- OE9. Validar cuestionario creado ad hoc para las menstruantes.

\section{METODOLOGÍA}

\subsection{FASES DE LA INVESTIGACIÓN}

En relación con la metodología seguida para llevar a cabo el objetivo de la investigación, ha sido de tipo descriptiva ya que el objetivo es conocer cómo se vivencia la gestión de la menstruación. A continuación se detallan las fases que se ha seguido y las tareas que se han desarrollado (Gráfico 2). 


\section{Fase 1: Revisión bibliográfica}

Revisión de investigaciones e instrumentos utilizados en estudios anteriores

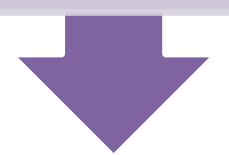

\section{Fase 2: Investigación cualitativa}

Implementación de talleres diagnósticos en Melilla Acoge y el Centro de Estancia Temporal de Inmigrantes (CETI) (Melilla). Entrevistas online con Instagram.

\section{Fase 3: Construcción de cuestionario}

Revisión y análisis talleres diagnósticos y entrevistas y construcción del instrumento de la presente investigación.

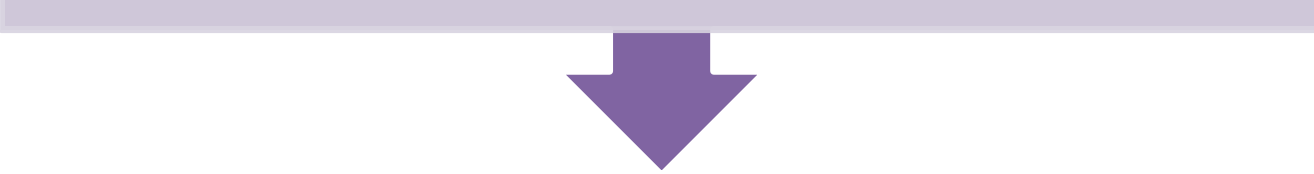

\section{Fase 4: Aplicación y validación del cuestionario}

Aplicación en la Universidad de Granada (Campus de Melilla).

Figura 2. Fases para la creación y validación del cuestionario.

\subsection{PARTICIPANTES}

El muestreo realizado para la selección de las participantes, ha sido no probabilístico de tipo incidental ya que se han elegido a las participantes que se encontraban en el momento en el Campus de Melilla. Además, como criterio de selección ha sido que tuviesen o que hubiesen tenido un cuerpo menstruante.

Así, el total de participantes ha sido de 100. El 98\% de las mismas se identifican con el género femenino y el $100 \%$ tienen vagina. En cuanto a la edad, la media de las participantes es de 24.87 y la desviación típica de 7.82, teniendo las de menor edad 18 
años y las mayores 55. Esta muestra se ha dividido en 3 grupos como se muestra en el siguiente gráfico: (1) de 18 a 21 años, (2) de 22 a 25 años y (3) mayores de 26 años

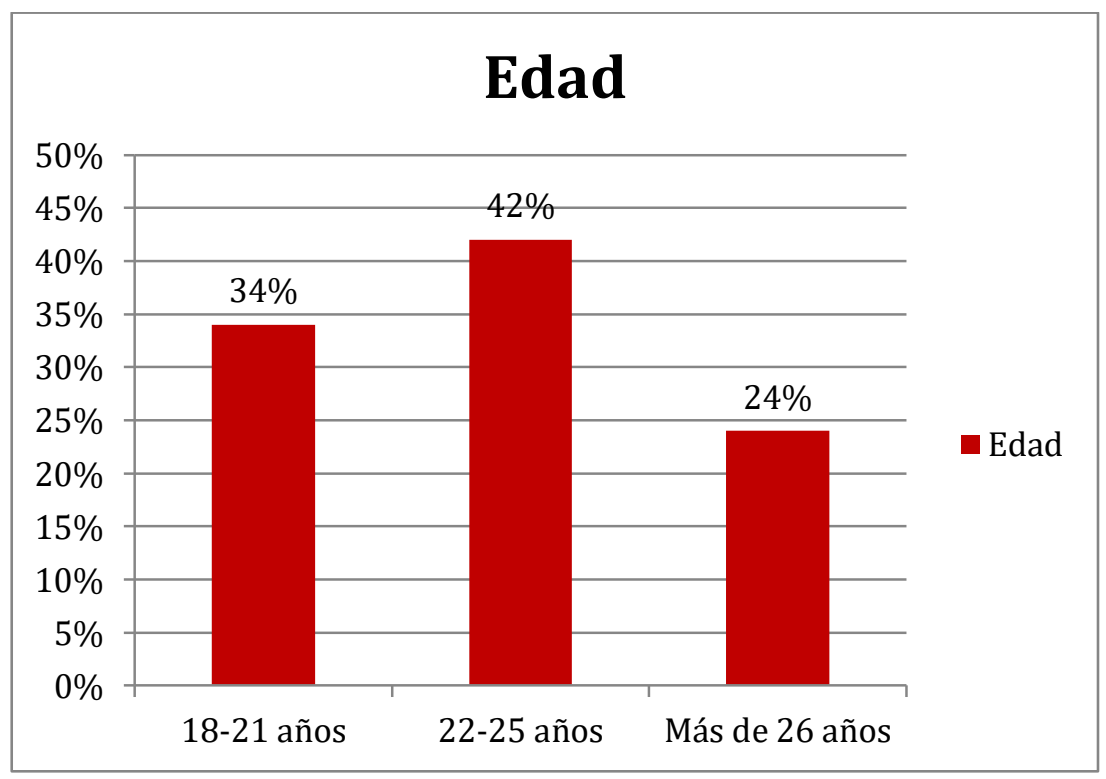

Gráfica 1.: Edad de las participantes

Atendiendo al país de procedencia, el 98\% son nacidas en España y las restantes en Marruecos. En cuanto a la religión o creencias de las mismas, nos encontramos con 4 grupos; cristianas, musulmanas, ateas-agnósticas y budistas. Las participantes que se definen como ateas y agnósticas, aunque no signifiquen lo mismo, se han unido para que tengan mayor representatividad. Dado el bajo porcentaje de budistas (3\%), se ha optado por desestimar la muestra. (Gráfico 2)

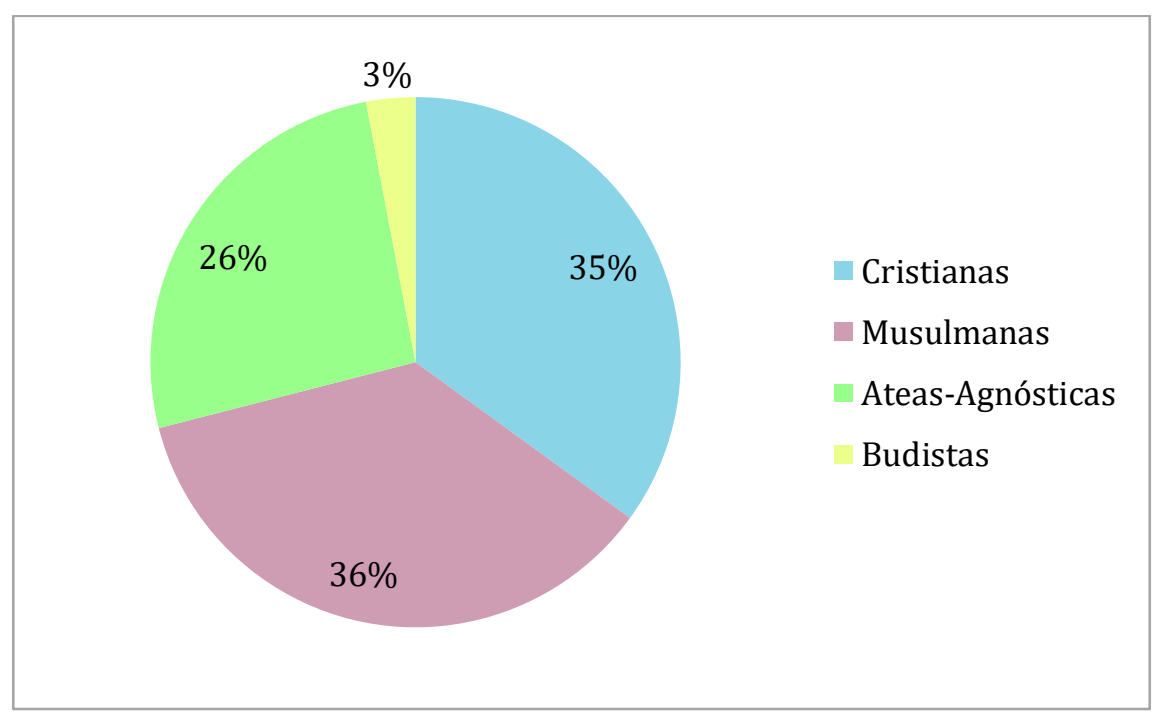

Gráfica 2. Religión o creencia de las participantes 
Así, el 36\% de las participantes se identifican como musulmanas, el 35\% como cristianas, el 26\% como ateas o agnósticas y únicamente el 3\% como budistas. Dado el bajo porcentaje de budistas, se analizarán los 3 primeros grupos.

En cuanto al nivel económico de las mismas, el $66 \%$ ronda entre ningún recurso o menos de 600 euros, siendo un $14 \%$ de 600 a 999, $8 \%$ de 1000 a 1499, $3 \%$ de 1500 a 2000 y $9 \%$ con más de 2000 euros.

En cambio, cuando miramos la ocupación de éstas, vemos que las que están sin trabajo responden a un $66 \%$ frente a quienes están trabajando, un 34\%. Ésto se puede explicar por la dependencia económica familiar, ya que el $90 \%$ son estudiantes y el 10\% trabajadoras.

En cuanto a los días de sangrado, las participantes tienen de media 5.56 días mensuales, siendo el mínimo de días 1 y el máximo 10, encontrando también un 5\% de ellas que no menstrúan porque al alcanzado ya la menopausia en una media de 47.2 años.

Analizando el nivel de estudios, la mayoría de ellas (72\%) son estudiantes o tienen el graduado, el $14 \%$ el máster o doctorado y el 14\% el colegio, bachiller o grado medio y grado superior.

\subsection{INSTRUMENTO}

Para la elaboración del instrumento, en la Fase 1, y una vez que se tuvo claro el objeto de estudio sobre el que se iba a trabajar, se comenzó con la revisión de trabajos científicos nacionales e internacionales como: Osseiran y Jasarevic (2014), Botello y Casado (2015), Guillo-Arakistain (2013), Mahon y Cavill (2012), Johnston-Robledo y Chrisler (2011), Alarcón-Nivia (2005) entre otros), que sirvieron de base para la construcción del marco teórico. También se realizó una búsqueda de instrumentos de medidas que sirvieran de referencia (Ramirez (2003), Dasgupta y Sarkar (2008), Guya, Mayo y Kimwaga (2013). Para completar la información se llevaron a cabo entrevistas on line a través de Instagram (Anexo 1) y talleres diagnósticos (Anexo 2), (Fase 2).

Una vez recopilada esta información, se pasó a la Fase 3: construcción de un cuestionario ad hoc, el cual costa de 4 bloques a analizar, como aparece en la siguiente imagen: 


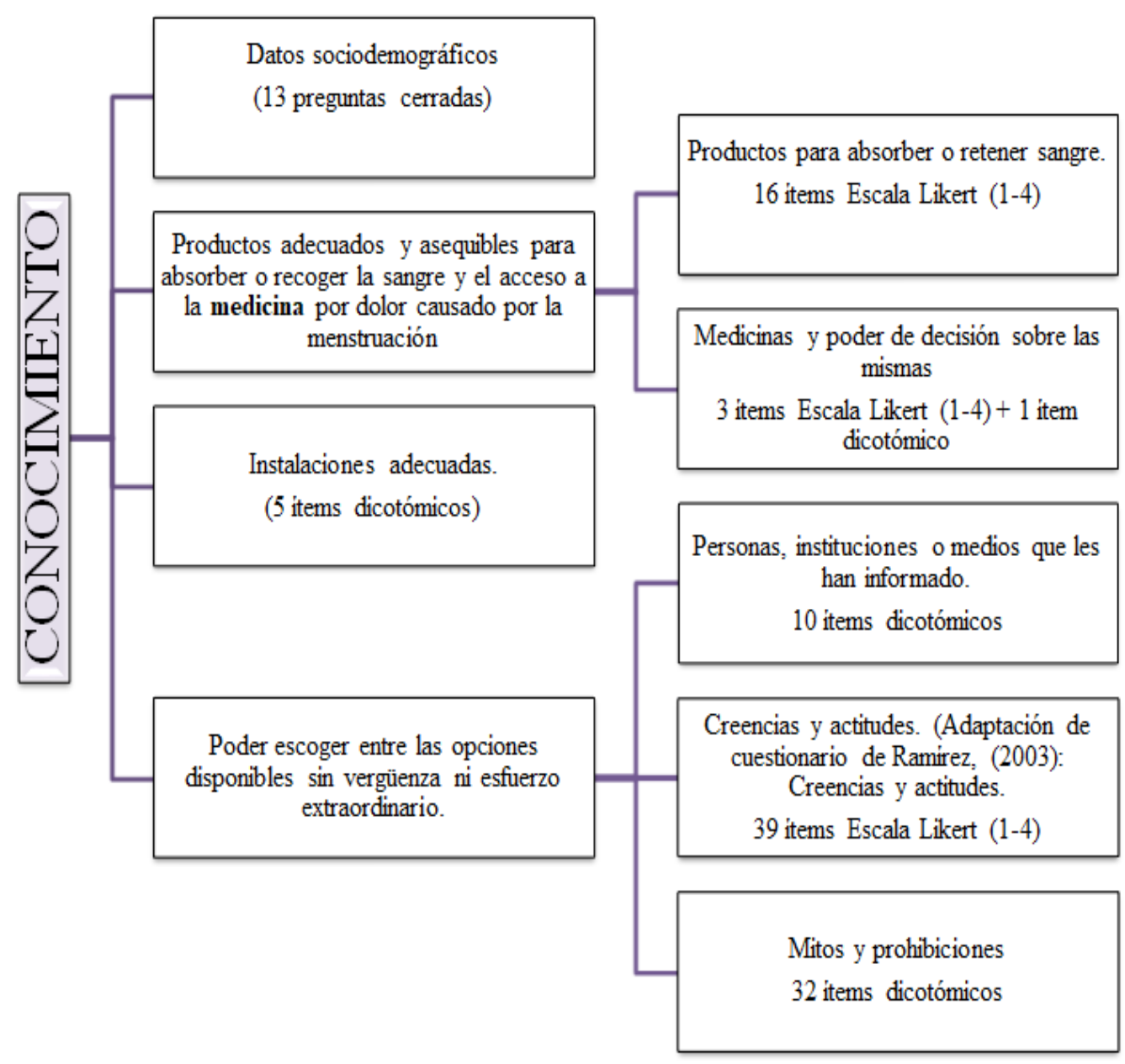

Figura 3. Bloques de los que se compone el cuestionario. Elaboración propia.

Los bloques de productos, medicina y mitos han sido creados a través de la revisión bibliográfica, entrevistas por Instagram (anexo 1), y talleres diagnósticos (anexo 2). El de instalaciones, siguiendo la propuesta de Human Rights Watch (2017) en la que está basada esta investigación.

El de creencias y actitudes acerca de la menstruación está basado y adaptado del cuestionario de Ramirez (2003) con algunas modificaciones a fin de que se adaptase a los objetivos de la presente investigación. En el mismo apartado, está incluido un apartado inspirado en el trabajo de Dasgupta y Sarkar (2008) sobre las causas de la menstruación.

El de "aprendizaje" está inspirado en la investigación realizada por Gulla, Mayo y Kimwaga (2013) añadiendo algunas variables como anuncios o personas de género masculino que puedan estar o haber estado en la vida de las menstruantes. 


\subsubsection{VARIABLES}

A continuación se representan las variables del cuestionario. Por un lado, se muestran las variables independientes, que corresponden al bloque 1(características sociodemográficas), y, por otro lado, las variables dependientes que son las que componen los siguientes bloques.

\begin{tabular}{|c|c|c|c|c|c|c|c|c|c|c|c|}
\hline Sociodemográficas & $\begin{array}{ll}\text { - } & \text { Edad } \\
\text { - } & \text { Género } \\
\text { - } & \text { Sexo }\end{array}$ & \multicolumn{2}{|c|}{$\begin{array}{ll}\text { - } & \text { Religión/ creencia } \\
\text { - } & \text { Nivel de escolaridad } \\
\text { - } & \text { Ocupación }\end{array}$} & \multicolumn{6}{|c|}{$\begin{array}{ll}\text { - } & \text { Recursos económicos } \\
\text { - } & \text { Dependiente/independiente física/mental } \\
\text { - } & \text { Asistencia a consulta ginecológica } \\
\end{array}$} & \multicolumn{2}{|c|}{$\begin{array}{l}\text { - } \quad \text { Días sangrado al mes } \\
\text { - } \quad \text { Edad menarquia y climaterio }\end{array}$} \\
\hline \multirow{4}{*}{$\begin{array}{l}\text { Productos adecuados y } \\
\text { asequibles para absorber o } \\
\text { recoger la sangre y el } \\
\text { acceso a la medicina por } \\
\text { dolor causado por la } \\
\text { menstruación }\end{array}$} & \multirow{4}{*}{$\begin{array}{l}\text { - } \text { Conocimiento } \\
\text { - Uso } \\
\text { - Facilidad de encontrar } \\
\text { - Acceso económico } \\
\text { - } \begin{array}{l}\text { Asistencia a la consulta } \\
\text { ginecológica }\end{array}\end{array}$} & \multicolumn{10}{|c|}{ Productos } \\
\hline & & \multicolumn{2}{|c|}{$\begin{array}{l}\text { Compresa } \\
\text { Salva-slip } \\
\text { Tampón } \\
\text { Compresa ecológica }\end{array}$} & \multicolumn{2}{|c|}{$\begin{array}{l}\text { Compresa lavable y } \\
\text { reutilizable } \\
\text { SalvaSlip lavable y } \\
\text { reutilizable } \\
\text { Tampón de crochet }\end{array}$} & \multicolumn{4}{|c|}{$\begin{array}{l}\text { Bragas absorbentes } \\
\text { Calzoncillos absorbentes } \\
\text { Esponja marina } \\
\text { Telas }\end{array}$} & \multicolumn{2}{|c|}{$\begin{array}{l}\text { Gasas } \\
\text { Bragas/calzoncillos de plástico } \\
\text { Pañales } \\
\text { Sangrado libre } \\
\text { Otros }\end{array}$} \\
\hline & & \multicolumn{10}{|c|}{ Medicina } \\
\hline & & \multicolumn{3}{|c|}{$\begin{array}{l}\text { Farmacológica } \\
\text { Natural }\end{array}$} & \multicolumn{3}{|c|}{$\begin{array}{l}\text { Remedios caseros } \\
\text { Otras }\end{array}$} & & \multicolumn{3}{|c|}{$\begin{array}{l}\text { Medicación por decisión propia } \\
\text { Medicación por desconocimiento }\end{array}$} \\
\hline \multicolumn{8}{|c|}{$\begin{array}{l}\text { Instalaciones adecuadas para cambiar materiales menstruales con privacidad, dignidad y seguridad y la posibilidad de usar } \\
\text { jabón y agua para lavar el cuerpo, teniendo en cuenta la necesaria disponibilidad en aquellos lugares en los que las mujeres } \\
\text { pasen gran parte del tiempo como pueda ser el lugar de trabajo, escuelas o centros de salud. }\end{array}$} & \multicolumn{3}{|c|}{\begin{tabular}{l|} 
Lugar de estudios \\
Lugar de trabajo \\
Centro médico
\end{tabular}} & $\begin{array}{l}\text { Lugar en el que vive } \\
\text { Vive en la calle } \\
\text { Otros }\end{array}$ \\
\hline \multirow{5}{*}{\multicolumn{2}{|c|}{$\begin{array}{l}\text { Conocimiento de la menstruación a fin de que sean las } \\
\text { mujeres y niñas las que puedan escoger entre las opciones } \\
\text { disponibles sin vergüenza ni esfuerzo extraordinario. }\end{array}$}} & \multicolumn{10}{|c|}{ Información } \\
\hline & & $\begin{array}{l}\text { Persona o } \\
\text { institución }\end{array}$ & $\begin{array}{l}\text { Madre } \\
\text { Padre } \\
\text { Hermana } \\
\text { Hermano }\end{array}$ & \begin{tabular}{|l|} 
Colegio/ins- \\
tituto \\
Amigas \\
Anuncios \\
\end{tabular} & \multicolumn{2}{|c|}{$\begin{array}{l}\text { Libros } \\
\text { Internet } \\
\text { Otros }\end{array}$} & 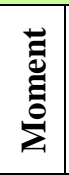 & \multicolumn{4}{|c|}{$\begin{array}{l}\text { Antes del primer sangrado } \\
\text { Después del primer sangrado }\end{array}$} \\
\hline & & \multicolumn{10}{|c|}{ Creencias, actituc } \\
\hline & & \multicolumn{2}{|c|}{$\begin{array}{l}\text { Secreto (12) } \\
\frac{1,2,6^{*}, 10,18,19}{22,25,27,29,32,33}\end{array}$} & \multicolumn{2}{|c|}{$\begin{array}{l}\text { Molesto(13) } \\
4,5,8,13,14,15,17 \\
20,24,26,28,35,38\end{array}$} & \multicolumn{3}{|c|}{$\begin{array}{l}\text { Debilitante (7) } \\
3,7,11,16,39 \\
41,43 .\end{array}$} & \multicolumn{2}{|c|}{$\begin{array}{l}\text { Positivo (7) } \\
21,30,31,34,40 \\
42,44 .\end{array}$} & $\begin{array}{l}\text { Conocimiento } \\
9,12,23,36,37 .\end{array}$ \\
\hline & & \multicolumn{10}{|c|}{ 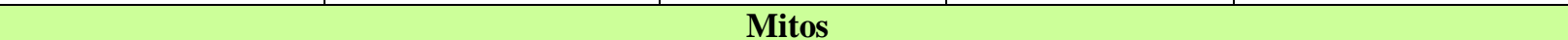 } \\
\hline \multicolumn{2}{|c|}{ *Los ítems 1,2 y 6 de evento secreto se califican de manera inversa. } & \multicolumn{10}{|c|}{$\begin{array}{l}\text { Prohibiciones y obligaciones menstruación (32) } \\
\text { Deber evitar :1-26 / Deber hacer: } 27-32\end{array}$} \\
\hline
\end{tabular}

Figura 3. Variables que componen el cuestionario. 


\section{RESULTADOS}

\subsection{CONOCIMIENTO DE PRODUCTOS}

En relación con el apartado del cuestionario en el que se analizan el conocimiento de los productos, como se ve en la Tabla 1, Los datos muestran que la asimetría es negativa en los ítems 1, 2, 3 y 4, lo que muestra que existe una mayor concentración de respuestas que denotan puntuaciones altas en esas cuestiones, es decir, alto conocimiento. En cambio, en el resto la simetría es positiva, indicando el bajo o nulo nivel de conocimiento de los mismos.

En relación con la fiabilidad, medida a través del índice de consistencia interna, el alfa de Cronbach es de .832, oscilando la correlación ítem-total corregida desde .152 (compresas) hasta .566 (gasas), tal como se recoge en la siguiente tabla.

Tabla 1.

Conocimiento sobre productos.

\begin{tabular}{|c|c|c|c|c|}
\hline & Mean & $\begin{array}{c}\text { Std. } \\
\text { Deviation }\end{array}$ & Asimetría & $\begin{array}{l}\text { Correlación } \\
\text { ítem total } \\
\text { corregida }\end{array}$ \\
\hline 1. Compresa & 3,95 & .32 & -7.88 & .15 \\
\hline 2. Salva Slip & 3,83 & .63 & -3.67 & .20 \\
\hline 3. Tampón & 3,51 & 1.01 & -1.86 & .43 \\
\hline 4. Copa menstrual & 2.57 & 1.31 & -.032 & .50 \\
\hline 5. Compresa ecológica & 1.85 & 1.20 & .95 & .50 \\
\hline 6. Compresa lavable y reutilizable & 1.54 & .99 & 1.65 & .56 \\
\hline 7. Salva Slip lavable y reutilizable & 1.41 & .88 & 2.08 & .50 \\
\hline 8. Tampón de crochet & 1.08 & .41 & 5.58 & .31 \\
\hline 9. Bragas absorbentes & 1.51 & .96 & 1.73 & .49 \\
\hline 10. Calzoncillos absorventes & 1.18 & .65 & 3.71 & .53 \\
\hline 11. Esponja marina & 1.20 & .69 & 3.55 & .51 \\
\hline 12. Telas & 1.83 & 1.16 & 1.00 & .55 \\
\hline 13. Gasas & 2.16 & 1.26 & 0.47 & .56 \\
\hline 14. Bragas/ calzoncillos de plástico & 1.31 & .78 & 2.67 & .43 \\
\hline 15. Pañales & 2.48 & 1.40 & 0.31 & .43 \\
\hline 16. No uso (sangrado libre) & 1.64 & 1.20 & 1.33 & .42 \\
\hline
\end{tabular}


Posteriormente, se procedió a medir la validez de este bloque mediante el Análisis Factorial Exploratorio (AFE), las pruebas de Kaiser, Meyer y Olkin $(\mathrm{KMO}=.758)$ y de Barlett $\left(\mathrm{c}^{2}=575.750 ; \mathrm{gl}=123 ; p<.001\right)$, encontrado valores que permiten la utilización del análisis factorial como técnica idónea para interpretar la información contenida en esta matriz.

Este bloque de ítems se distribuye en 4 factores o dimensiones, claramente delimitados (Tabla 2), que explican el $59.368 \%$ de la varianza total, siendo esta proporción aceptable.

Tabla 2.

Conocimiento de productos de absorción o retención de sangre por factores.

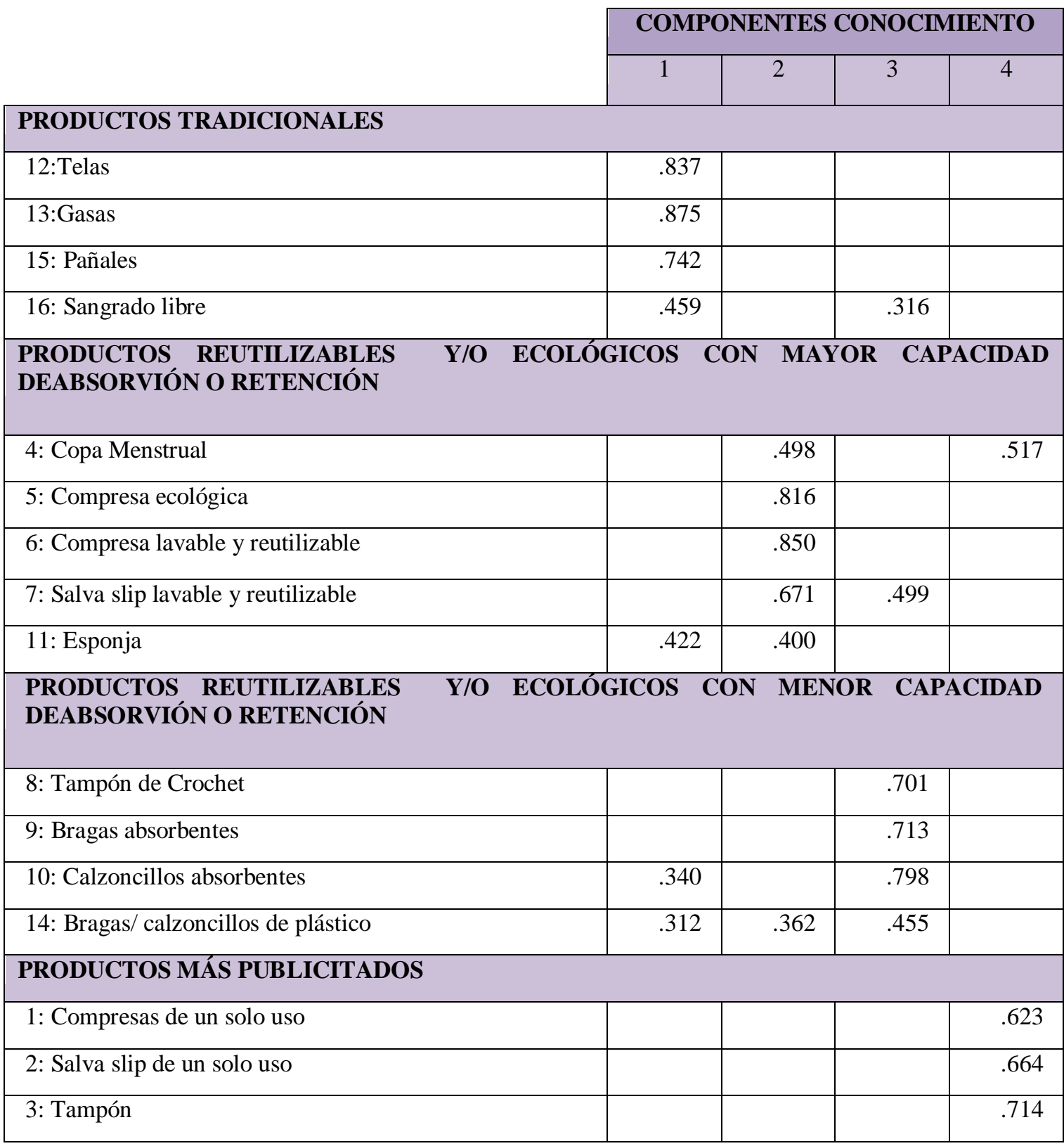


En cuanto a la facilidad para encontrar los mismos productos, como se refleja en la siguiente gráfica, las compresas, tampones, copas menstruales, telas, gasas, pañales y sangrado libre son las que las participantes consideran más accesibles, coincidiendo con el conocimiento de los mismos.

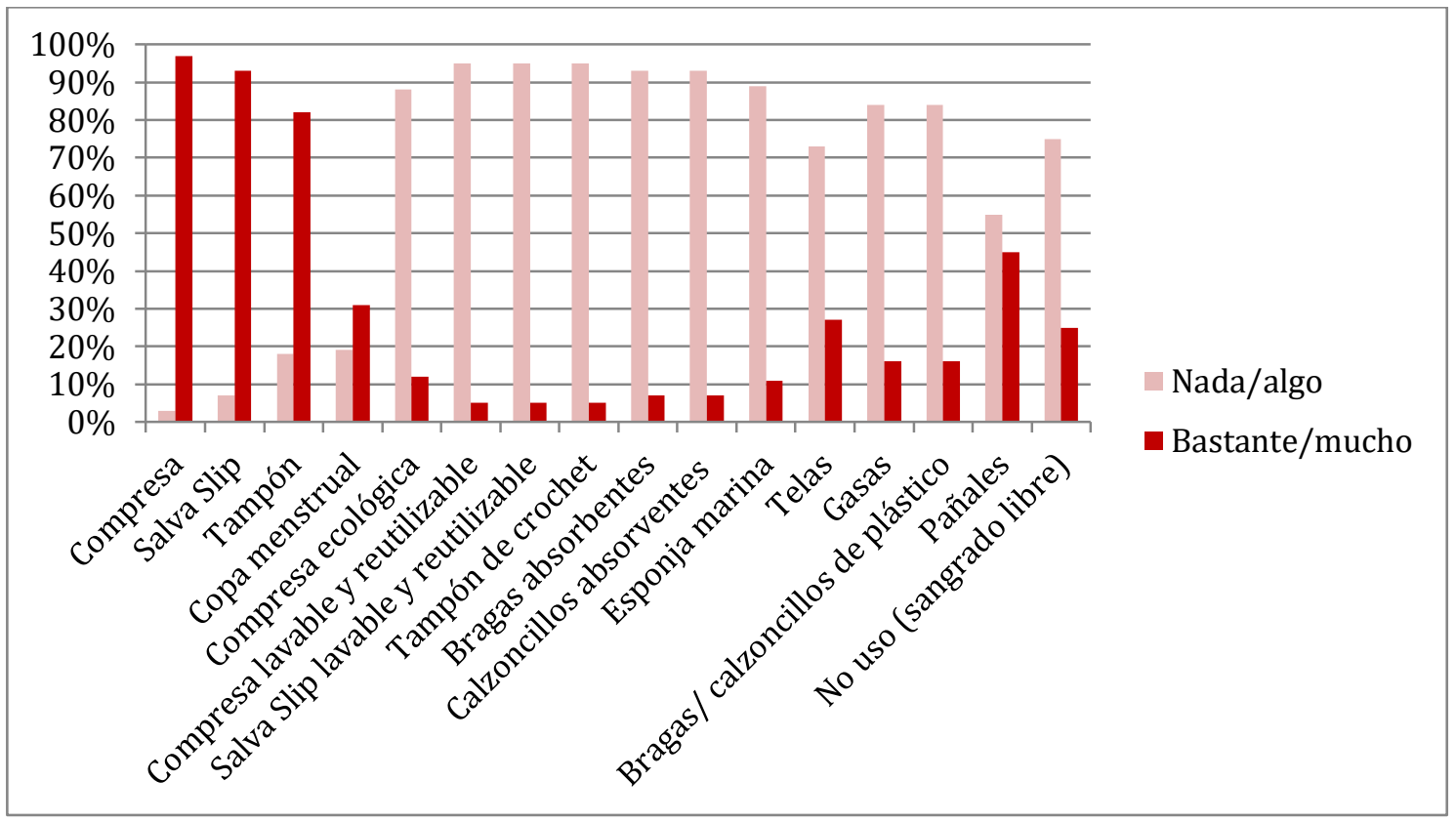

Gráfica 4. Facilidad para encontrar los diferentes productos de absorción o retención de sangre.

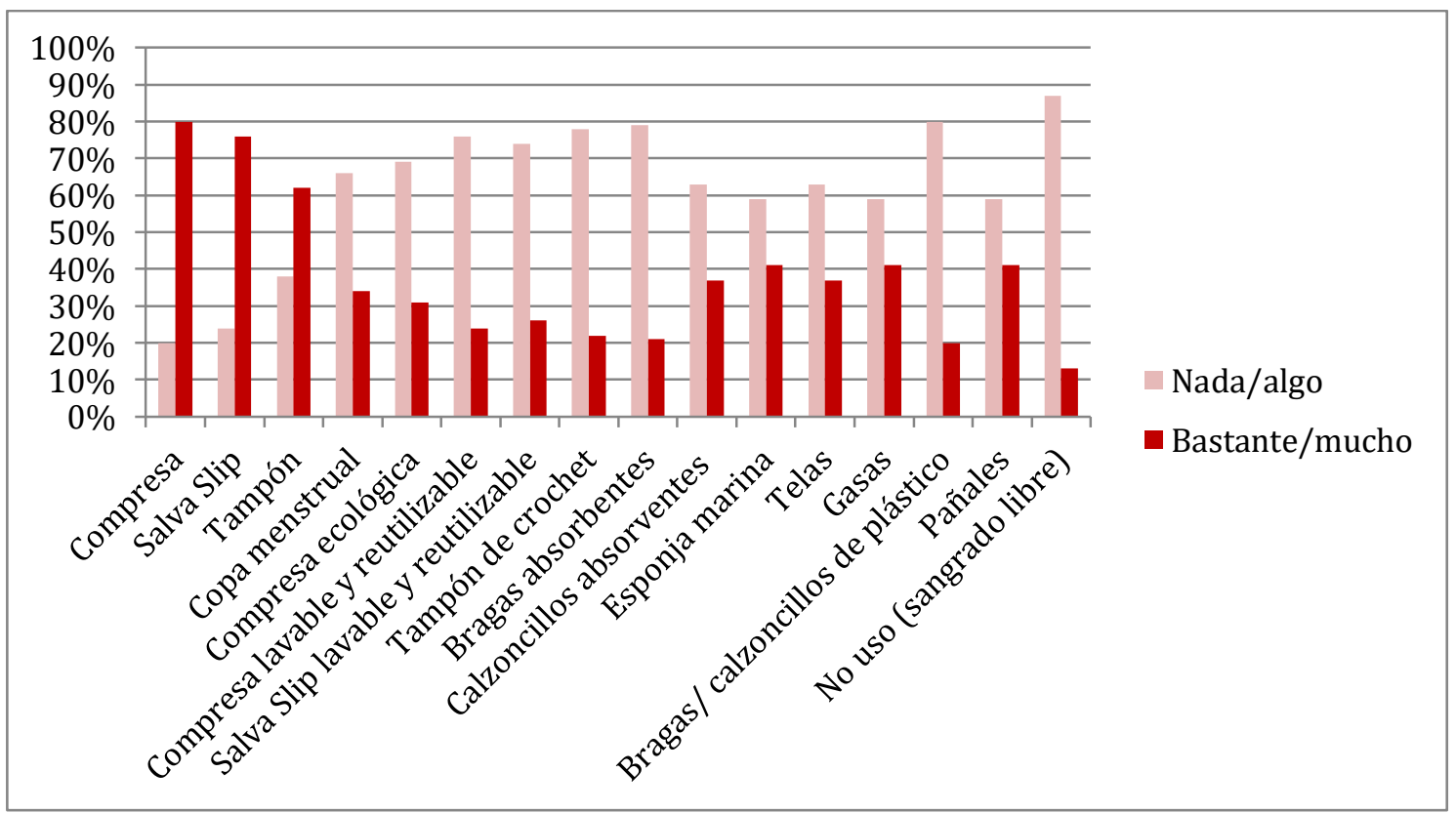

Gráfica 5. Accesibilidad económica de los diferentes productos de absorción o retención de sangre. 
Como se ve en el gráfico 5, las participantes presentan accesibilidad económica para la mayoría de los productos, siendo las compresas, salva slip, tampones, copas menstruales, calzoncillos, esponjas, telas, gasas y pañales en los que más. Comparando la facilidad para encontrar el producto más puntuado (compresas), vemos que es de un 97\%, es decir, casi todas las participantes tienen acceso a él, en cambio, la accesibilidad económica al mismo varía, siendo un $80 \%$ las que pueden comprarlo con facilidad.

A continuación se procedió a analizar la relación de conocimiento, uso, accesibilidad y economía en relación a las características sociodemográficas de la población. En primer lugar, se analizara si la religión o creencias de las participantes guardan relación con estas variables.

En cuanto a la relación entre conocimiento y religión, no existen diferencias significativas, aunque en el factor 3 de conocimiento (productos reutilizables y/o ecológicos con menor capacidad de absorción o retención), son las musulmanas las que las que tienen más conocimiento $\left(\mathrm{M}_{\text {cristianas }}=4.65 ; \mathrm{M}_{\text {musulmanas }}=5.44 ; \mathrm{M}_{\mathrm{AGT}}=4.64\right)$. En el factor 1, aunque no existen diferencias en el, sí que existen ene 1 ítem 12 (telas) (conocimiento de los productos tradicionales), se observan diferencias en el conocimiento de las telas, siendo las musulmanas las que obtienen mayores medias $\left(\mathrm{M}_{\text {cristianas }}=1.54 ; \mathrm{M}_{\text {musulmanas }}=2.13 ; \mathrm{M}_{\mathrm{AGT}}=1.57 ; \mathrm{F}=3.12 ; \mathrm{p}<.05\right)$.

Con respecto al uso de los productos, existen diferencias en el factor 4 (productos más publicitados), siendo las cristianas las que puntúan más alto, es decir, son las que más usan compresas, salva slip y tampones, existiendo una diferencia significativa en el uso del tampón, siendo las cristianas las que más lo usan y las que menos las musulmanas. $\left(\mathrm{M}_{\mathrm{CRIS}}=2.68 ; \mathrm{M}_{\mathrm{MSL}}=1.39 ; \mathrm{M}_{\mathrm{ATG}}=1.96 ; \mathrm{F}=12.66 ; \mathrm{p}<.001\right)$.

En la siguiente gráfica se analiza el uso en función de las variables religión y edad. Los datos reflejan que las mujeres cristianas son las que hacen más uso del tampón, siendo las que más lo usa, las de la franja de edad de 22 a 25, seguidas de las de 26 en adelante. 


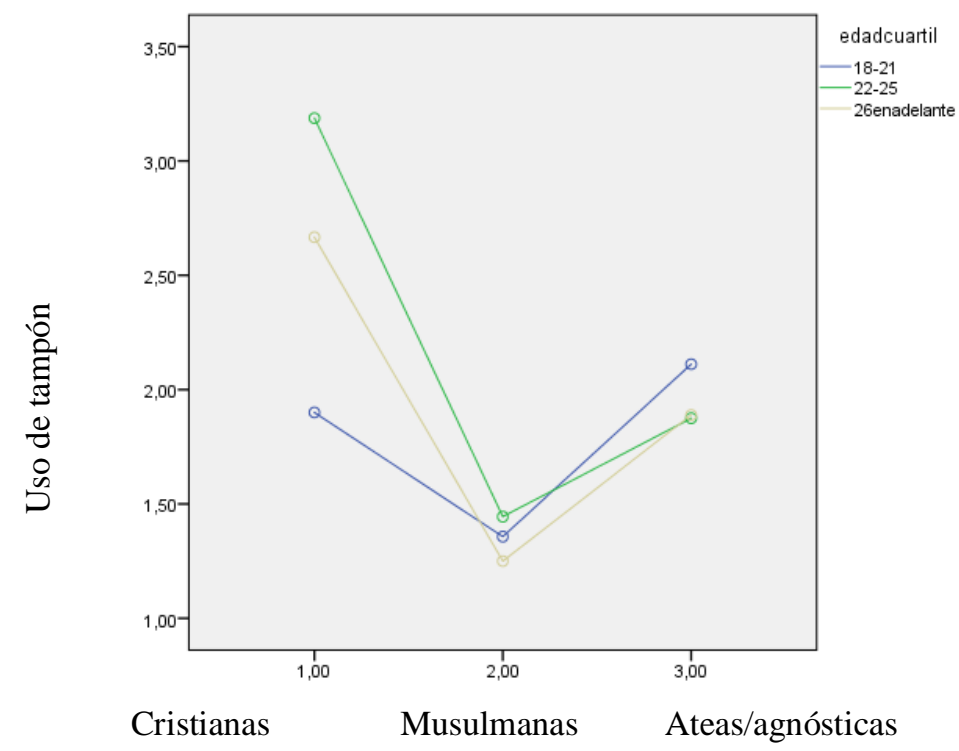

Gráfica 6. Relación entre religión o creencia, edades y uso del tampón.

Por otro lado, en cuando a la capacidad para encontrar, existen diferencias significativas en el factor 4 (Productos reutilizables y/o ecológicos con menor capacidad de absorción o retención) en relación a la religión o creencia, siendo en el en especial en calzoncillos o bragas de plástico las ateas o agnósticas las que mayor dificultad encuentran para encontrarlos y las musulmanas las que menos $\left(\mathrm{M}_{\mathrm{CRIS}}=1.31\right.$; $\left.\mathrm{M}_{\mathrm{MSL}}=1.47 ; \mathrm{M}_{\mathrm{ATG}}=0.88 ; \mathrm{F}=3.19 ; \mathrm{p}<.05\right)$. No existen diferencias significativas en relación a la edad con facilidad para encontrar.

En relación a la accesibilidad económica, existen diferencias en el factor 1, siendo las mujeres musulmanas las que responden tener mayor accesibilidad económica con respecto a las cristianas, ateas y agnósticas $\left(\mathrm{M}_{\mathrm{CRIS}}=1.77 ; \mathrm{M}_{\mathrm{MSL}}=2.47 ; \mathrm{M}_{\mathrm{ATG}}=1.50\right.$; $\mathrm{F}=4.14 ; \mathrm{p}<.05)$. Esta misma tendencia se observa con el producto "pañales" $\left(\mathrm{M}_{\mathrm{CRIS}}=2.17 ; \mathrm{M}_{\mathrm{MSL}}=2.47 ; \mathrm{M}_{\mathrm{ATG}}=1.30 ; \mathrm{F}=5.387 ; \mathrm{p}<.05\right)$. Se entiende que, como estos productos son más conocidos por las mujeres musulmanas, son más conscientes del precio de los mismos, ya que el $21 \%$ del total de las musulmanas responde que sí los conocen. También hay diferencias en el factor 4, considerando las cristianas mayor accesibilidad económica para las compresas siendo las que menos las ateas y agnósticas $\left(\mathrm{M}_{\mathrm{CRIS}}=3.42 ; \mathrm{M}_{\mathrm{MSL}}=3.25 ; \mathrm{M}_{\mathrm{A} / \mathrm{GN}}=2.84 ; \mathrm{F}=3.16 ; \mathrm{p}<.05\right)$. 


\subsection{CONOCIMIENTO MEDICINA Y CONSULTA GINECOLÓGICA}

En el siguiente apartado del cuestionario en el que se analiza los productos utilizados para paliar molestias, tratar enfermedades, desórdenes hormonales u otras razones relacionadas con la menstruación, nos encontramos con que en el apartado “conocer", siendo 1 nada y 4 mucho, en productos farmacológicos el 87\% responde tener bastante o mucha información, frente al $47 \%$ que conoce medicación natural y el $53 \%$ los remedios caseros.

En cuanto al uso, el $63 \%$ se medica bastante o mucho con medicación farmacológica frente al $23 \%$ natural y $32 \%$ remedios caseros, es decir, mayoritariamente conocen y hacen mayor uso de los medicamentos farmacológicos frente a otras alternativas, caseras o naturales.

Realizado un análisis inferencial en función de la variable religión o creencia y en función del conocimiento de estos productos, los datos indican que existen diferencias significativas, siendo las musulmanas las que más remedios caseros conocen $\left(\mathrm{M}_{\mathrm{CRIS}}=2.77 ; \mathrm{M}_{\mathrm{MSL}}=2.91 ; \mathrm{M}_{\mathrm{ATG}}=1.92 ; \mathrm{F}=5.30 ; \mathrm{p}<.05\right)$. En la misma línea, hay diferencias en cuanto al uso, siendo las musulmanas las que más utilizan los remedios caseros $\left(\mathrm{M}_{\mathrm{CRIS}}=2.08 ; \mathrm{M}_{\mathrm{MSL}}=2.30 ; \mathrm{M}_{\mathrm{ATG}}=1.03 ; \mathrm{F}=3.43 ; \mathrm{p}<.05\right)$.

Analizando el cuestionario en función de la variable recursos económicos, los datos muestran que no existen diferencias con respecto a la misma.

Los estadísticos descriptivos muestran que, de las personas que toman medicación, el $56.9 \%$ dice que la toma porque considera que es la mejor opción frente al $43.1 \%$ porque "no conocen otra opción".

En cuanto a la asistencia a la consulta ginecológica, el $36.1 \%$ no ha ido nunca, habiendo una diferencia significativa en cuanto a religión o creencia $\left(\mathrm{M}_{\mathrm{CRIS}}=1.11\right.$; $\mathrm{M}_{\mathrm{MSL}}=1.62 ; \mathrm{M}_{\mathrm{ATG}}=1.35 ; \mathrm{F}=9.58 ; \mathrm{p}<.001$ ), siendo las cristianas las que más han ido a la consulta y las musulmanas las que menos.

En relación con la variable edad, encontramos diferencias significativas, siendo las que más han ido las de la franja de edad mayores de 26 años y las que menos las de 18 a 21 años $\left(\mathrm{M}_{18-21}=1.66 ; \mathrm{M}_{22-25}=1.27 ; \mathrm{M}_{+26}=1.13 ; \mathrm{F}=7.57 ; \mathrm{p}<.001\right)$. 
Por último, en cuanto al análisis inferencial en función de la variable nivel económico, existen diferencias significativas, siendo las que se encuentran en la franja de mayor capacidad económica quienes han ido alguna vez a la consulta ginecológica, y las que menos ingresos tienen las que menos han ido $\left(\mathrm{M}_{\mathrm{NINGUNO}}=1.65 ; \mathrm{M}_{<600}=1.27\right.$; $\left.\mathrm{M}_{</=600 \mathrm{~A} 999}=1.18 ; \mathrm{M}_{1000 \mathrm{~A} 1499}=1.16 ; \mathrm{M}_{1500 \mathrm{~A} 2000}=1.00 ; \mathrm{M}_{>2000}=1.00 ; \mathrm{F}=4.041 ; \mathrm{p}<.003\right)$.

\subsection{ESPACIOS}

Otro apartado a analizar en el cuestionario es el de los espacios, es decir, si las menstruantes cuentan con un espacio con privacidad y las condiciones necesarias para poder cambiarse y lavarse con dignidad. Hay que tener en cuenta en este apartado que las participantes pertenecen a la misma universidad, por lo que el baño a utilizar por ellas en ese espacio el mismo. En cambio, las percepciones son diferentes, siendo el $64 \%$ de las encuestadas quienes consideran que cumple las condiciones, frente al $36 \%$ que responde que no.

En cuanto a las trabajadoras, el $70.6 \%$ expresa que el baño que hay en su trabajo cumple las condiciones frente al $29.4 \%$ que no. En el hospital, un $76 \%$ considera que el espacio está adaptado frente a un $24 \%$ que responde que no. Por último, el $97 \%$ de las participantes tienen un baño que responde a sus necesidades donde vive actualmente, frente a un $3 \%$ que responde no contar con él.

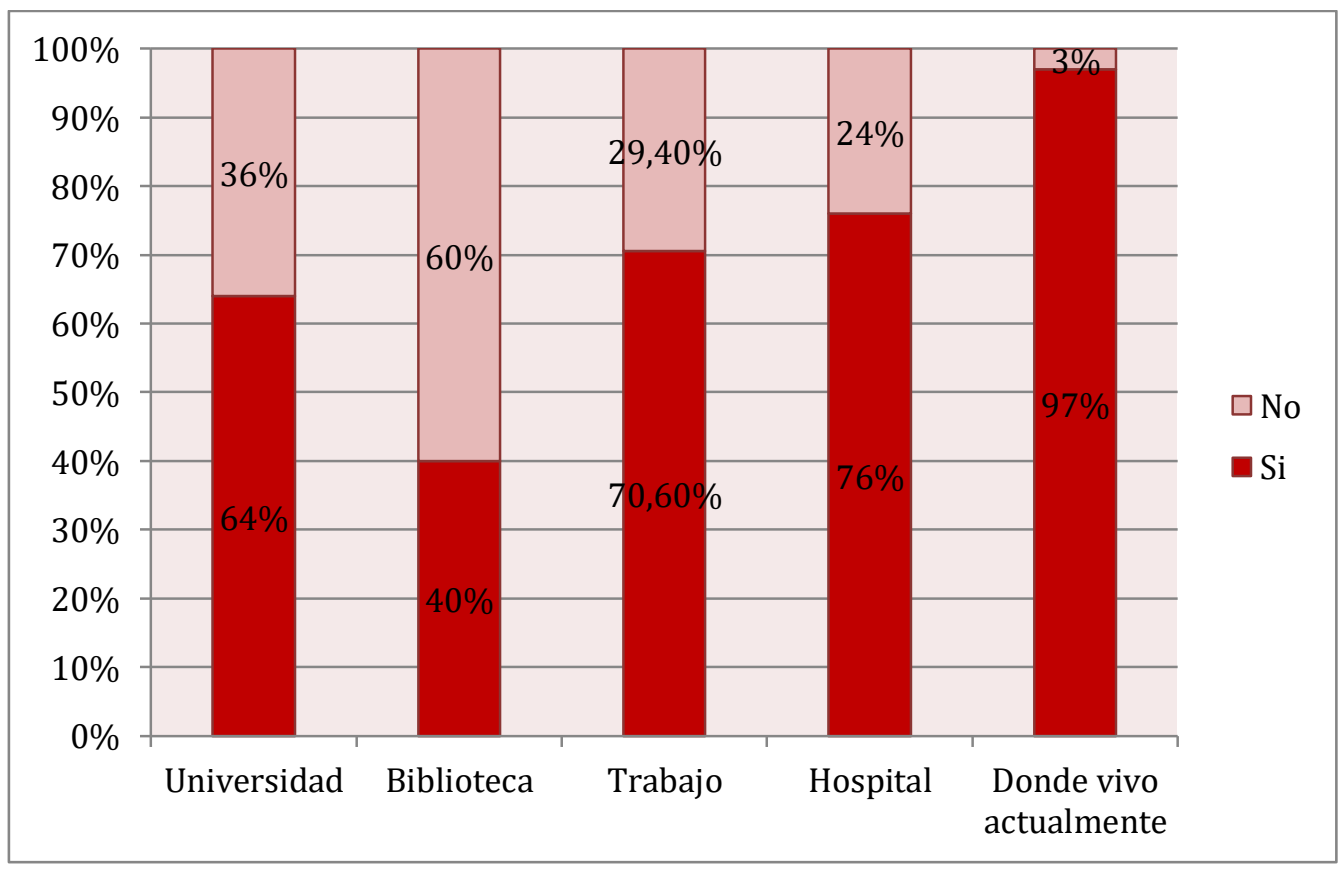

Gráfico 7: Instalaciones adecuadas para cambiar los materiales 


\subsection{CANALES DE INFORMACIÓN SOBRE LA MENSTRUACIÓN}

En relación con los análisis descriptivos relacionados con las personas o instituciones que les han informado sobre la menstruación, tanto antes como después del primer sangrado, los resultados indican que la información la adquirieron mayoritariamente a través de su madre y amigas y en menor porcentaje a través de anuncios publicitarios. Esta tendencia se da también después del primer sangrado, siendo la madre la principal transmisora de conocimientos, seguida de amigas y medios de comunicación (Tabla 3).

Tabla 3

Personas o instituciones de las que han recibido información.

\begin{tabular}{|c|c|c|c|c|}
\hline \multirow{3}{*}{ ¿Quién/ dónde? } & \multicolumn{4}{|c|}{ ¿Cuándo? } \\
\hline & \multicolumn{2}{|c|}{ Antes del primer sangrado } & \multicolumn{2}{|c|}{ Después del primer sangrado } \\
\hline & sí & NO & sí & NO \\
\hline Madre & $83 \%$ & $17 \%$ & $83 \%$ & $17 \%$ \\
\hline Padre & $12 \%$ & $88 \%$ & $18 \%$ & $88 \%$ \\
\hline Hermana & $26 \%$ & $74 \%$ & $30 \%$ & $70 \%$ \\
\hline Hermano & $2 \%$ & $98 \%$ & $9 \%$ & $91 \%$ \\
\hline Colegio/ instituto & $42 \%$ & $58 \%$ & $39 \%$ & $61 \%$ \\
\hline Amigas & $58 \%$ & $42 \%$ & $67 \%$ & $33 \%$ \\
\hline $\begin{array}{c}\text { Anuncios } \\
\text { publicitarios }\end{array}$ & $45 \%$ & $55 \%$ & $50 \%$ & $50 \%$ \\
\hline Libros & $21 \%$ & $79 \%$ & $29 \%$ & $71 \%$ \\
\hline Internet & $33 \%$ & $67 \%$ & $54 \%$ & $46 \%$ \\
\hline Tías & $13 \%$ & $87 \%$ & $9 \%$ & $91 \%$ \\
\hline
\end{tabular}

En relación con los análisis inferenciales y en función de la variable edad, los datos indican que existen diferencias significativas en el ítem "aprender a través de internet" antes del primer sangrado, siendo el grupo de mujeres mayores de 26 años las que no han recibido información a través de este medio $\left(\mathrm{M}_{18-21}=1.529 ; \mathrm{M}_{22-25}=1.642\right.$; $\left.\mathrm{M}_{+26}=1.91 ; \mathrm{F}=5.260 ; \mathrm{p}<.05\right)$.

Analizando los datos en función de la variable religión, existen diferencias significativas en cuanto a la información recibida, tanto antes como después del primer 
sangrado, siendo en ambos casos las musulmanas las que menos información han recibido a través de los anuncios publicitarios $\left(\mathrm{M}_{\text {CRISantes }}=1.542 ; \mathrm{M}_{\text {MSLantes }}=1.361\right.$; $\left.\mathrm{M}_{\text {ATGantes }}=1.80 ; \quad \mathrm{F}=6.731 ; \quad \mathrm{p}<.005\right) \quad / \quad\left(\mathrm{M}_{\text {CRISdespués }}=1.57 ; \quad \mathrm{M}_{\text {MSLdespués }}=1.333 ;\right.$ $\left.\mathrm{M}_{\text {ATGdespués }}=1.615 ; \mathrm{F}=3.14 ; \mathrm{p}<.005\right)$.

Por otro lado, no hay diferencias significativas en las variables formación, edad de menarquía o recursos económicos.

\subsection{CREENCIAS, ACTITUDES Y TABÚES}

\subsubsection{CREENCIAS Y ACTITUDES}

Para medir las creencias y actitudes, se ha utilizado una adaptación del cuestionario de Ramirez (2003). En relación con la fiabilidad, medida a través del índice de consistencia interna, el alfa de Cronbach es de .864. En cuanto a la estructura factorial, se ha mantenido la que sigue la de la autoría del cuestionario anterior, organizada en 4 factores: secreto, debilitante, molesto y positivo. Aun así, puesto que todos los factores tenían una connotación negativa, se ha hecho una modificación del factor positivo, invirtiendo en el análisis los resultados del mismo, configurándolo como a más puntuación, más negativa la respuesta.

Haciendo un análisis descriptivo de cada uno de los factores, vemos en el siguiente gráfico, las creencias y las actitudes de las participantes según cuartiles.

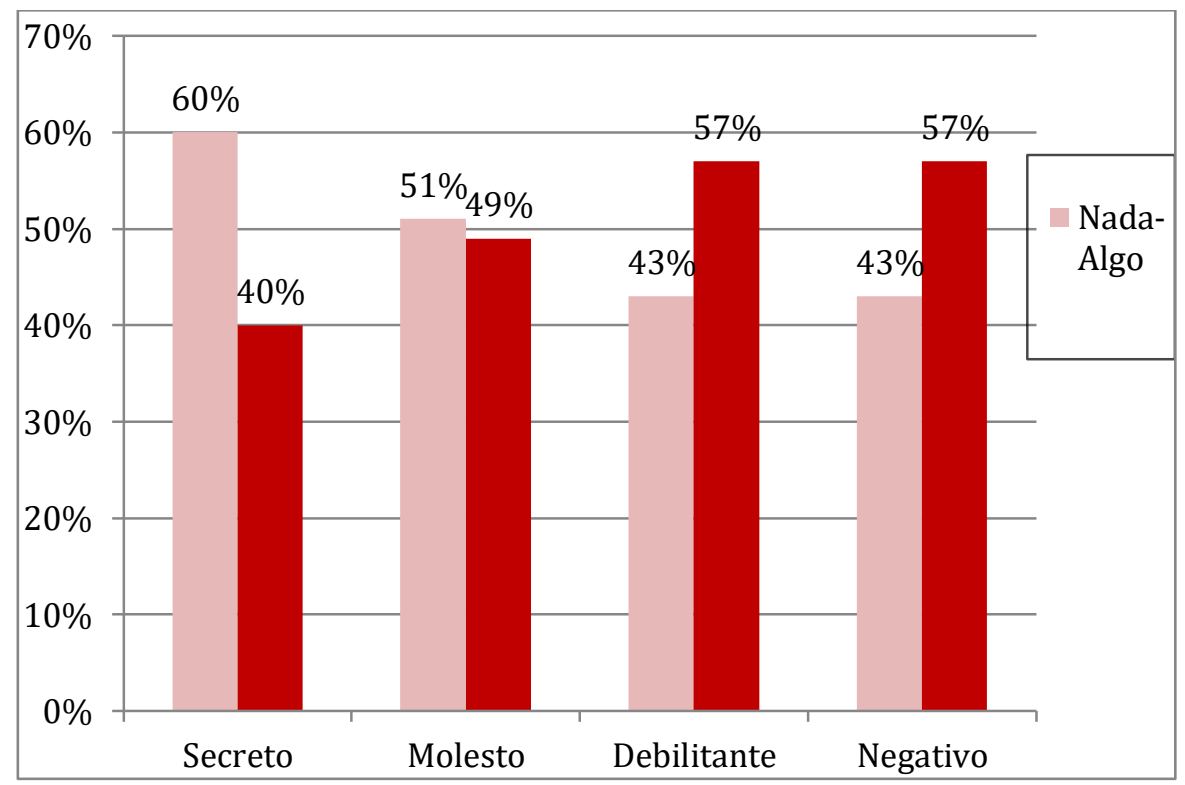

Gráfico 8. Creencias y actitudes hacia la menstruación. 
Como podemos ver, el factor en el que se muestran más en desacuerdo, es en Factor Evento Secreto, siendo un 60\% de las respuestas entre nada o poco de acuerdo. Por otro lado, en el que se muestran más de acuerdo, en ambos casos por encima del $50 \%$, es en el de la menstruación como Evento Debilitante y Negativo.

Analizados los datos del cuestionario creencias y actitudes con un análisis correlacional, los datos indican que la puntuación total del cuestionario correlaciona con cada uno de los factores que lo componen como se muestra en la siguiente tabla:

Haciendo un análisis inferencial en función de la variable religión o creencias, los datos indican que solo existen diferencias significativas en cuanto a la menstruación como Evento Secreto, siendo las musulmanas las que tienen mayores puntuaciones, es decir, las que más secreto lo consideran $\left(\mathrm{M}_{\mathrm{CRIS}}=14.31 ; \mathrm{M}_{\mathrm{MSL}}=18.16 ; \mathrm{M}_{\mathrm{ATG}}=15.61\right.$; $\mathrm{F}=6.99 ; \mathrm{p}<.005)$. No hay diferencias significativas en cuento a la capacidad económica de las participantes, formación ni edad.

Posteriormente, se correlacionó el Evento Secreto con la asistencia a la consulta ginecológica, siendo las que más lo consideran como elemento secreto las que menos han ido a la consulta $\left(\mathrm{r}_{\text {SECRETO/CONSULTA }}=.366 ; \mathrm{p}<.005\right)$.

Además, se realizó un análisis inferencial relacionando Evento Molesto con días al mes de sangrado, vemos que hay diferencias significativas $\left(\mathrm{M}_{\mathrm{NADAPOCO}}=4.25\right.$; $\left.\mathrm{M}_{\mathrm{ALGO}}=5.88 ; \mathrm{M}_{\mathrm{BASTANTE}}=5.48 ; \mathrm{M}_{\mathrm{MUCHO}}=5.66 ; \mathrm{F}=4.43 ; \mathrm{p}<.05\right)$ y son las que más sienten la menstruación como Evento Molesto las que tienen entre 5 y 6 días de sangrado.

En cambio, no existen diferencias significativas para consulta médica, economía, formación u otras variables independientes.

\subsubsection{TABÚES}

Como se muestra en la Tabla 4, en la que se analizan los mitos que tienen interiorizados las menstruantes, en los datos se refleja que la asimetría es negativa en los ítems $4,8,9,12,15,16,17,18,19,20,21,22,23,24,25,26$, lo que muestra que existe una mayor concentración de respuestas que denotan puntuaciones altas, es decir, menos escuchados. En cambio, en el resto la asimetría es positiva, es decir, más escuchado. 
En relación con la fiabilidad, medida a través del índice de consistencia interna, el alfa de Cronbach es de .959, oscilando la correlación ítem-total corregida desde .252 (ítem 6: "mantener relaciones sexuales") hasta .879 (ítem 25: "tocar semillas"), tal y como se recoge en la siguiente Tabla.

Tabla 4.

Mitos y tabúes sobre la menstruación

\begin{tabular}{|c|c|c|c|c|}
\hline & Media & $\begin{array}{l}\text { Desviación } \\
\text { estándar }\end{array}$ & Asimetría & $\begin{array}{l}\text { Correlación } \\
\text { total de } \\
\text { elementos } \\
\text { corregida }\end{array}$ \\
\hline 1. Bañarse & 1.4900 & .73161 & 1.141 & .288 \\
\hline 2. Comer algo frío & 1.8300 & .89955 & .345 & .532 \\
\hline 3. Lavar la cabeza & 1.7700 & .87450 & .469 & .558 \\
\hline 4. Hacer la matanza a un animal & 2.0200 & .97421 & -.041 & .721 \\
\hline 5. Dormir con su pareja & 1.9700 & .92611 & .060 & .687 \\
\hline 6. Mantener relaciones sexuales & 1.4600 & .71661 & 1.235 & .252 \\
\hline 7. Hacer deporte o esfuerzo físico & 1.8400 & .81303 & .303 & .409 \\
\hline 8. Depilarse & 2.0300 & .90403 & -.060 & .687 \\
\hline 9. Hacer la colada & 2.2300 & .87450 & -.469 & .832 \\
\hline 10. Asistir a la consulta ginecológica & 1.9100 & .90000 & .180 & .578 \\
\hline 11. Donar sangre & 1.9800 & .94259 & .040 & .679 \\
\hline $\begin{array}{l}\text { 12. Tirar algo manchado de sangre donde } \\
\text { alguien pueda verlo }\end{array}$ & 2.1200 & .89081 & -.240 & .711 \\
\hline 13. Cocinar ciertos alimentos & 1.9400 & .91916 & .120 & .478 \\
\hline 14. Beber ciertas cosas & 1.9900 & .92654 & .020 & .695 \\
\hline 15. Orar & 2.0800 & .90654 & -.160 & .744 \\
\hline 16. Asistir a prácticas religiosas & 2.1100 & .89775 & -.220 & .726 \\
\hline 17. Entrar en un templo & 2.1600 & .91806 & -.326 & .779 \\
\hline 18. Andar descalza & 2.0900 & .88871 & -.179 & .692 \\
\hline 19. Cortarse las uñas & 2.2400 & .93333 & -.500 & .840 \\
\hline 20. Tocar un libro sagrado & 2.2200 & .85965 & -.444 & .675 \\
\hline 21. Orinar en el campo & 2.3000 & .90453 & -.635 & .859 \\
\hline 22. Ponerse ropa ajustada & 2.1700 & .86521 & -.339 & .657 \\
\hline 23. Comer ciertos alimentos & 2.0900 & .90000 & -.180 & .678 \\
\hline 24. Divorciarse & 2.2000 & .95346 & -.414 & .835 \\
\hline 25. Tocar semillas & 2.3000 & .92660 & -.637 & .879 \\
\hline 26. Coger un bebé & 2.2800 & .92201 & -.590 & .815 \\
\hline $\begin{array}{l}\text { 32. Introducir producto en la vagina antes } \\
\text { de la primera relación sexual con } \\
\text { penetración }\end{array}$ & 1.9300 & .91293 & 140 & .552 \\
\hline
\end{tabular}

Posteriormente, se procedió a medir la validez de este bloque mediante el Análisis Factorial Exploratorio (AFE), las pruebas de Kaiser, Meyer y Olkin (KMO = .908) y de Barlett $\left(\mathrm{c}^{2}=2094.072 ; \mathrm{gl}=351 ; p<.001\right)$, encontrado valores que permiten la 
utilización del análisis factorial como técnica idónea para interpretar la información contenida en esta matriz.

Este bloque de ítems se distribuye en 5 factores o dimensiones, claramente delimitados (Tabla 5), que explican el $69.233 \%$ de la varianza total, siendo esta proporción aceptable.

Tabla 5.

Análisis Factorial Exploratorio del cuestionario "mitos y tabúes"

\begin{tabular}{|c|c|c|c|c|c|}
\hline & \multicolumn{5}{|c|}{ Componente } \\
\hline & 1 & 2 & 3 & 4 & 5 \\
\hline \multicolumn{6}{|l|}{ RELACIONADOS CON LA PRÁCTICA RELIGIOSA } \\
\hline 15. Orar & .768 & & & .329 & \\
\hline 16. Asistir a prácticas religiosas & .803 & & & & \\
\hline 17. Entrar en algún templo & .788 & & & & \\
\hline 20. Tocar textos sagrados & .791 & & & & \\
\hline 24. Divorciarse & .643 & .439 & & .330 & \\
\hline $\begin{array}{l}\text { 32. Introducir producto en la vagina antes de la primera } \\
\text { relación sexual con penetración }\end{array}$ & .566 & & & .331 & \\
\hline \multicolumn{6}{|c|}{ RELACIONADOS CON ACTIVIDADES DE LA VIDA DIARIA } \\
\hline 5. Dormir con pareja & .464 & .305 & & .545 & \\
\hline 9. Hacer la colada & .642 & .480 & & & \\
\hline 10. Ir a consulta ginecológica & & .739 & & & \\
\hline 11. Donar sangre & .398 & .588 & & & \\
\hline 12. Tirar algo manchado de sangre donde puedan verlo & .621 & .621 & & & \\
\hline 18. Andar descalza & .683 & .339 & & & \\
\hline 21. Orinar en el campo & .767 & .386 & & & \\
\hline 22. Ponerse ropa ajustada & .538 & .332 & .350 & & \\
\hline 25. Tocar semillas & .768 & .404 & & & \\
\hline 26. Coger un bebé & .727 & .399 & & & \\
\hline \multicolumn{6}{|c|}{ RELACIONADOS CON LA ALIMENTACIÓN Y EL ASEO DIARIO } \\
\hline 1. Bañarse & & & .751 & & \\
\hline 2. Comer algo frío & .328 & & .694 & & \\
\hline 3. Lavar cabeza & & .313 & .726 & & \\
\hline 8. Depilar & & .475 & .346 & .364 & .410 \\
\hline 14. Beber ciertas cosas & .458 & & .476 & & \\
\hline 19. Cortar las uñas & .629 & .496 & .307 & & \\
\hline 20. Comer ciertos alimentos & .473 & .313 & .364 & & \\
\hline \multicolumn{6}{|c|}{ RELACIONADOS CON LA MANIPULACIÓN DE ALIMENTOS } \\
\hline 4. Hacer la matanza & .426 & .378 & & 649 & \\
\hline 13. Cocinar ciertos alimentos & & & & .710 & \\
\hline \multicolumn{6}{|l|}{ RELACIONADOS CON ACTIVIDAD FÍSICA } \\
\hline 6. Mantener relaciones sexuales & & & & & .844 \\
\hline 7. Hacer deporte o esfuerzo físico & & & .448 & & .564 \\
\hline
\end{tabular}


Haciendo un análisis factorial, no existen diferencias significativas en ninguna de las variables estudiadas, como religión o creencias, edad, nivel económico, etc.

Como se muestra en la siguiente tabla, hay diferencias significativas en el análisis factorial entre los diferentes cuestionarios. Cuando analizamos la relación existente entre Eventos, (Secreto, Molesto, Debilitante y Negativo), y los diferentes factores de mitos o creencias (Práctica religiosa, Actividades de la vida diaria, Alimentación y el aseo diario, Manipulación de alimentos y Actividad física), vemos que sí existe relación con los Eventos Secreto y Negativo.

En cuando a la las creencias o mitos del factor "Práctica religiosa" vemos que tiene correlación positiva con los elementos Secreto y Negativo, es decir, mientras más han escuchado o evitado los mitos propuestos, más secreta y negativa sea su percepción sobre la menstruación.

Otro factor en el que hay una correlación positiva es el de "Manipulación de alimentos" con Evento Positivo, es decir, mientras más hayan escuchado o evitado las afirmaciones relativas a manipulación de alimentos, más percepción negativa tienen a cerca de la menstruación.

Tabla 6.

Relación entre cuestionario de creencias y cuestionario de mitos

\begin{tabular}{|c|c|c|c|c|}
\cline { 2 - 5 } \multicolumn{1}{c|}{} & Secreto & Molesto & Debilitante & Negativo \\
\hline Secreto & .332 & .048 & .002 \\
\hline Molesto & .048 & .000 & .000 & .038 \\
\hline Debilitante & .002 & .038 & .321 & .321 \\
\hline Negativo & .065 & .770 & .753 & .000 \\
\hline $\begin{array}{c}\text { Práctica } \\
\text { religiosa }\end{array}$ & .068 & .620 & .678 & .001 \\
\hline $\begin{array}{c}\text { Actividades de } \\
\text { la vida diaria }\end{array}$ & .017 & .427 & .225 & .020 \\
\hline $\begin{array}{c}\text { Alimentación y } \\
\text { el aseo diario }\end{array}$ & .450 & .222 & .058 & .019 \\
\hline $\begin{array}{c}\text { Manipulación } \\
\text { de alimentos }\end{array}$ & .195 & .249 & .945 & 953 \\
\hline Actividad física & & & & \\
\hline
\end{tabular}


Vemos que también existe relación positiva entre el Evento Secreto con el Debilitante y el Negativo, es decir, a más secreto, más debilitante y negativo es y entre Evento Molesto y Negativo siendo más negativo cuando más molesto es.

Tabla 7.

Porcentajes de respuestas en cuestionario "Mitos y tabúes a evitar"

\begin{tabular}{|l|c|c|c|}
\cline { 2 - 3 } \multicolumn{1}{c|}{} & Escuchad & Evitado & $\begin{array}{c}\text { Ni escuchado } \\
\text { ni evitado }\end{array}$ \\
\hline 1. Bañarse & $65 \%$ & $21 \%$ & $14 \%$ \\
\hline 2. Comer algo frío & $50 \%$ & $17 \%$ & $33 \%$ \\
\hline 3. Lavar la cabeza & $52 \%$ & $19 \%$ & $29 \%$ \\
\hline 4.Hacer la matanza a un animal & $46 \%$ & $6 \%$ & $48 \%$ \\
\hline 5. Dormir con su pareja & $44 \%$ & $15 \%$ & $41 \%$ \\
\hline 6. Mantener relaciones sexuales & $\mathbf{6 7 \%}$ & $20 \%$ & $13 \%$ \\
\hline 7. Hacer deporte o esfuerzo físico & $42 \%$ & $\mathbf{3 2 \%}$ & $26 \%$ \\
\hline 8. Depilarse & $39 \%$ & $19 \%$ & $42 \%$ \\
\hline 9. Hacer la colada & $29 \%$ & $19 \%$ & $52 \%$ \\
\hline 10. Asistir a la consulta ginecológica & $45 \%$ & $19 \%$ & $36 \%$ \\
\hline 11. Donar sangre & $45 \%$ & $12 \%$ & $43 \%$ \\
\hline $\begin{array}{l}\text { 12. Tirar algo manchado de sangre donde alguien pueda } \\
\text { verlo }\end{array}$ & $34 \%$ & $20 \%$ & $46 \%$ \\
\hline 13. Cocinar ciertos alimentos & & & \\
\hline 14. Beber ciertas cosas & $45 \%$ & $16 \%$ & $39 \%$ \\
\hline 15. Orar & $43 \%$ & $15 \%$ & $42 \%$ \\
\hline 16. Asistir a prácticas religiosas & $37 \%$ & $18 \%$ & $45 \%$ \\
\hline 17. Entrar en un templo & $35 \%$ & $19 \%$ & $46 \%$ \\
\hline 18. Andar descalza & $35 \%$ & $14 \%$ & $51 \%$ \\
\hline 19. Cortarse las uñas & $35 \%$ & $21 \%$ & $44 \%$ \\
\hline 20. Tocar un libro sagrado & $34 \%$ & $8 \%$ & $58 \%$ \\
\hline 21. Orinar en el campo & $38 \%$ & $22 \%$ & $50 \%$ \\
\hline 22. Ponerse ropa ajustada & $30 \%$ & $23 \%$ & $47 \%$ \\
\hline 23. Comer ciertos alimentos & $37 \%$ & $6 \%$ & $45 \%$ \\
\hline 24. Divorciarse & $32 \%$ & $6 \%$ & $\mathbf{6 2 \%}$ \\
\hline 25. Tocar semillas & $37 \%$ & $8 \%$ & $60 \%$ \\
\hline 26. Coger un bebé & $17 \%$ & $38 \%$ \\
\hline $\begin{array}{l}\text { 32. Introducir producto en la vagina antes de la prime- } \\
\text { ra relación sexual con penetración }\end{array}$ & & \\
\hline
\end{tabular}


Como se puede ver, en el apartado las afirmaciones que más han escuchado las participantes son "Mantener relaciones sexuales", seguida de "Bañarse", "Lavarse la cabeza", "Comer algo frío" y "Hacer la matanza de un animal".

En relación a las que han evitado llevar a cabo, la que más respuestas tiene es "Hacer deporte o esfuerzo físico", seguida por "Ponerse roja ajustada", "Tocar un libro sagrado", "Bañarse” y “Andar descalza".

La afirmación menos escuchada por las participantes es la de "Tocar semillas", seguida de "Coger un bebé", "Orinar en el campo", "Cortarse las uñas" y "Divorciarse".

Hay que tener en cuenta que las afirmaciones son más escuchadas que llevadas a cabo, es decir, evitado. Como se ha visto, el mayor porcentaje de las que han escuchado es un $67 \%$ y el de evitado llevar a cabo un $32 \%$.

Tabla 8.

Porcentajes ítems cuestionario "Mitos, creencias y tabúes" que únicamente se pueden hacer menstruando.

\begin{tabular}{|l|c|c|c|}
\cline { 2 - 4 } \multicolumn{1}{c|}{} & $\begin{array}{c}\text { Escuchad } \\
\text { o }\end{array}$ & Hecho & $\begin{array}{c}\text { Ni escuchado } \\
\text { ni evitado }\end{array}$ \\
\hline 28. Poder comer en Ramadán & $\mathbf{4 7 \%}$ & $\mathbf{3 6 \%}$ & $17 \%$ \\
\hline 29. Comer en Ramadán sin ser vista & $39 \%$ & $26 \%$ & $35 \%$ \\
\hline 30. Pintarse las uñas & $42 \%$ & $19 \%$ & $\mathbf{3 9 \%}$ \\
\hline 31. Purificarse una vez haber terminado el sangrado & $41 \%$ & $25 \%$ & $34 \%$ \\
\hline
\end{tabular}

Las afirmación más escuchada y más llevada a cabo sobre lo que únicamente se puede hacer cuando estén sangrando es la de "Poder comer en Ramadán". En cuanto a la que menos han escuchado es la de "Únicamente poder pintarse las uñas"

Por último, hay una pregunta sobre si han escuchado alguna vez la expresión de "Tener la regla nos hace ser mujeres" ('ítem 27). Ante esta pregunta, un 78\% la han escuchado frente a un $22 \%$ que nunca la han escuchado. 


\section{DISCUSIÓN Y CONCLUSIONES}

Vemos en los datos extraídos a través de los cuestionarios que las participantes no gozan de todos los elementos necesarios para tener una gestión de la menstruación adecuada propuestos en la guía en la que se basa esta investigación de Human Rights Watch y WASH United (2017).

Tal y como se ha visto en los resultados, existen diferencias en el manejo de la misma y la percepción que varían en función de la edad, religión o creencia que sigan, el nivel de estudios, la ocupación y el presupuesto económico con el que cuentan al mes. Aun así, hay que resaltar que las diferencias no son tan visibles puesto que, como hemos visto, los cuestionarios fueron pasados en un campus universitario por lo que la muestra es relativamente homogénea. Analizaremos todos los factores a tener en cuenta del cuestionario.

\subsection{CONOCIMIENTO}

Comenzando por el apartado de conocimiento de los productos existentes, vemos que los más conocidos son la compresa, salva slip, tampón y copa menstrual, siendo los que más las compresas, seguidas de los tampones y salva slip. Como se ha expuesto, son los productos más publicitados y, por ende, comercializados, a pesar de que sean los más nocivos tanto para la salud de las menstruantes como para el medio ambiente como explican Guillo-Arakistain (2013) y Ortiz (2018). La copa menstrual, aunque sea conocida es usada únicamente por el $11 \%$ de las participantes. Siendo los más utilizados las compresas, seguidos por los salva slip y los tampones, al igual que en el estudio realizado por Omar, Aggarwal y Perkins (1998). En conclusión, en este aspecto, las participantes no cuentan con la opción de escoger el producto que más se adapte a sus necesidades ya que no conocen el abanico existente y, por tanto, no han probado nunca para poder elegir el que se adapte mejor a sus necesidades.

Aun así, la situación es mejor que la de las participantes de los estudios de ElGilany, Badawi y El-Fedawy (2005), Zehtabchi et. al. (2018), quienes no conocían ninguno, nada más que compresas o trapos o no tenían acceso a los mismos. Vemos que nuestras participantes, sí que tienen acceso tanto para encontrarlos como para asumir los gastos, aunque presentan más facilidad para encontrarlos que para pagarlos.

\subsection{ACCESO A MEDICAMENTOS}


En cuanto al acceso a medicamentos para tratar molestias relacionadas con la menstruación o desórdenes hormonales, nos encontramos con que mayoritariamente cuentan con acceso y usan medicinas farmacológicas, seguidas de remedios caseros y, por último, naturales. A pesar de esto, casi la mitad de las mismas, se medican porque no conocen otra opción y, aunque lo hagan, más de un cuarto de las participantes no han asistido nunca a la consulta ginecológica, cuando, como hemos visto, la recomendación es que se vaya una vez al año a partir de la primera relación sexual con penetración o a los 20 años. (OMS (Organización Mundial de la Salud) y la SEGO (Sociedad Española de Ginecología y Obstetricia), (Citados en Fernández, 2018). En los resultados se perciben diferencias en cuanto a nivel económico y de estudios, así, como explican Regidor et. al.. (2006), en torno al 30\% de las consultas a especialistas se realizan sin financiación pública. Según la OMS (2009), los sistemas de salud están incumpliendo con sus obligaciones con las mujeres, con carencias en los mismos que las privan de asistencia sanitaria. Las mujeres tienen mayores gastos en salud que los hombres al hacer mayor uso de los servicios asistenciales pero suelen ser más pobres, estar en desempleo o trabajar a tiempo parcial o informal sin prestaciones sanitarias (OMS, 2009).

\subsection{INSTALACIONES PARA CAMBIAR MATERIALES MENSTRUALES}

En el cuestionario en el que se muestran los cuartos de baño existen diferencias en cuanto un mismo baño (universidad) ya que hay quienes lo perciben adecuado y quienes no siendo el mismo. Haciendo una observación se ve que dos de ellos, aunque no cumplan el $100 \%$ de las características exigidas por Human Rights Watch y WASH United, (2017) se acercan mucho, ya que es un espacio mixto, privado, con agua para lavar las manos y jabón -casi siempre-, aunque no cuenta con un espacio cómodo en el que lavar la vulva al cambiar el producto al vaciarlo y limpiarlo para volverlo a introducir, como podría ser un bidé, ducha o una manguera. Puede que la percepción varíe de unas a otras porque no sepan cuáles son las condiciones mínimas exigidas por Human Rights Watch y WASH United, (2017) (privacidad, agua, jabón para lavar el cuerpo y algo para secarlo). Por lo demás, prácticamente todas cuentan con un espacio así en su casa y en otros sitios donde pasen gran cantidad de tiempo como biblioteca, hospital o trabajo.

Aun así, en comparación con el estudio llevado a cabo por Gulla E., Mayo A.W. y Kimwaga, R., (2013) en la India, en el que el 48,3\% de las adolescentes únicamente 
tenían agua, el 35,6\% agua y jabón, el 15,4\% papel higiénico en los baños y el 0,7\% otros materiales. Como podemos ver, la situación dista mucho de las estudiantes en la India y las del campus de Melilla (España), por lo que es difícil a comparación entre estas dos realidades, dadas las características culturales, sociales, económicas, etc. de ambos países. Por esto se debe seguir investigando en contextos y realidades diversas y realidades para conocer la situación de la gestión de las menstruantes a nivel global.

\subsection{CANALES DE INFORMACIÓN SOBRE LA MENSTRUACIÓN}

Nuestras participantes, al igual que en el estudio llevado a cabo por Gulla, Mayo y Kimwaga, (2013) en Tanzania, han recibido información sobre la menstruación principalmente a través de su madre. En comparación con el mismo, nuestras participantes sí que han recibido más información a través de la escuela o instituto $42 \%$ en comparación con el $2 \%$ en el estudio del que hablamos. Aun así, sigue siendo un porcentaje muy bajo ya que es uno de los agentes principales de aprendizaje en la vida de todas

La persona que transmite más información dentro de la familia, sigue siendo la madre en ambos resultados, representando las figuras masculinas únicamente un $10 \%$ del total frente al $51 \%$ de las femeninas.

Los canales de donde procede la información y cómo es la misma, tienen gran importancia en nuestra manera de sentir la menstruación. Que unas de las principales fuentes de información en las participantes sean los anuncios publicitarios con los mensajes tan estigmatizantes y falsos que tienen como explica Pessi (2009), tiene consecuencias negativas en nuestra manera de entenderla y comportarnos cuando estamos sangrando, convirtiendo la principal preocupación de la menstruante en evitar que alguien se dé cuenta de que estamos menstruando y no hablar del tema.

\subsection{CREENCIAS O PERCEPCIONES}

Los resultados de las percepciones de nuestras participantes a cerca de su propia menstruación, muestran que mayoritariamente lo ven como algo negativo y debilitante, aunque en su mayoría es considerado como algo de lo que se puede hablar y, por tanto, que no se debe mantener en secreto y en cuanto a entenderlo como algo molesto queda en torno a un $50 \%$ entre que lo consideran como tal y que no. 
Como hemos visto, es muy importante la percepción que tengamos sobre nuestra menstruación ya que, como explican Chrisler y Levy (1990), pensando que nuestro ciclo afecta a nuestro estado fisiológico, tendemos a atribuir los cambios que podamos experimentar en esos días como consecuencia del ciclo menstrual. Así, tendemos a aborrecer o menospreciar algo con lo que vivimos una gran parte de nuestra vida. $\mathrm{Si}$ esto fuese a la inversa, es decir, si fuese apreciada, podría tener un impacto positivo en el bienestar de todas las menstruantes y en su condición social (Johnston-Robledo y Chrisler, 2011).

Las creencias, como se ha visto en las participantes, guardan relación con actividades cotidianas, como por ejemplo el ir a la consulta ginecológica. Como hemos visto, son las que más perciben el tema de la menstruación como evento secreto, las que menos han ido a la consulta. Aquí se aprecia claramente la importancia que tiene la percepción de la misma con algo tan importante como la necesidad de hacerse revisiones médicas para diagnosticar o prevenir enfermedades.

\subsection{TABÚES Y MITOS}

Al analizar el cuestionario de los mitos, vimos que no existían diferencias significativas en cuanto a la religión o creencia que profesan, tal y como explicaba Gómez (1976), en cuanto a que los tabúes religiosos que guardan relación con la sangre son universales pues constituyen el denominador común de todas las culturas (citado en Perea, 2008). Perea (2009) también comparó los diferentes textos sagrados como en el Levítico, la Mishná, las Leyes Sagradas Griegas, el Pentateuco o los Manuscritos del Mar Muerto entre otros, y concluyó que existen una serie de normas coincidentes sobre la menstruación basada en la impureza y los tabúes, como la prohibición de tener relaciones sexuales o bañarse. La purificación tras la menstruación viene también recogida en textos sagrados como Levítico o libro de la biblia de la Tribu de Leví, donde se dedica un capítulo a explicar cómo limpiarse de dos impurezas: la gonorrea y la menstruación (Alarcón-Nivia, 2005). Así, las respuestas de nuestras participantes sobre este asunto son que el $41 \%$ de ellas ha escuchado que se deben purificar tras el sangrado menstrual y el $25 \%$ de ellas lo ha hecho.

Aun así, como hemos visto, hay unos mitos más extendidos que otros, como por ejemplo el evitar mantener relaciones sexuales, bañarse o hacer ejercicio físico. Así, como explican Botello y Casado (2015) los mitos van acompañados con miedos, como a que se corte, a quedarse tonta, a volverse loca... Así, analizando la relación entre los 
mitos y creencias o percepciones a cerca de la propia menstruación de las participantes, vemos que a más escuchan ciertos mitos, como los relacionados con la práctica religiosa, más secreta y negativa es su percepción sobre la menstruación. Lo mismo ocurre con los mitos relacionados con la manipulación de alimentos y la percepción de la menstruación como un evento negativo.

Así, estos mitos sin fundamento transmitidos de generación en generación, afectan a nuestra manera de percibir nuestra menstruación y nuestro ciclo y, por ende, nuestro cuerpo durante la mayor parte de nuestra vida. Esto en muchas ocasiones, como en el estudio llevado a cabo por UNICEF Bangladesh (2008), tiene efectos negativos directos en las menstruantes en su salud, causando serias infecciones en su cuerpo por el hecho de no lavar ni secar bien los trapos a fin de que nadie los vea (citado por House, Mahon y Cavill, 2012).

Es relevante también la -errónea- idea transmitida y asumida que la menstruación nos hace ser mujeres. Como explica Guillo-Arakistain (2013), esto no es solo una representación biomédica sino que también es algo común en la cultura popular. Así, se refleja en las respuestas de nuestras participantes, donde casi un $80 \%$ de las mismas lo ha escuchado.

En conclusión, ninguno de los tres puntos a analizar definidos por Human Rights Watch y WASH United (2017) se cumplen en las participantes en su totalidad, aunque sí que tienen acceso a la mayoría de los productos que conocen, instalaciones adecuadas en el lugar en el que viven y con casi todas las características exigidas en la universidad en la que estudian, aunque no en otros lugares en los que pasan la mayor parte de su tiempo diario como el trabajo. Por último, en cuanto a las percepciones de su propia menstruación y los mitos, vemos que comparten la mayoría de ellos y se privan de realizar muchas actividades en su día a día a causa de los mismos.

\section{PROPUESTAS DE MEJORA}

Una vez realizado el cuestionario, se han visto posibles mejoras y propuestas de investigaciones futuras. Aunque los instrumentos sean fiables, sería conveniente añadir información en algunos y prescindir de información en otros. Se podría mejorar en los siguientes aspectos el instrumento:

- Cabría la opción de añadir más características sociodemográficas a fin de poder correlacionar más variables. 
- Sería más enriquecedor poner una escala Likert con los ítems "Nada, algo, mucho, poco" en la parte del cuestionario de espacios y en la que hace referencia a la persona o institución de la que han recibido algún tipo de información.

- Sería interesante añadir un apartado para saber cuál es el conocimiento sobre su propio cuerpo, poniendo preguntas en relación a esto como los días que pasan de un ciclo a otro, el color y olor de la sangre, color del flujo, si tienen coágulos, si le dan otros usos a la sangre como por ejemplo para regar las plantas, hacerse mascarillas...

En cuanto a las posibles líneas futuras de investigación, sería interesante realizarlas por grupos culturales y más heterogéneos afín de obtener una muestra diversa con el objetivo de comparar diferentes percepciones y maneras de gestionarla.

También sería interesante, realizar estudios transversales con talleres de educación y empoderamiento menstrual haciendo pre y post cuestionarios para visibilizar la importancia de los mismos usando el cuestionario como instrumento para medir la calidad de los talleres analizando la repercusión de los mismos en las participantes.

Debe de ser muy enriquecedor hacer comparaciones entre diferentes zonas geográficas como, por ejemplo, entre Escocia y España ya que en el primero sí que tienen políticas en relación a la misma y así ver la situación de posible ventaja en la que están las menstruantes o en diferentes zonas de habla hispana con proyectos como Argentina donde hay una movilización importante a nivel nacional sobre el tema a tratar.

Por todo esto, lo que es importante es seguir trabajando e investigando sobre la gestión de la menstruación con el propósito de mejorar la calidad de vida de las menstruantes del mundo. 


\section{REFERENCIAS}

Alarcón-Nivia, M.A. (2005). Algunas consideraciones antropológicas y religiosas alrededor de la menstruación. Revista Colombiana de Obstetricia y Ginecología. 56 (1), 35-45. Recuperado de: http://www.scielo.org.co/pdf/rcog/v56n1/v56n1a05.pdf

Aspilcueta-Gho, D. (2013). Rol del varón en la anticoncepción, como usuario y como pareja. Revista Perú Medicina Exp Salud Publica. 30 (3), 480-486. Recuperado de:

https://www.scielosp.org/article/ssm/content/raw/?resource_ssm_path=/media/a ssets/rpmesp/v30n3/a18v30n3.pdf

Bharadwaj, S. y Patkar, A. (2004). Menstrual hygiene and management in developing countries: taking stock. Mumbai: Junction Social Social Development Consultant.

Botello, A. y Casado, S. (2015). Miedos y temores relacionados con la menstruación: estudio cualitativo desde la perspectiva de género. Seguência (Florianópolis). 24 (1). 13-21. Recuperado de: http://www.scielo.br/pdf/tce/v24n1/es 0104-0707tce-24-01-00013.pdf

Cardozo, S. (2015). Sangre menstrual: una aproximación sociológica (Tesis licenciatura). Recuperado de: http://docplayer.es/59639272-Sangre-menstrualuna-aproximacion-sociologica.html

Chacón, M. (27 de septiembre de 2018). Los países donde se eliminó el impuesto a toallas higiénicas y tampones. Semana la FM. Recuperado de: https://www.lafm.com.co/internacional/los-paises-donde-se-elimino-elimpuesto-toallas-higienicas-y-tampones

Chrisler, J. C. y K. B. Levy (1990). The media construct a Menstrual Monster: A content Anaysis of PMS Articles in the Popular Press. Women \& Health, 16(2), 89-104.

Claripharm, (2018). [Claripharm]. (2018, 21 de marzo). Comment utiliser la coupe menstruelle Claricup? Recuperado de: https://www.youtube.com/watch?v=Sq8bTS6LbXk 
Collins, S. (23 de junio de 2016). NYC Becomes The First City To Pass Menstrual Equality Bills. Vibe. Recuperado de https://www.vibe.com/2016/06/nyc$\underline{\text { menstrual-equality-bill }}$

Dasgupta, A., Sarkar, M., (2008). Menstrual Hygiene: How Hygienic is the Adolescent Girl? Indian Journal of Community Medicine. 33 (2), 77-80. Recuperado de: https://www.researchgate.net/publication/40453982_Menstrual_Hygiene_How _Hygienic_is_the_Adolescent_Girl

Declaración Universal de los Derechos Humanos. Resolución 217 A (III) de la Organización de las Naciones Unidas, París, Francia, 10 de diciembre de 1948. (Declaración Universal de los Derechos Humanos, 1948).

De Beauvoir S. El segundo sexo. $2^{\mathrm{a}}$ ed. Madrid (ES): Cátedra; 2008.

El-Gilany, A.H., Badawi, K. \& El-Fedawy, S. (2005) Menstrual Hygiene among Adolescent Schoolgirls in Mansoura, Egypt, Reproductive Health Matters. 13 (26) 147-152. Recuperado de: https://www.tandfonline.com/doi/pdf/10.1016/S0968-8080\%2805\%2926191$\underline{8 ? \text { needAccess }=\text { true }}$

Esteban, M. L. (2003). El género como categoría analítica. Revisiones y aplicaciones a la salud. En Cuadernos de Psiquiatría comunitaria. 3 (1), 22-39. Recuperado de: https://www.aen.es/web/docs/Cuadernos3.1.pdf

Fernández, J. M. (2018). Revisión ginecológica anual. No te olvides de ella. Instituto de Medicina EG. Recuperado en: https://www.egr.es/revision-ginecologica-anual/

Frazer, JG. (1981). La rama dorada. Magia y religión. (Elizabeth y Tadeo L. Campuzano) Madrid: Ediciones F.C.E. España (1890). Recuperado de: https://antroporecursos.files.wordpress.com/2009/03/frazer-j-g-1890-la-ramadorada.pdf

Freedman, J. (2004). Feminismo, ¿Unidad o conflicto? (Trans. J. López Ballester). Madrid, España: Narcea S.A. De Ediciones. (Trabajo original publicado en 2001).

Guillo-Arakistain, M. (2013). La in-corporación de la investigación: políticas de la menstruación y cuerpos (re)productivos. Nuevos nómadas. 39 (1), 233-245.

Gulla E., Mayo A.W. y Kimwaga, R. (2013). Menstrual Hygiene Management in Secondary schools in Tanzania. International Journal of Science and 
Technology. 3 (1), 27-40. Recuperado de: https://www.researchgate.net/publication/287209989 Menstrual Hygiene Man agement_in_Secondary_schools_in_Tanzania

Hezeman, (2018). [MissHezeman]. (2018, 27 de noviembre). DIY I La serviette hygiénique lavable faite main! Recuperado de: https://www.youtube.com/watch?v=HXcfjOYKWEk

House, S., Mahon, T. y Cavill, S. (2012). Menstrual hygienne Matters. A resource for improving menstrual hygiene around the world.Uk. WaterAid. Recuperado de: https://menstrualhygieneday.org/wp-content/uploads/2016/12/Menstrualhygiene-matters-low-resolution.pdf

Human Rights Watch, (2017, 31 de agosto). Understanding Menstrual Hygiene Management \& Human Rights. Recuperado de: https://www.hrw.org/sites/default/files/news attachments/mhm practitioner gu ide_web.pdf

INE, (2008). Encuesta de Discapacidad, Autonomía Personal y Situaciones de Dependencia. Población con discapacidad según tipo de discapacidad por edad y sexo. Madrid: Instituto Nacional de Estadística. Recuperado de: http://www.ine.es/jaxi/Datos.htm?path=/t15/p418/a2008/hogares/p01/modulo1/ $\underline{10 / \& \text { file }=01002 . p x}$

INE, (2012). Encuesta a las personas sin hogar: Personas sin hogar por sexo y nacionalidad. Madrid: Instituto Nacional de Estadística. Recuperado de: http://www.ine.es/jaxi/Datos.htm?path=/t25/p454/e02/a2012/\&file=01002.px

Johnston-Robledo, Ingrid \& Chrisler, Joan. (2011). The Menstrual Mark: Menstruation as Social Stigma. Sex Roles. 68(1), 1-10. Recuperado de: https://www.researchgate.net/publication/225143159_The_Menstrual_Mark_M enstruation_as_Social_Stigma

Jung, L. (s.f.). Perfil nacional de legislación laboral: Japón. Organización Internacional del Trabajo. Recuperado de: http://www.ilo.org/ifpdial/informationresources/national-labour-law-profiles/WCMS_159159/lang--es/index.htm

Lennon, M. (2017) Ending Period Poverty. A proposal of a Bill to ensure free access to sanitary products, including in schools, colleges and universities. Consolations by Monica Lennon. Member of the Scottish Parliament Of Central Scotland. Augusto 2017. Recuperado de: 
https://www.parliament.scot/S5MembersBills/Consultation_Summary_FINAL.p

$\underline{\mathrm{df}}$

Ley Orgánica 14/1986, de 25 de abril, General de Sanidad. Boletín Oficial del Estado, Madrid, España, 29 de abril de 1986. Recuperado de: https://www.boe.es/buscar/act.php?id=BOE-A-1986-10499

Ley Orgánica 39/2006, de 14 de diciembre, Promoción de la Autonomía Personal y Atención a las personas en situación de dependencia. Boletín Oficial del Estado, Madrid, España, 14 de diciembre de 2006. Recuperado de: https://www.boe.es/buscar/pdf/2006/BOE-A-2006-21990-consolidado.pdf

Ley Orgánica 3/2007, de 22 de marzo, Para la igualdad efectiva entre mujeres y hombres. Boletín oficial del Estado, Madrid, España. 23 de marzo del 2017. Recuperado de: https://www.boe.es/buscar/act.php?id=BOE-A-2007-6115

Lugones, M., Yamilé, T. y Cruz, Y. (1997). Anticoncepción hormonal. Revista Cubana de Medicina General Integra. 13 (1). Recuperado de http://scielo.sld.cu/scielo.php?script=sci_arttext\&pid=S0864$\underline{21251997000100009}$

Nissim, R. (1984). Manual de ginecología natural para mujeres. (Villegas, I.). Suisse: Editions Dispensaire des femmes. Recuperado de: https://drive.google.com/file/d/1pjH8JeRuYXu4SzuTb_getgH_Mj9IoeyX/view $? \mathrm{ts}=5 \mathrm{c} 880 \mathrm{cb} 0$

Manzano, R., Martínez, G. y Gavilán, D. (2018). Identidad de género, consumo y discriminación a través del precio. Revista Latina de Comunicación Social, 73 (1), $385 \quad$ - $400 . \quad$ Recuperado de: http://www.revistalatinacs.org/073paper/1261/20es.html

Mahon, T y Fernandes, S. (2014). Menstrual hygiene in South Asia A neglected issue for WASH (water, sanitation and hygiene) programmes. WaterAid.

Moran, C., (2013), Cómo ser mujer (Marta Salís, trad.), Barcelona, España, Editorial Anagrama. (Obra original publicada en 2011).

Oficina Internacional del Trabajo, (2008). ABC de los derechos de las trabajadoras y la igualdad de género. (2a. ed.). Ginebra, Suiza: OIT. Recuperado de: http://www.ilo.org/wcmsp5/groups/public/---dgreports/--gender/documents/publication/wcms_094520.pdf

Online World Maps (2018). Political white world map - b6a. Recuperado de: http://www.outline-world-map.com/political-white-world-map-b6a 
Omar, H., Aggarwal S. y PErkins KC, (1998). Tampon use in young women. J Pediatr Adolesc Gynecol. 11 (3), 143-6.

Organización Mundial de la Salud [OMS], (2009). Las mujeres y la salud. Ginebra, Suiza. Recuperado

de: https://apps.who.int/iris/bitstream/handle/10665/70121/WHO IER MHI STM. 09.1_spa.pdf?sequence $=1$

Osseiran, N. y Jasarevic, T. (8 de mayo de 2014). La OMS y el UNICEF destacan la necesidad de continuar mejorando el acceso a fuentes de agua potable y servicios de saneamiento mejorados. Organización Mundial de la Salud (OMS). Recuperado de: https://www.who.int/es/news-room/detail/08-05-2014-whounicef-highlight-need-to-further-reduce-gaps-in-access-to-improved-drinkingwater-and-sanitation

Ortiz, M. (2018). Impacto Ambiental y Económico del uso de productos de Higiene Íntima femenina. Innovation in Education andInclusion. LACCEI International Multi-Conference for Engineering, Education, and Technology, Lima,Peru. Recuperado de https://docplayer.es/94265599-Impacto-ambiental-yeconomico-del-uso-de-productos-de-higiene-intima-femenina.html

Parlamento Europeo (2018). Pregunta parlamentaria con respuesta escrita E-004724-18 a la Comisión. Asunto: Tasa rosa en Europa. (18 de septiembre del 2018). Recuperado de: http://www.europarl.europa.eu/doceo/document//E-8-2018$\underline{004724 \text { ES.html }}$

Perea, S. (2008). Prescripciones rituales sobre la impureza sexual de la mujer. Coincidencias funcionales entre algunas Leyes Sagradas griegas y Septuaginta (1 $1^{\mathrm{a}}$ parte). Collectanea Christiana Orientalia, (CCO) Lv 12 y 15, 18-33. Recuperado de: http://www.uco.es/servicios/publicaciones/revistas/index.php/cco/article/view/1 $\underline{01 / 98}$

Perea, S. (2009). Prescripciones rituales sobre la impureza sexual de la mujer. Coincidencias funcionales entre algunas Leyes Sagradas griegas y Septuaginta ( $2^{\mathrm{a}}$ parte). Collectanea Christiana Orientalia, (CCO). Lv 12 y 15, 18-33. Recuperado de: http://www.uco.es/servicios/publicaciones/revistas/index.php/cco/article/view/1 $\underline{20 / 117}$ 
Pessi, M. S., (2009). Comunicación y tabú. Análisis de la publicidad de productos para la higiene femenina. Questión ISSN 1669 6581. 1 (21). Buenos Aires, Argentina. Recuperado

de: https://dialnet.unirioja.es/servlet/articulo?codigo $=5702359$

Portos, L. (2017). \#Menstruacción es proyecto de ley. Cosecha Roja. Marzo 2017. Recuperado de http://cosecharoja.org/menstruaccion-es-proyecto-de-ley/

Proposición de no Ley No de expediente 161/000274. Diario de Sesiones Del Congreso de Diputados. España, Madrid, 25 de octubre del 2016. Recuperado el 16/04/18 en http://www.congreso.es/public_oficiales/L12/CONG/DS/CO/DSCD-12-CO38.PDF

Proposición de no Ley No de expediente 161/000676. Diario de Sesiones Del Congreso de Diputados. España, Madrid, 25 de octubre del 2016. Recuperado el 16/04/18 en http://www.congreso.es/public oficiales/L12/CONG/DS/CO/DSCD-12-CO$\underline{38 . P D F}$

Ramírez (2003) .Creación de un instrumento para medir creencias y actitudes acerca de la menstruación.

Recuperado

de: http://catarina.udlap.mx/u_dl_a/tales/documentos/lps/sanchez_d_ma/apendiceA. pdf

Regidor et al. (2006). Asociación de los ingresos económicos con la utilización y la accesibilidad de los servicios sanitarios en España al inicio del siglo XXI. Gaceta Sanitaria, 20(5), 352-359. Recuperado de: http://scielo.isciii.es/scielo.php?pid=S0213$91112006000500003 \&$ script $=$ sci_abstract\&tlng=pt

Rojas, A.M. \& Galeano, S. (2014). Cuerpos censurados: construcción de identidad de género en el tránsito de lo femenino a lo masculino en hombres transexuales de la ciudad de Santiago de Cali y la incidencia de este proceso en sus relaciones familiares. (Trabajo de fin de grado). Universidad del valle facultad de humanidades escuela de trabajo social y desarrollo humano, Santiago de Cali. Recuperado de: http://bibliotecadigital.univalle.edu.co/bitstream/10893/9347/1/CB0495215.pdf

TamponsFromCanada (2016). TamponsFromCanada. España. Recuperado de: http://tamponsfromcanada.com/?fbclid=IwAR12Ig7IXyQvljQjNU0C 3SPq9vh AhokM4J7nyFnOATump175g_2Jrvw0RE 
The Vulva Gallery (2016). [TheVulvaGallery]. [Cuenta de Instagram]. Recuperado de: https://www.instagram.com/the.vulva.gallery/?hl=es

Torres-Blanco, C. (2019). [cuerposmenstruantes]. [Cuenta de Instagram]. Recuperado de: https://www.instagram.com/cuerposmenstruantes/

Perea, S. (2008). Prescripciones rituales sobre la impureza sexual de la mujer. Coincidencias funcionales entre algunas Leyes Sagradas griegas y Septuaginta Lv 12 y 15, 18-33 ( $1^{\text {a }}$ parte). Córdoba, Argentina. Collectanea Christiana Orientalia 5.

VentaDesechablesOnline, (2013). [VentaDesechablesOnline]. (2013, 7 de mayo). Esponjas para la regla BEPPY. Recuperado de: https://www.youtube.com/watch?v=NOu9XVuYmdg

Wash United (2014). 28 May - Menstrual Higiene Day. WASH United: http://www.wash-united.org/our-work/programs/mh-day/articles/menstrualhygiene-day

Zehtabchi, R. et al. (productoras) y Zehtabchi, R. (directora), (2018). Period. End of Sentence. [documental]. Estados Unidos: Netflix. 


\section{ANEXOS}

\section{ANEXO 1. ENTREVISTAS INSTAGRAM}

Se creó una cuenta en Instagram con contenido exclusivo sobre menstruación con el trabajo de diferentes artivistas en las redes sociales llamada @cuerposmenstruantes por Torres-Blanco (2019) a fin de llegar al máximo número de personas posibles vía online.

Se llevaron a cabo cuatro preguntas a contestar por las participantes: (1) ¿Hay algo que te hayan dicho que no puedas hacer mientras estás menstruando? (2) ¿Hay algo que te hayan dicho que únicamente puedas hacer mientras estás menstruando? (3) ¿Qué haces para tratar enfermedades o desórdenes hormonales? (4) ¿Hay algo sobre la menstruación que no es como te habían enseñado? 


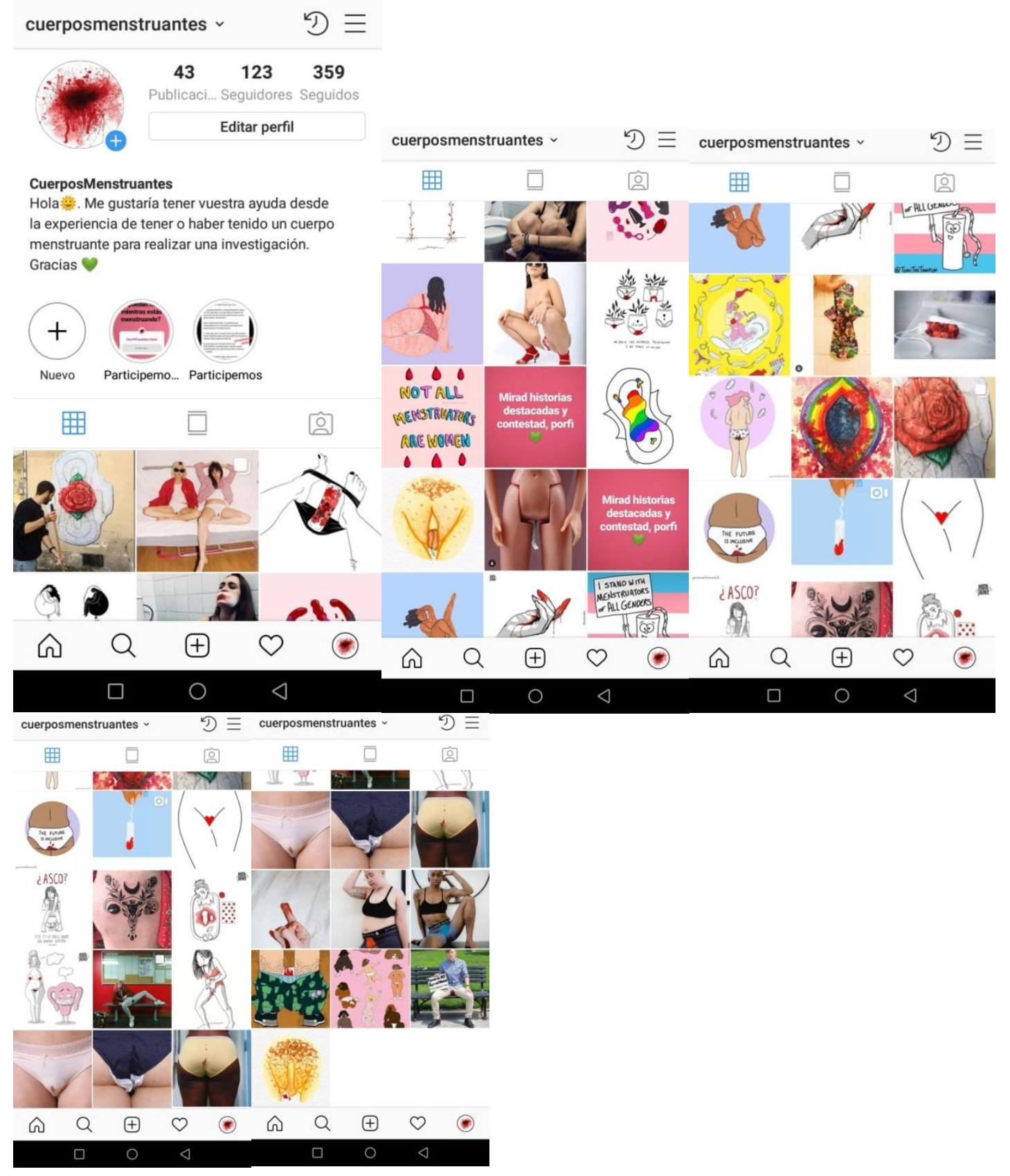


¿Hay algo que te hayan dicho que

NO puedas hacer mientras estás menstruando?

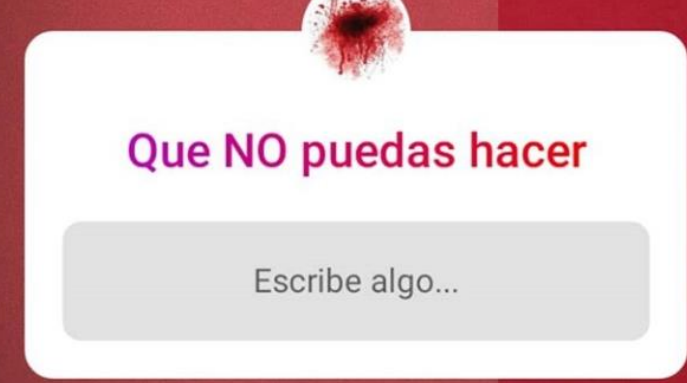

E. Lavarte el pelo, regar las plantas, entrar en una bodega, rezar...

$\leftarrow$ Respuestas

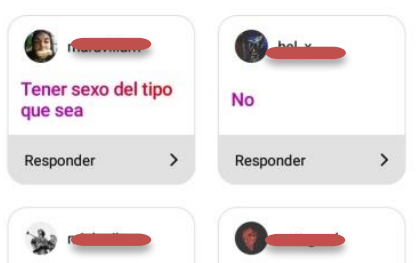

pisar uva para el

pisar uva pa
vino

Responder >

No

Responder >

هi

Posiciones

invertidas (Yoga)

Responder

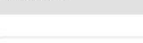

(2)

acercarme a

plantas

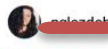

Bañarme, ir en bici o

tener sexo

Responder

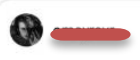

Teñirte

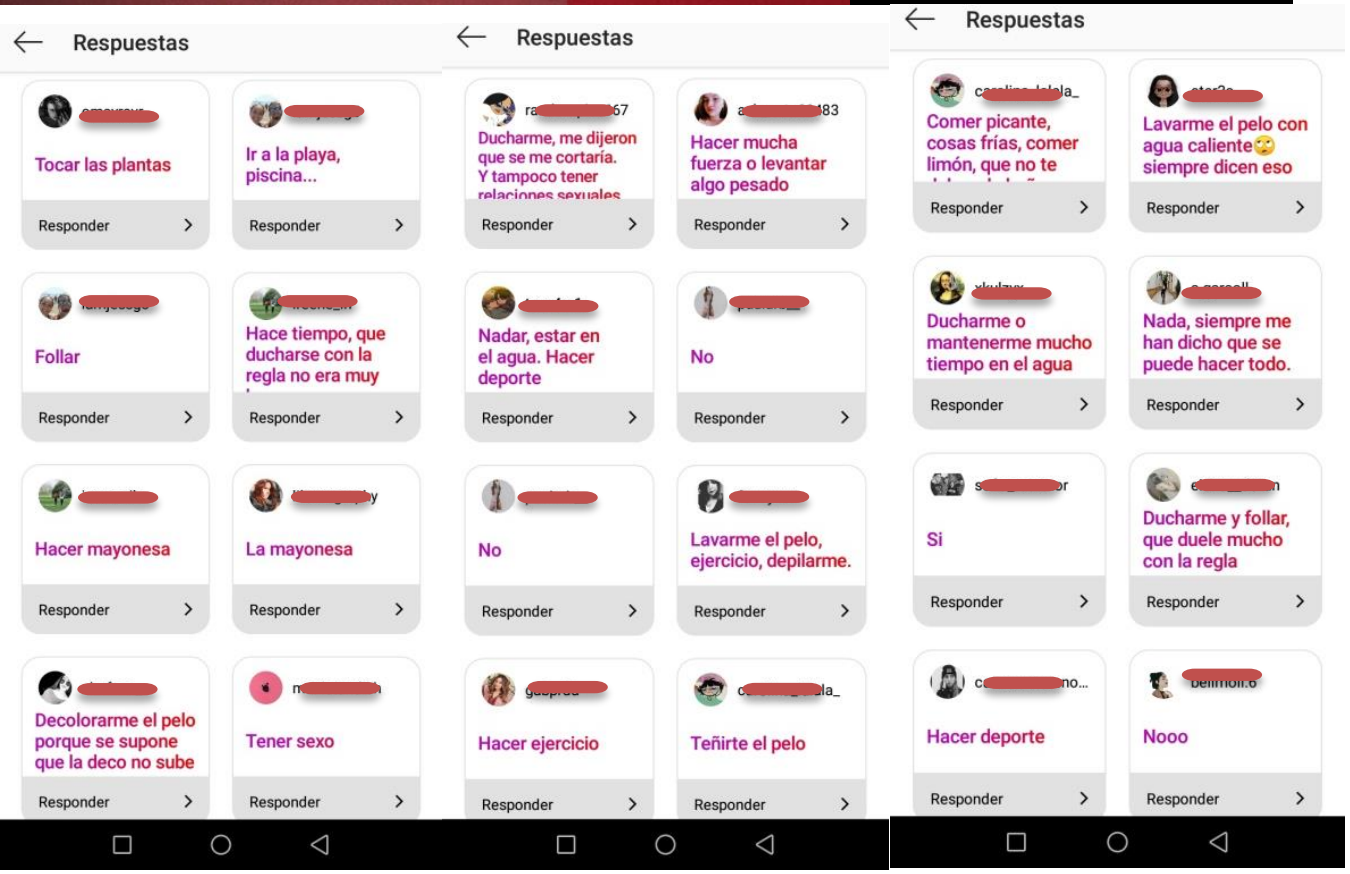


$\leftarrow$ Respuestas

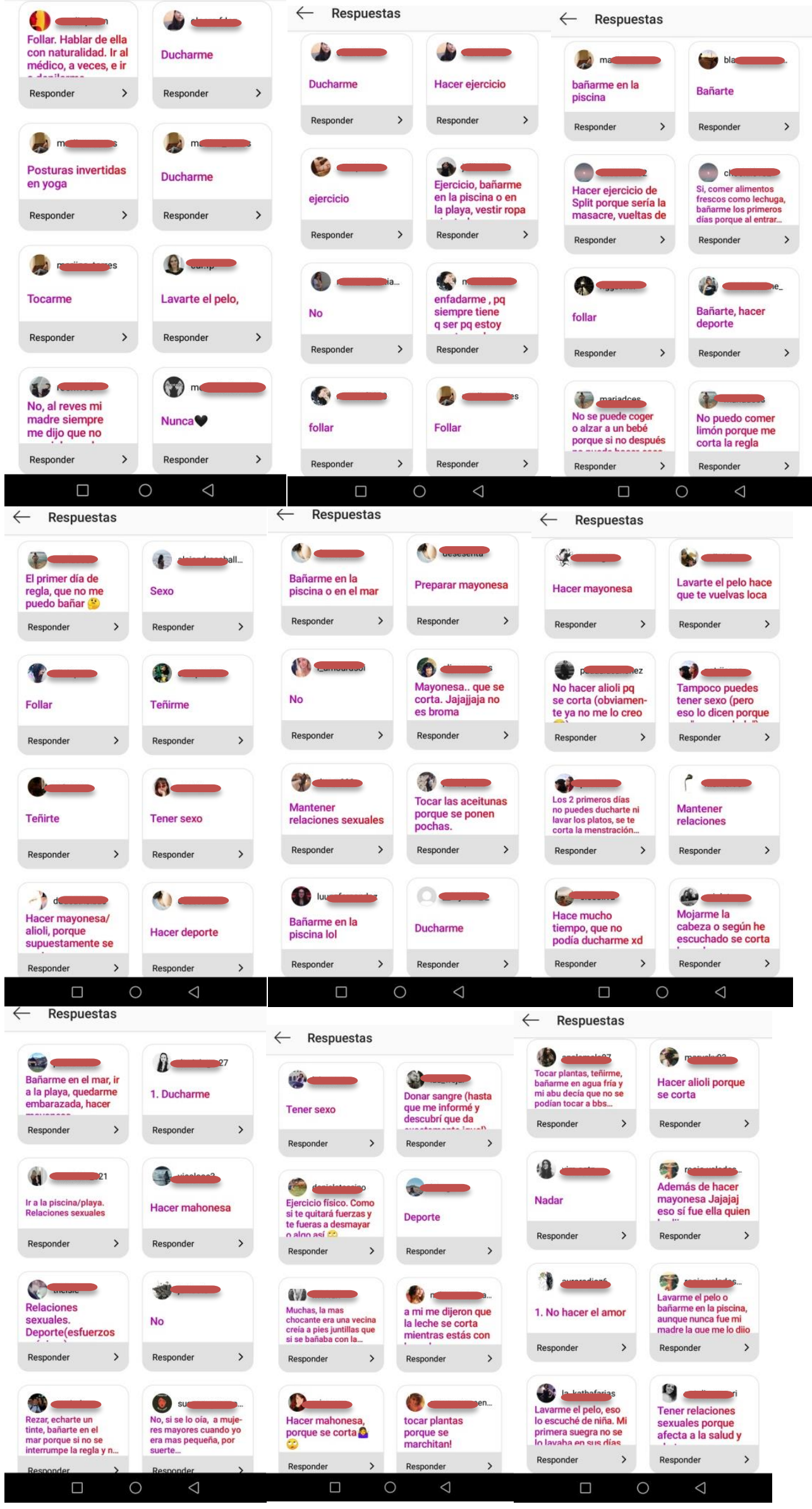



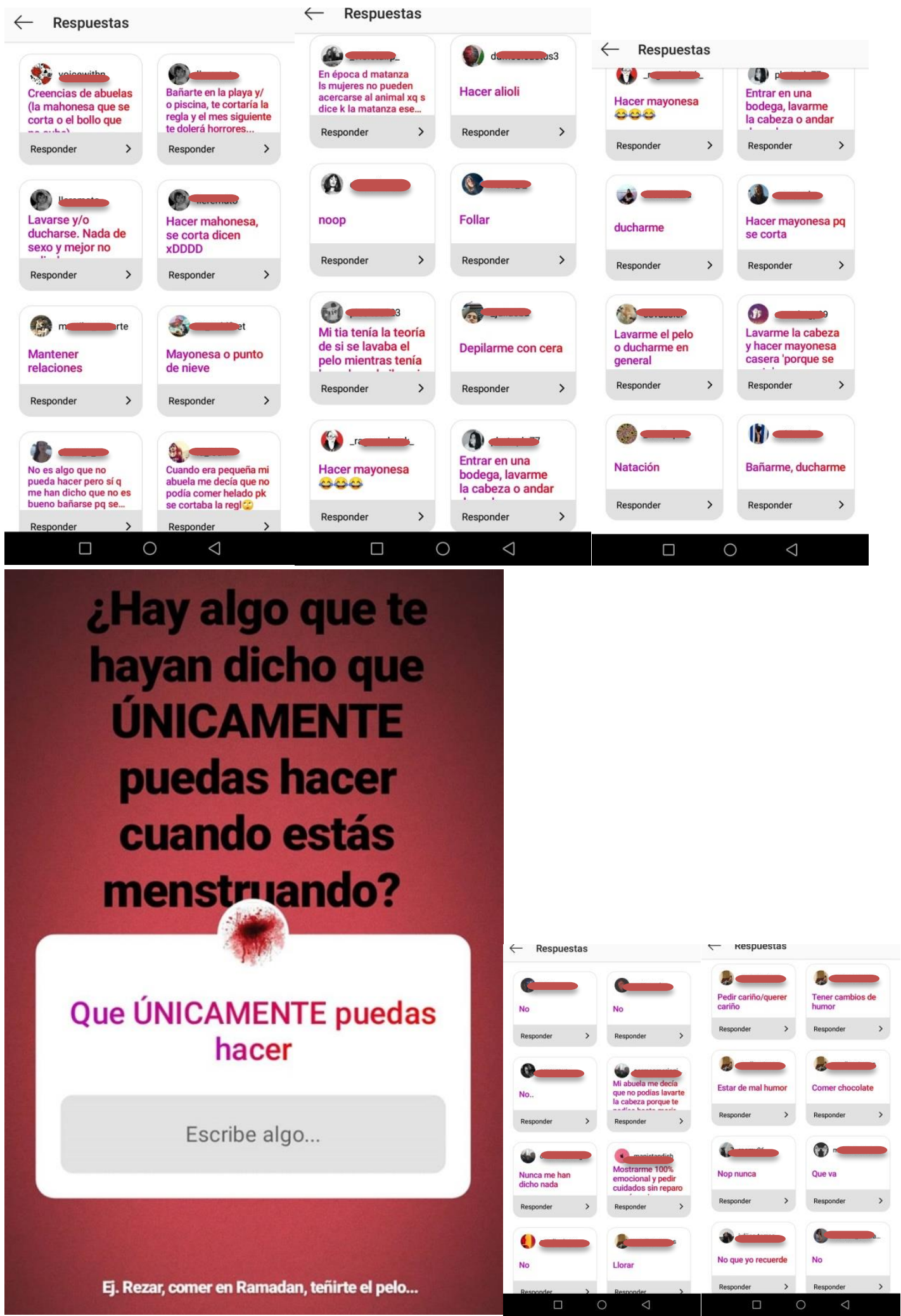


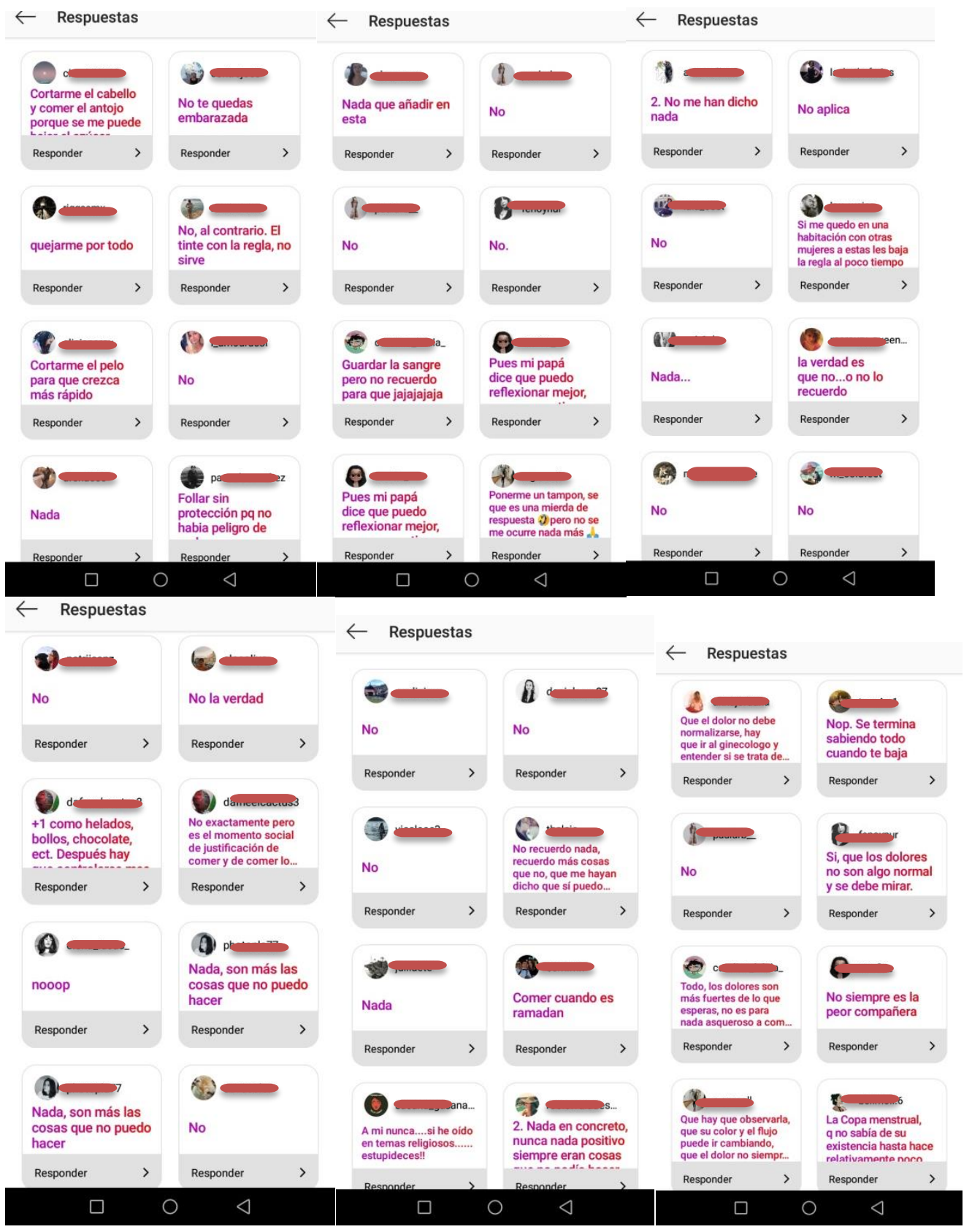




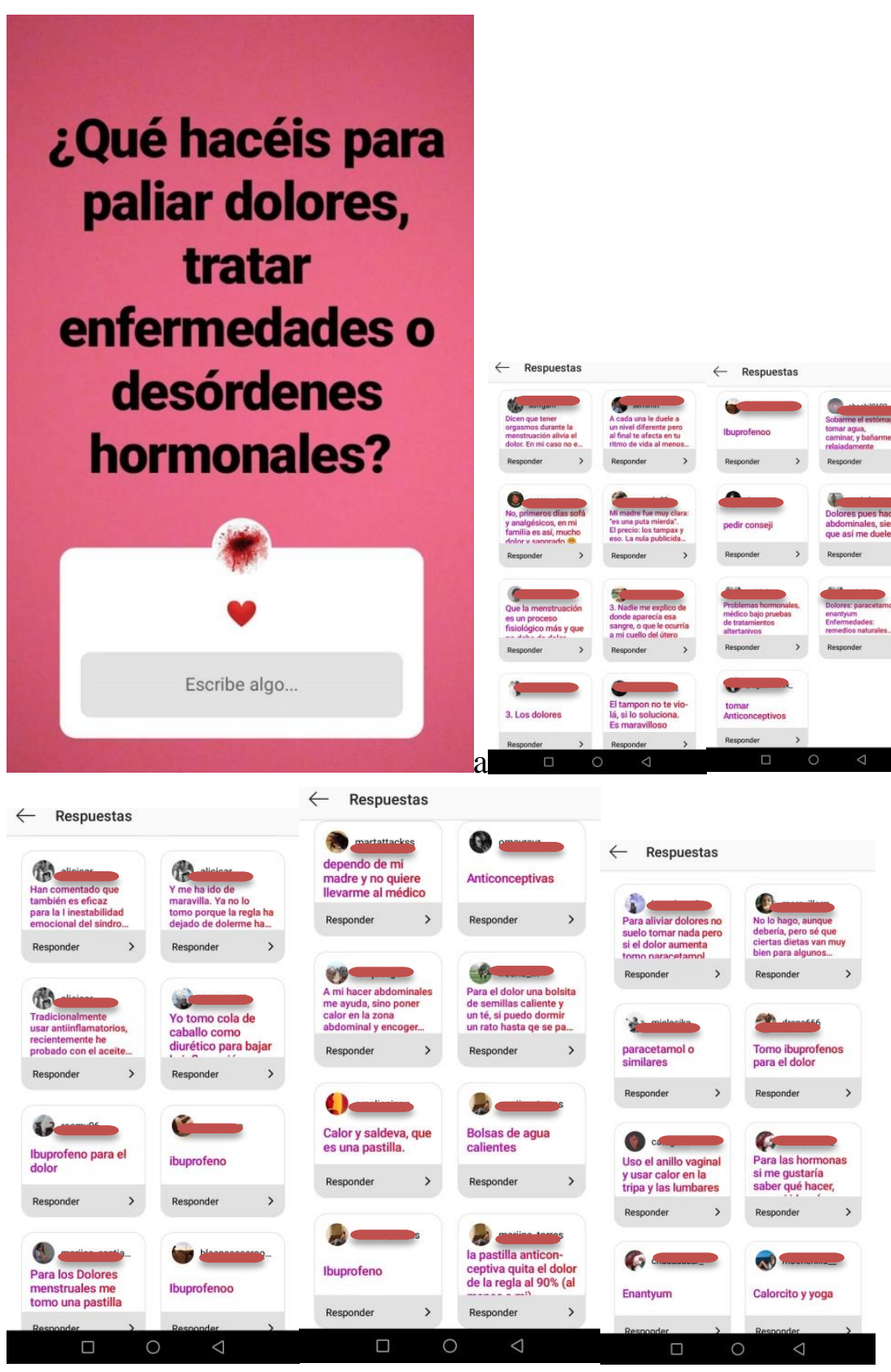




\section{¿Has descubierto algo sobre la}

\section{menstruación que NO es como te habían enseñado?}

Escribe algo..

$\leftarrow$ Respuestas

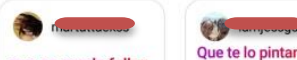

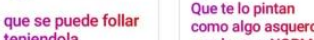

\begin{tabular}{l|l} 
teniendola & yemo algo asqueroso \\
y lo mas NORMAL
\end{tabular}

Responder

Responder

6.

Que no está tan inves:-
gada como pensaba,

Responder

lo que ese.

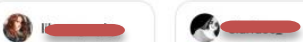

Nadie me enseñó la Siempre he pensado

responter

porque mis ciclos no

a)

Creía que sangraba

continuamente las
24 horas.

- 1 sh

$\leftarrow \quad$ Respuestas

$\leftarrow$ Respuestas

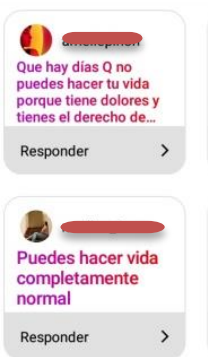

$\leftarrow$ Respuestas

\section{(1) $\mathrm{m}$}

Se ve las cosas

como el dolor

Responder

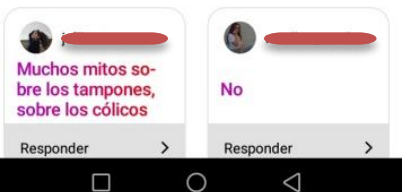

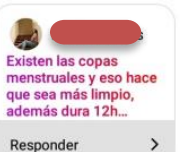

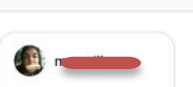

Que no es sucia

Responder

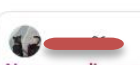

No me explicaron mucho/nada hast

Responder

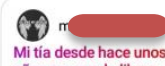

Mi tía desde hace unos años me regala libros

tal. ven ellos pues no +

Responder

\section{(6)}

Lo nutritiva que es, por ejemplo p

Responder

Si,alternativas a
los tamponesy
compressas, leer/
interpretar el ciclo

interpretar

\section{co \\ 4}

es bueno
tantisimo
Que realmente no

\section{5}

hacer el amor e inclus
me gusta mas (lo

me gusta mas (lo
descubri al tener pat

que me qiere de verdad)

Responder

(3)

Puedes hacer lo

que te venga en

gana

Responder

Que no huele mal

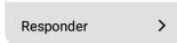

C

que no debería

q te impida hacer

Responder

C

1. Es un proceso
doloroso(en plan usarlo

como excusa y decir es
ue tiene la regla)2. El...

Responder

B

que no debería

doler de un modo

q te impida hacer

Responder

\section{(2)}

que no duele illo,

ol mundo Le duele menos a mi, soy

Los dolores

Responder

\section{6}

Que realmente la
egla no huele.

Huele la fibra de

Que due

Responder

muchísimo, q

(4)

La cantidad de

sangre puede varia
de un ciclo a otro

Responder 


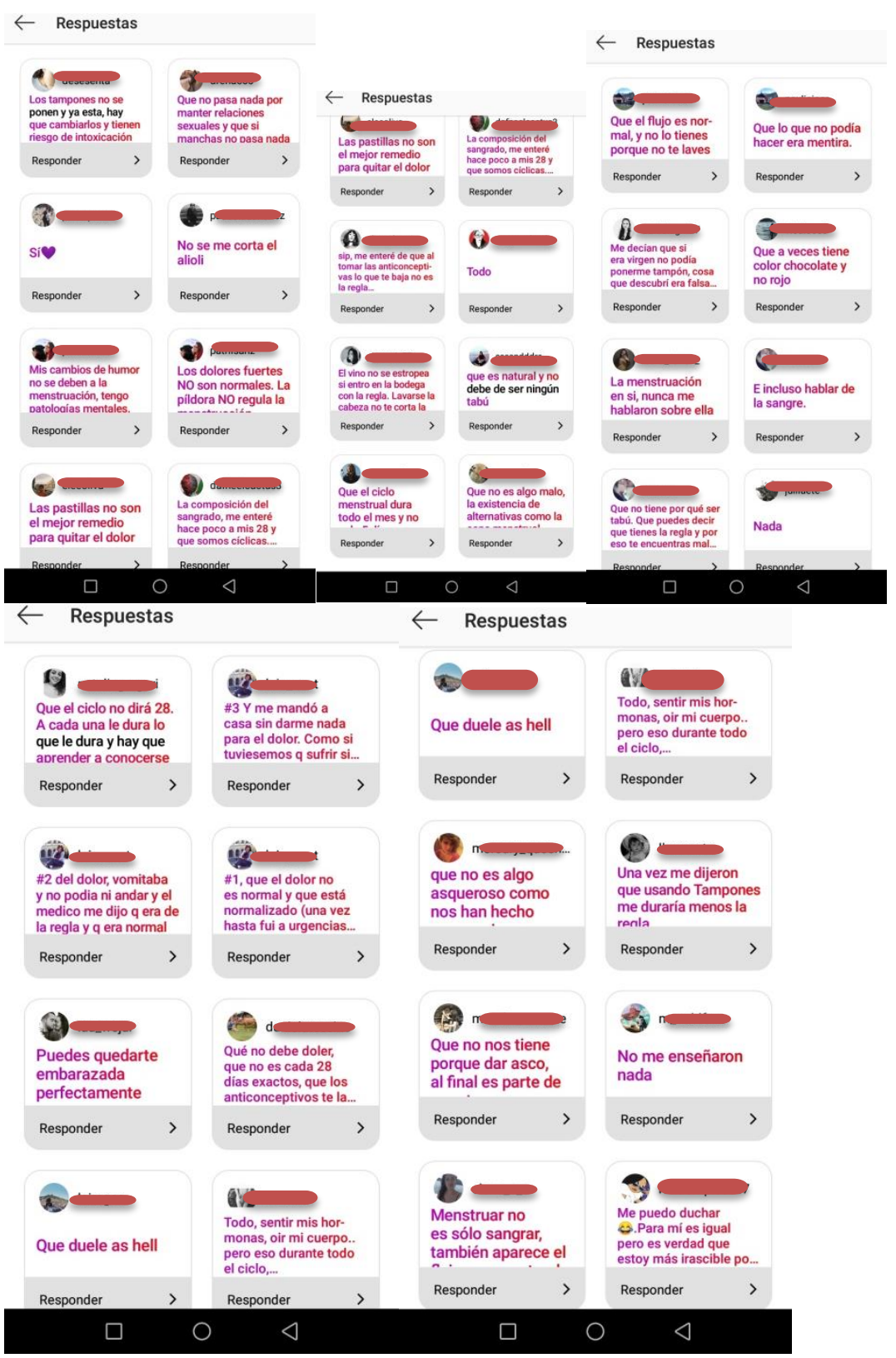




\section{ANEXO 2. TALLERES DIAGNÓSTICOS}

Los talleres diagnósticos fueron resultado de un proyecto realizado durante las prácticas de campo del mismo máster. El proyecto, llamado Investigación y Empoderamiento Menstrual por Torres-Blanco, (2019) fue realizado a fin de nutrir la investigación con la representatividad más interseccional posible. Las participantes del mismo eran mujeres del Centro de Estancia Temporal de Inmigrantes (CETI a partir de ahora) y usuarias de Melilla Acoge, en la que tienen la finalidad de abordar las necesidades principales de las personas migrantes o migradas a través de equipos multidisciplinares realizando una atención social integral desde la mediación intercultural.

Fueron dos los objetivos generales del mismo. (1) Ofrecer un espacio donde las mujeres puedan hablar y aprender de la menstruación, fomentando el proceso de resiliencia y empoderamiento de las mismas. (2) Obtener información para la creación del cuestionario desde la experiencia de las participantes de tener o haber tenido un cuerpo menstruante.

Se llevaron a cabo los siguientes talleres y para el enriquecimiento de la investigación, se hicieron unas fichas anecdóticas.

Taller 1 - Información y empoderamiento

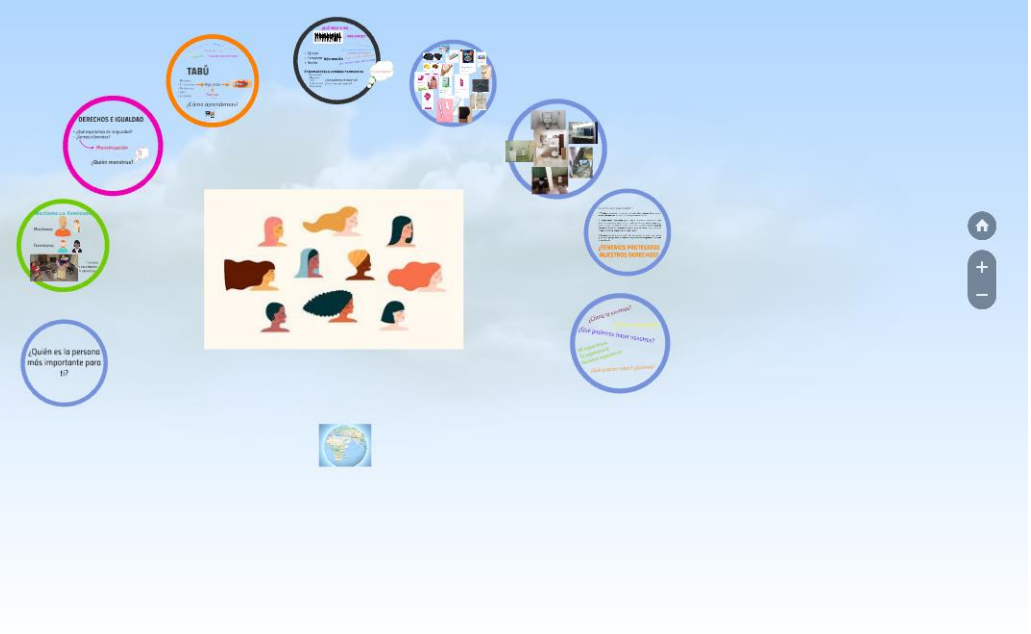



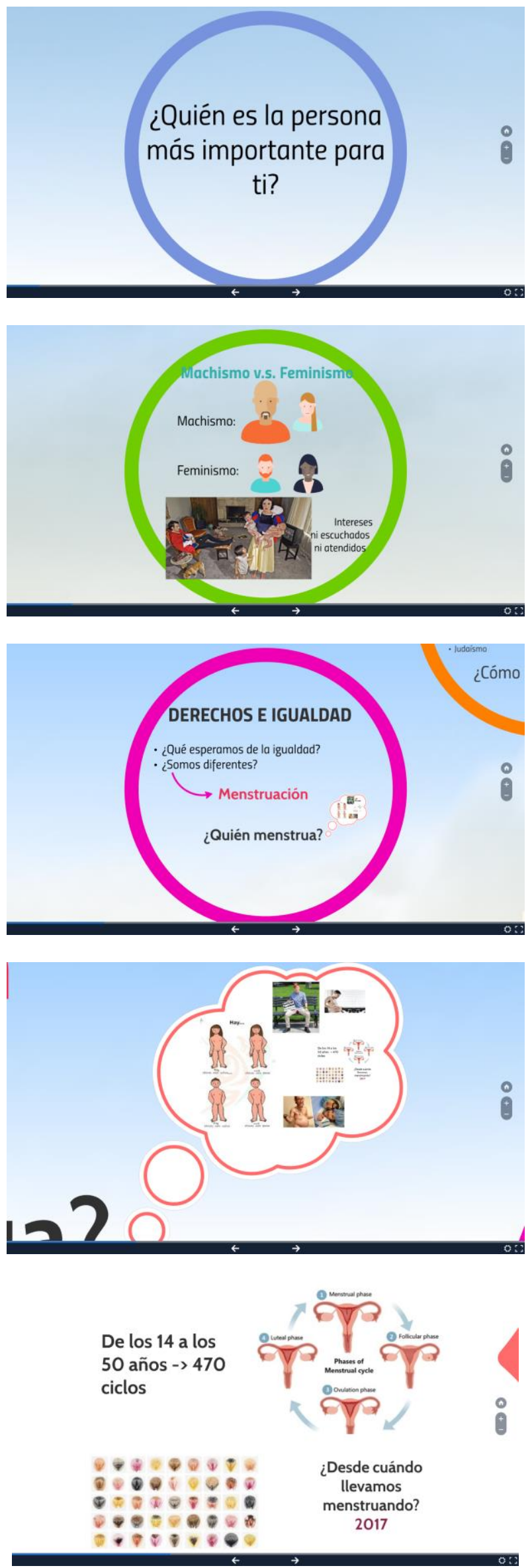

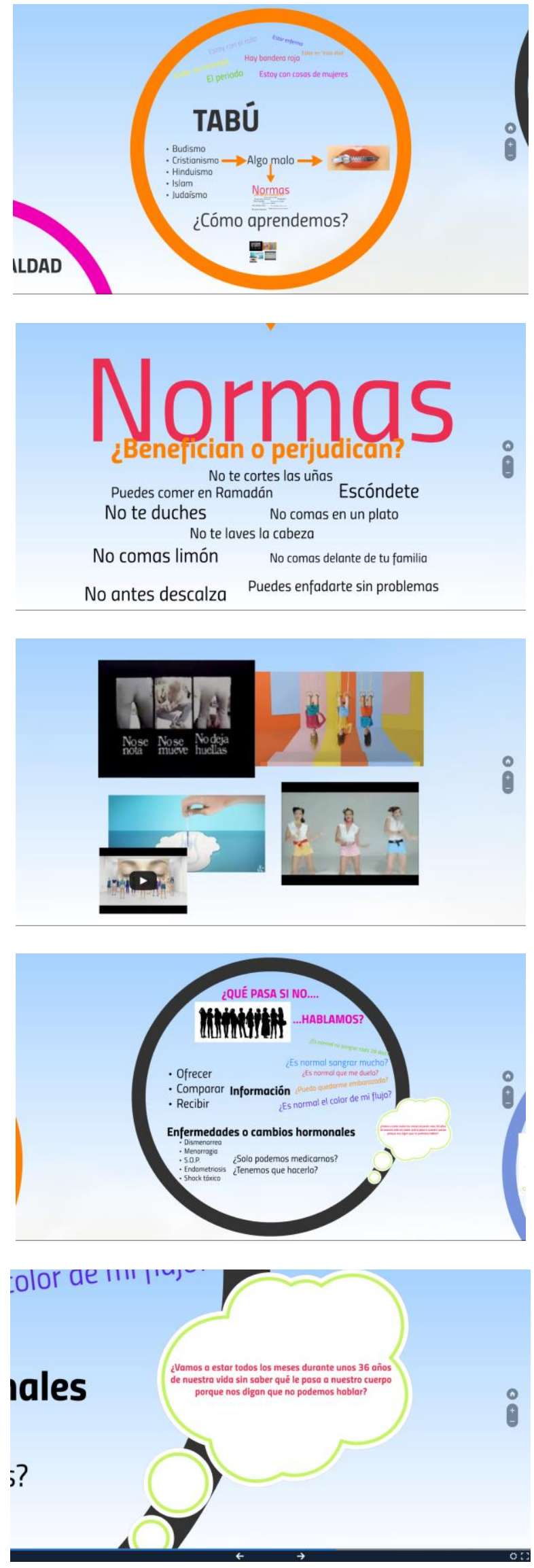

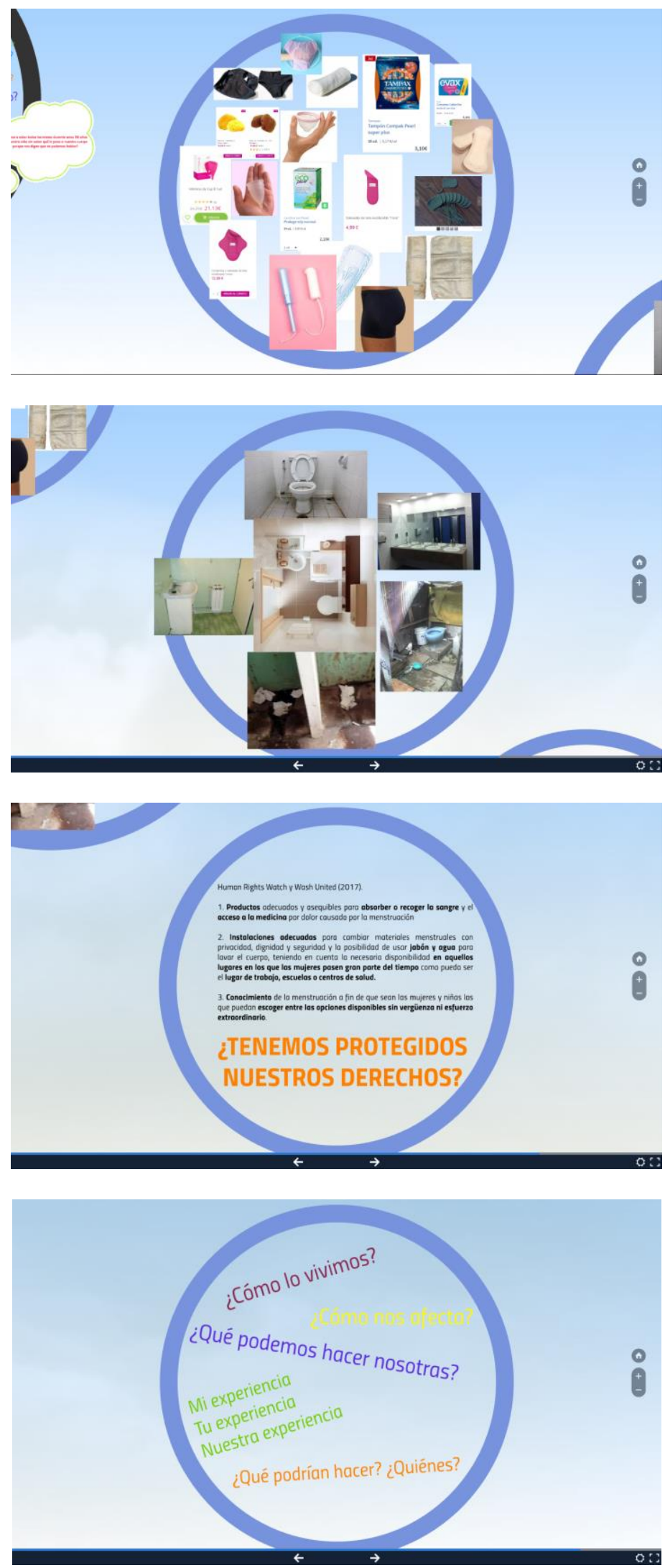
Taller 2 - Cinefórum

1. Cinefórum - Vídeo documental "Una revolución en toda regla"

- ¿Creéis que estas mujeres tienen conocimiento sobre los productos que existen?

- ¿Creéis que tienen normas para cuando están con la menstruación?

- ¿Creéis que tienen un baño en condiciones donde asearse?

- ¿Creéis que es un tema que les avergüence hablar?

- ¿Veis algo en común entre estas mujeres y nosotras que se parezca?

- ¿Tenemos normas en común? ¿Cuáles?

2. Vídeos Youtube en los que se muestra cómo usar los productos de retención/absorción de sangre.

- Zehtabchi, R. et al. (productoras) y Zehtabchi, R. (directora), (2018). Period. End of Sentence. [documental]. Estados Unidos: Netflix. )

- Claripharm, (2018). [Claripharm]. (2018, 21 de marzo). Comment utiliser la coupe menstruelle Claricup? Recuperado de: https://www.youtube.com/watch?v=Sq8bTS6LbXk

- VentaDesechablesOnline, (2013). [VentaDesechablesOnline]. (2013, 7 de mayo). Esponjas para la regla BEPPY. Recuperado de: https://www.youtube.com/watch?v=NOu9XVuYmdg

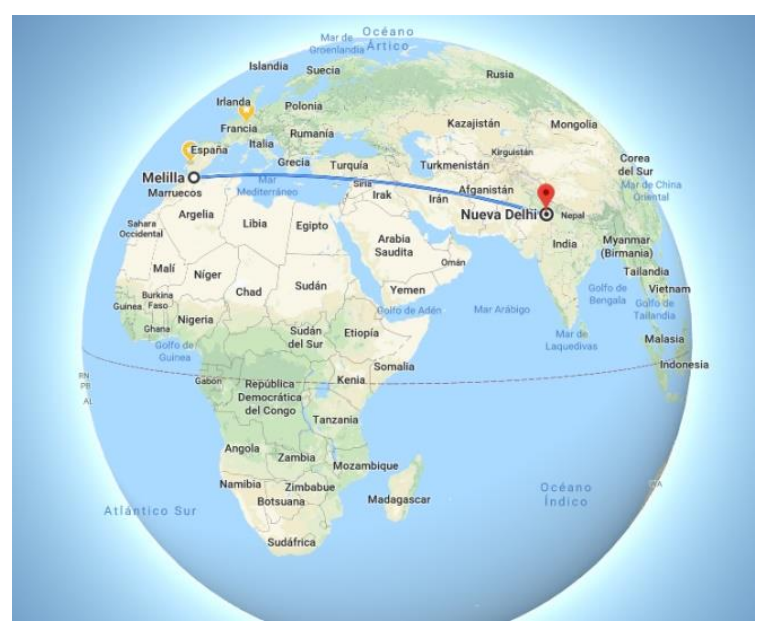


ANEXO 3. CUESTIONARIO R,E,G,L,A,R,

Hola, compañera/o.

Me gustaría que realizases este cuestionario desde la experiencia de tener o haber tenido un cuerpo menstruante. La finalidad del mismo no es otra que conocer la situación en la que estamos y visibilizarla.

El cuestionario es completamente anónimo y no hay ninguna respuesta verdadera o falsa. Responde con sinceridad.

Muchas gracias.

\begin{tabular}{|c|c|}
\hline & Número de días en que menstruo al mes: \\
\hline $\begin{array}{l}\text { Edad con la que empecé a menstruar: } \\
\text { Edad con la que acabó mi menstruación }\end{array}$ & $\begin{array}{l}\text { Me encuentro en situación de dependencia } \\
\text { (Necesito ayuda para realizar mis actividades } \\
\text { diarias) } \\
\square \quad \text { Sí } \\
\square \text { No }\end{array}$ \\
\hline Lugar de nacimiento (país) & $\begin{array}{l}\text { Religión/creencia con la que me } \\
\text { identifico }\end{array}$ \\
\hline $\begin{array}{l}\text { Género con el que me identifico: } \\
\begin{aligned} \square & \text { Femenino } \\
\square & \text { Masculino } \\
\square & \text { Otro (especifica) }\end{aligned}\end{array}$ & $\begin{array}{l}\text { Atributos sexuales que poseo actualmente: } \\
\quad \square \quad \text { Vagina } \\
\square \quad \text { Soy intersexual }\end{array}$ \\
\hline 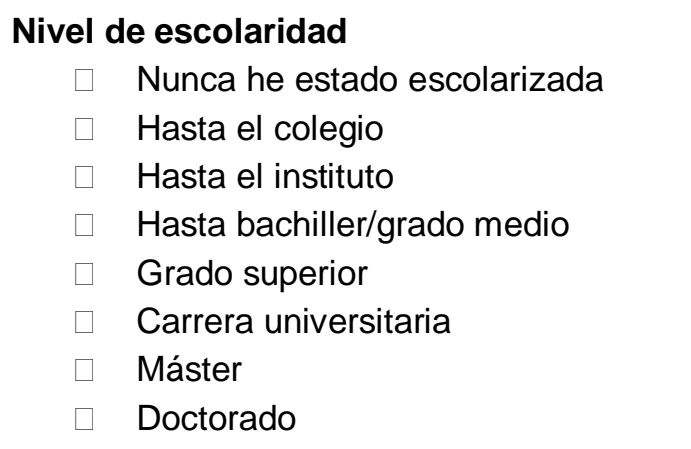 & $\begin{array}{l}\text { Ocupación actual } \\
\qquad \begin{aligned} & \square \text { Trabajo en casa/ cuidando (trabajo no } \\
& \text { remunerado) } \\
& \square \text { Estoy en el paro } \\
& \square \text { Soy estudiante trabajando } \\
& \square \text { Soy estudiante en desempleo } \\
& \square \quad \text { Tengo un trabajo remunerado }\end{aligned}\end{array}$ \\
\hline \multicolumn{2}{|c|}{ Recursos económicos con los que cuento actualmente al mes } \\
\hline $\begin{array}{ll}\square & \text { Ninguno } \\
\square \quad \text { Menos de } 600 \text { euros } \\
\square \quad \text { Entre } 600 \text { y } 999 \text { euros }\end{array}$ & $\begin{array}{ll}\square \quad \text { Entre } 1000 \text { y } 1499 \text { euros } \\
\square \quad \text { Entre } 1500 \text { y } 2000 \text { euros } \\
\square \quad \text { Más de } 2000 \text { euros }\end{array}$ \\
\hline
\end{tabular}


Conozco: Conocimiento que tengo de los productos.

Uso: Frecuencia con la que utilizo o hago uso de estos productos.

Facilidad de encontrar: Capacidad $u$ oportunidad que tengo actualmente para encontrar estos productos.

Accesibilidad económica: Posibilidad que tengo actualmente de afrontar los gastos de estos productos.

\section{1: Nada 2: Algo 3: Bastante 4: Mucho}

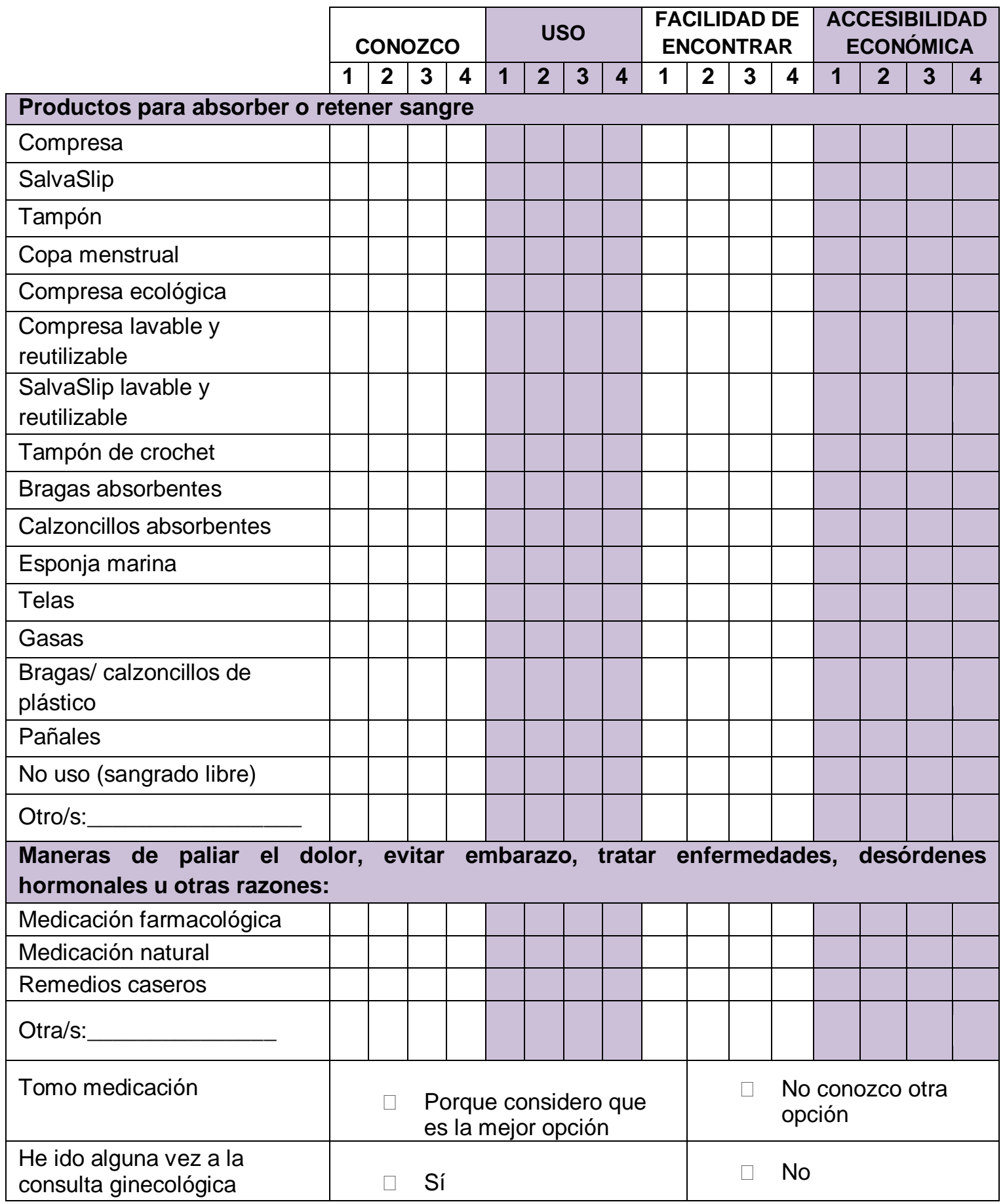




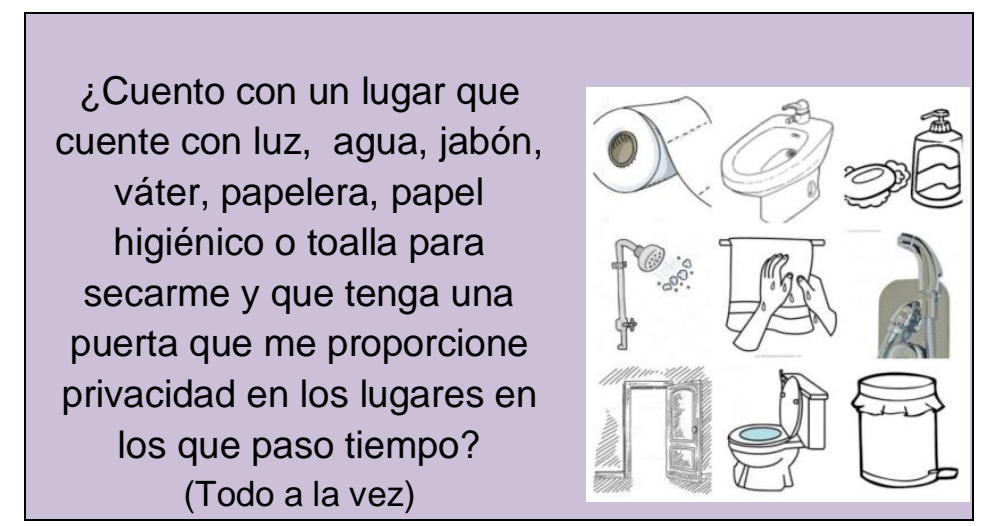

\begin{tabular}{|l|l|l|}
\cline { 2 - 3 } \multicolumn{1}{c|}{} & \multicolumn{1}{c|}{ Sí } & NO \\
\hline En la escuela, instituto o universidad & & \\
\hline En la biblioteca & & \\
\hline En el trabajo & & \\
\hline En el hospital & & \\
\hline Donde vivo actualmente & & \\
\hline Actualmente vivo en la calle & & \\
\hline Otros (especifica) & & \\
\hline
\end{tabular}

\begin{tabular}{|l|l|l|l|l|}
\hline \multirow{2}{*}{$\begin{array}{c}\text { ¿Quién te ha } \\
\text { informado sobre } \\
\text { la menstruación? }\end{array}$} & \multicolumn{4}{|c|}{ ¿Cuándo? } \\
\cline { 2 - 5 } & Antes del primer sangrado & \multicolumn{2}{c|}{$\begin{array}{c}\text { Después del primer } \\
\text { sangrado }\end{array}$} \\
\cline { 2 - 5 } & Sí NO & \multicolumn{2}{c|}{ Sí NO } \\
\hline Madre & & & & \\
\hline Padre & & & & \\
\hline Hermana & & & & \\
\hline Hermano & & & & \\
\hline Colegio/ instituto & & & & \\
\hline Amigas & & & & \\
\hline Anuncios & & & & \\
\hline Libros & & & & \\
\hline Internet & & & & \\
\hline Otros & & & & \\
\hline
\end{tabular}


A continuación se presentan una serie de afirmaciones sobre lo que pensamos o sentimos cuando estamos menstruando. Califica de 1 (nada de acuerdo) a 4(muy de acuerdo) según tu experiencia.

1. Es importante hablar de la regla con los hombres

2. Es importante que el tema de la regla sea discutido en la escuela con niños y niñas juntas.

3. La regla me afecta en el trabajo en casa

4. La regla para mí es un gran problema

5. La regla es sucia

6. Es importante discutir el tema de la regla abiertamente en casa

7. Necesito más atención de la gente cuando estoy menstruando

8. Los hombres tienen una gran ventaja al no tener la molestia de la regla

9. Menstruamos porque tenemos una enfermedad

10. Suelo esconder cualquier cosa que muestre que estoy menstruando

11. La regla me afecta a la labor en el trabajo

12. El órgano que hace que menstruamos es el útero

13. Me gustaría que el periodo menstrual durara pocos minutos

14. La regla es un gran fastidio

15. Me incomoda menstruar

16. La regla me incapacita

17. La regla para mí es molesta

18. Me suelo comprar los productos para la menstruación sin que me vean

19. Las mujeres debemos alejarnos de los hombres cuando estamos menstruando

20. Me gustaría que la menstruación no existiera

21. Me emocioné cuando tuve mi primera regla

22. Normalmente me incomoda hablar de la regla

23. Menstruamos por un proceso fisiológico 


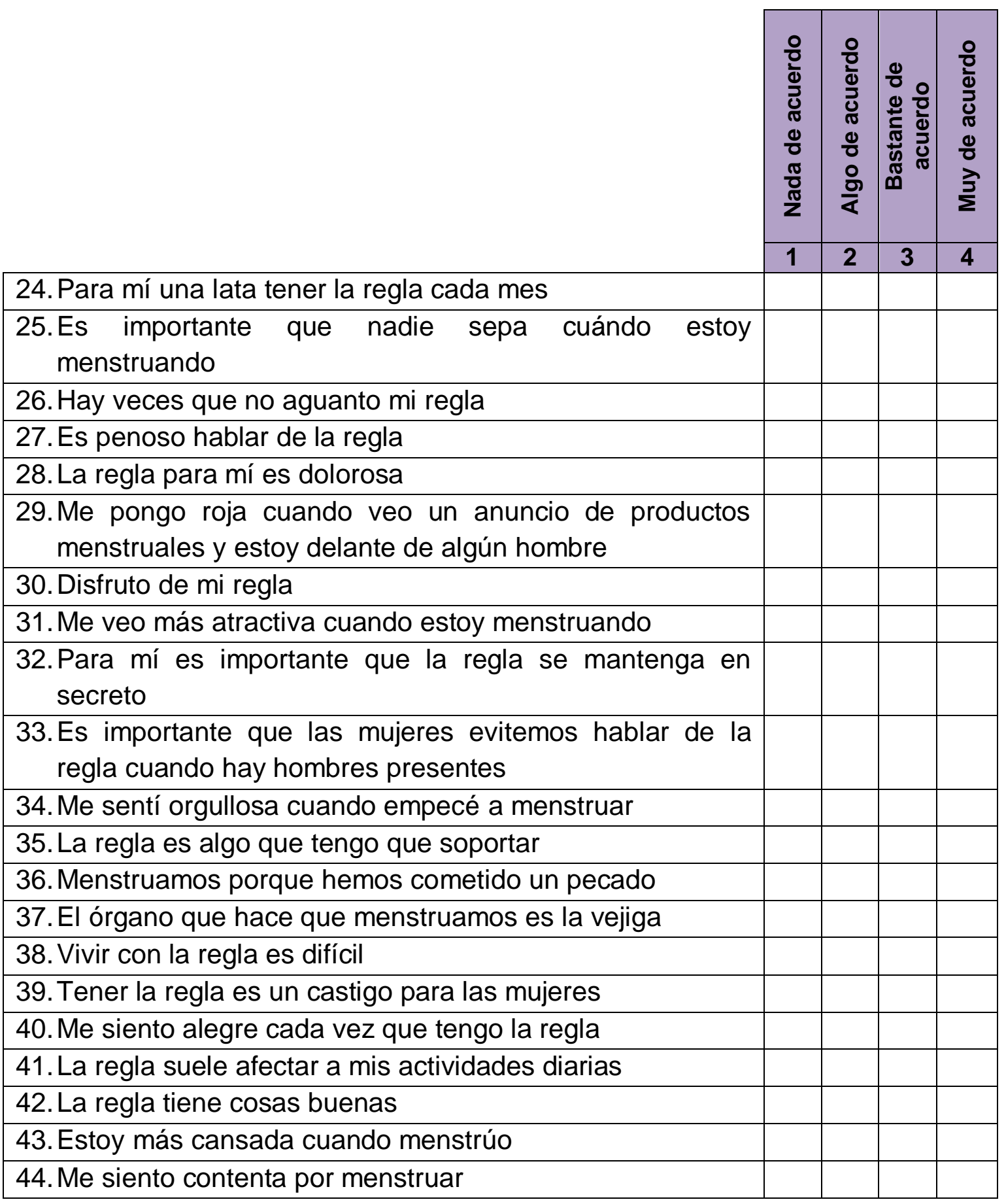


Marca con una $X$ aquellas afirmaciones que hayas escuchado y/o practicado.

\section{Las siguientes afirmaciones con (“"”) comienzan con}

\section{DEBO EVITAR}

1. (")" bañarme cuando estoy con la regla

2. ("') comer cosas frías durante la regla

3. ("') lavarme la cabeza cuando estoy con la regla

4. ("') hacer la matanza de un animal cuando estoy menstruando

5. ("') dormir con mi pareja cuando estoy menstruando

6. ('") mantener relaciones sexuales cuando estoy menstruando

7. ("') hacer deporte o esfuerzo físico cuando estoy menstruando

8. (") depilarme cuando estoy menstruando

9. ("') hacer la colada cuando estoy menstruando

10. ("') ir a la consulta de ginecología cuando estoy menstruando

11. (") donar sangre cuando estoy menstruando

12. ("') tirar algo que esté manchado de mi sangre donde puedan encontrarlo

13. ("') cocinar ciertos alimentos como yogurt o mahonesa

14. (") beber ciertas cosas cuando estoy con la regla

15. ("') orar cuando esté menstruando

16. ("') asistir a prácticas religiosas cuando estoy menstruando

17. ("') entrar en algún templo sagrado cuando estoy menstruando

18. (“") andar descalza cuando estoy menstruando

19. (") cortarme la uñas cuando estoy menstruando

20. ("') tocar un libro sagrado cuando estoy menstruando

21. ("') orinar en el campo si estoy menstruando

22. (") ponerme ropa ajustada si estoy menstruando

23. ("') comer ciertos alimentos cuando estoy con la regla

24. ("') divorciarme mientras esté menstruando

25. ("') tocar semillas mientras esté menstruando

26. ("') coger un bebé si estoy con la regla

¿Y estas otras?

27. Tener la regla nos hace ser mujeres

28. Cuando es Ramadán puedo comer si tengo la regla

29. Cuando es Ramadán puedo comer si tengo la regla sin que me vean

30. Solamente puedo pintarme las uñas cuando estoy con la regla

31. Debo purificarme cuando termine de sangrar

32. Si soy virgen, no debo introducir ningún utensilio en mi vagina (tampones, copa menstrual...) porque perderé la virginidad 

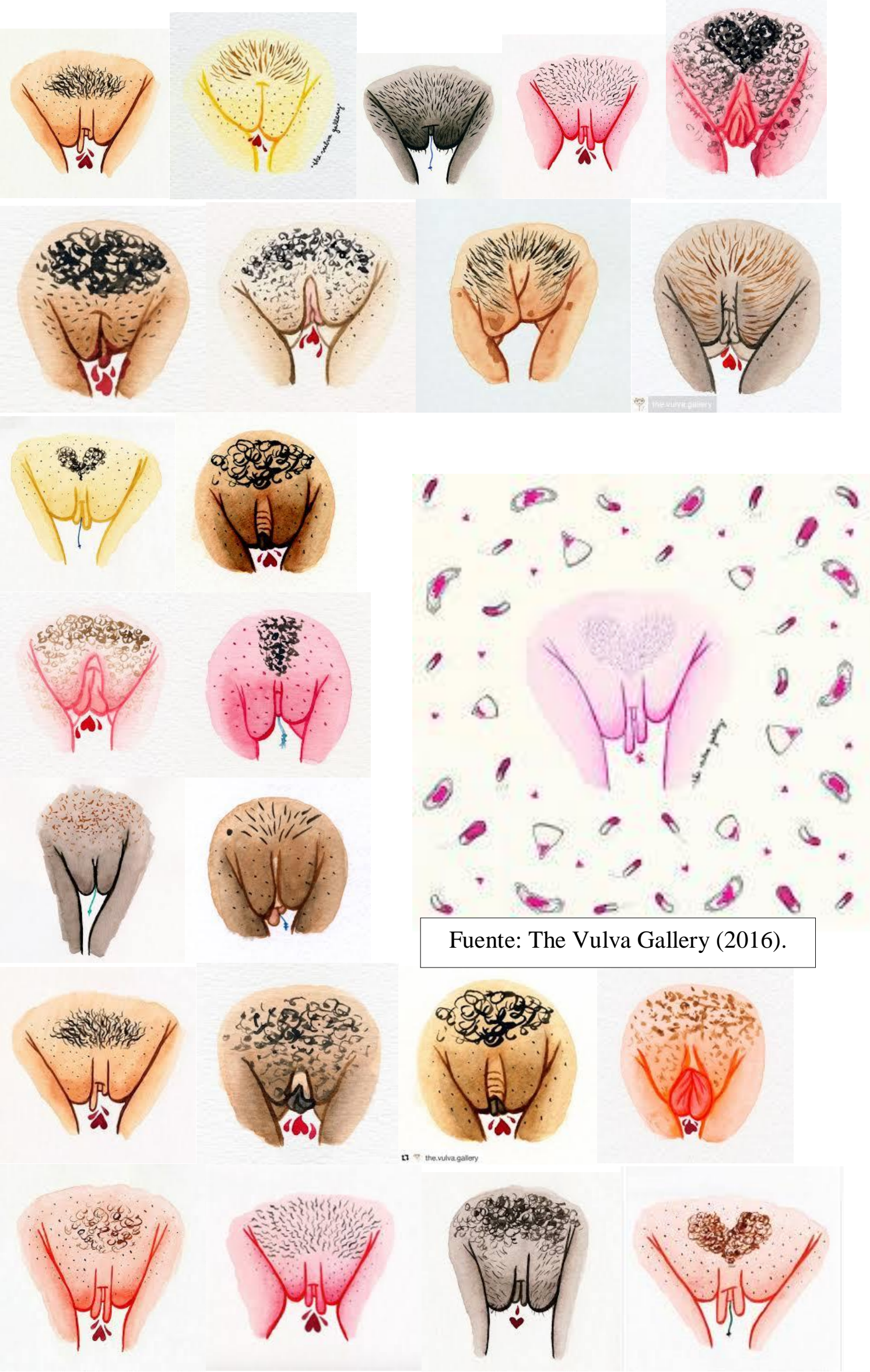
TORRES-BLANCO, Carlota (2019) 